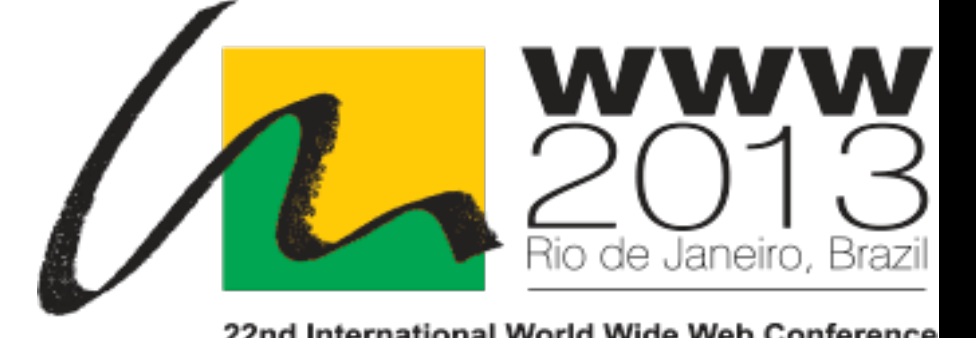

22nd International World Wide Web Conference Windsor Barra Hotel $\cdot 13$ th -17 th, May

\title{
MEASURING USER ENGAGEMENT
}

MOUNIA LALMAS, YAHOO! LABS

HEATHER O'BRIEN, UNIVERSITY OF BRITISH COLUMBIA

ELAD YOM-TOV, MICROSOFT RESEARCH

(C) Lalmas, O'Brien \& Yom-Tov 


\section{WHY IS IT IMPORTANT TO ENGAGE USERS?}

- In today's wired world, users have enhanced expectations about their interactions with technology

... resulting in increased competition amongst the purveyors and designers of interactive systems.

- In addition to utilitarian factors, such as usability, we must consider the hedonic and experiential factors of interacting with technology, such as fun, fulfillment, play, and user engagement.

- In order to make engaging systems, we need to understand what user engagement is and how to measure it.
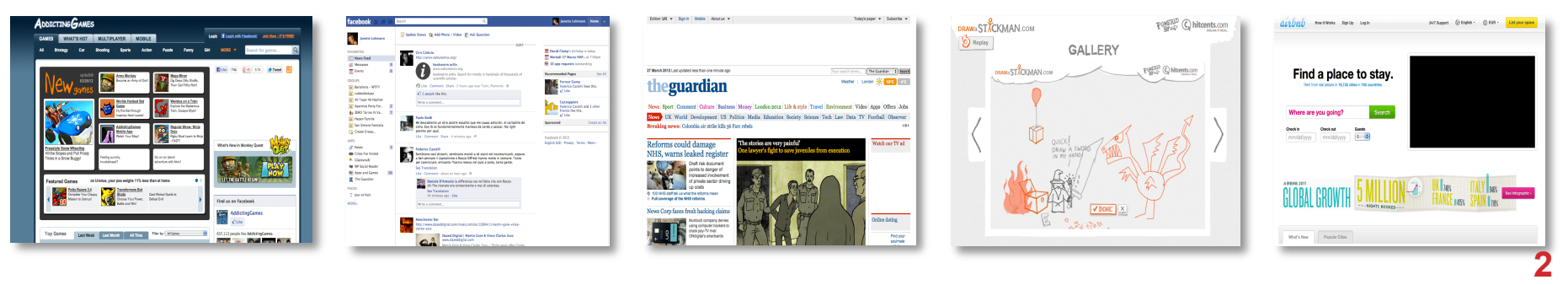


\section{WHY IS IT IMPORTANT TO MEASURE AND INTERPRET USER ENGAGEMENT WELL?}

... for example

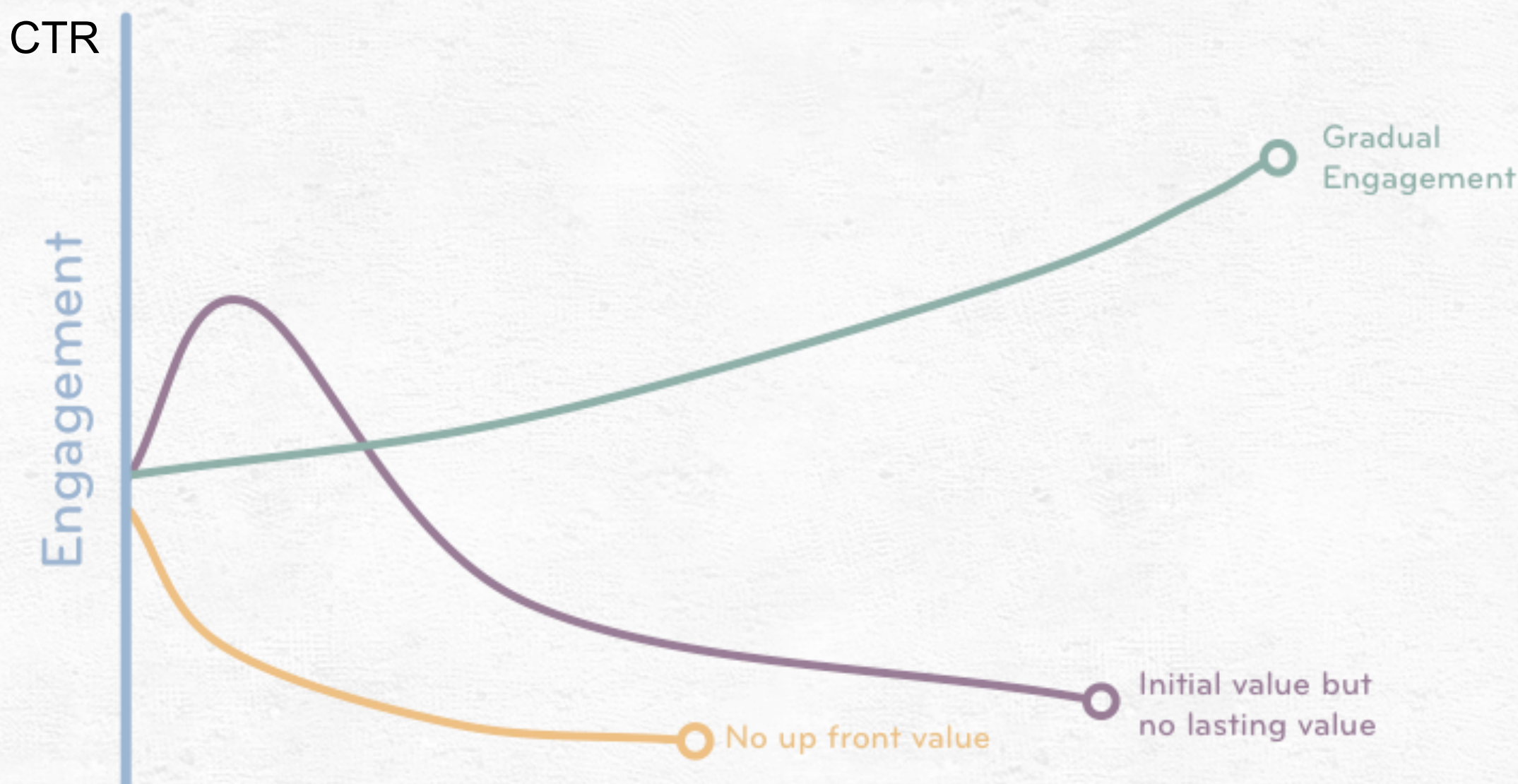

Time 
- Introduction and Scope

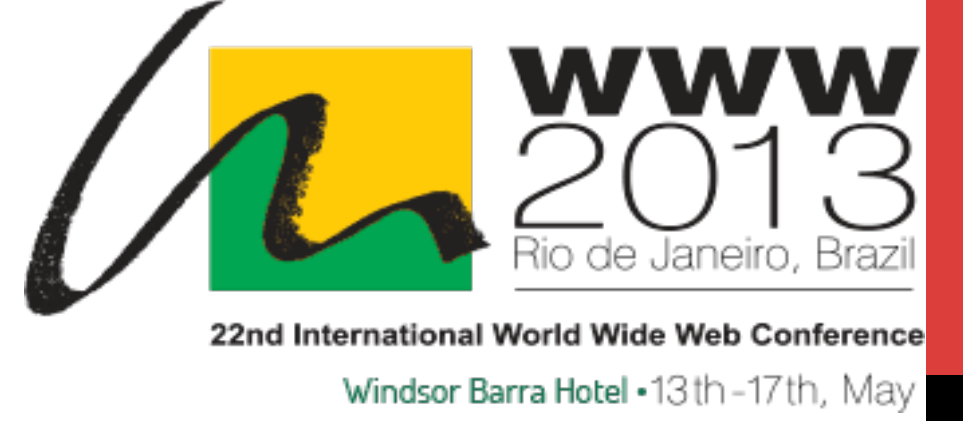

- Part I - Foundations

1. Approaches based on self-report measures

2. Approaches based on web analytics

3. Approaches based on physiological measures

- Part II - Advanced Aspects

1. Measuring user engagement in mobile information searching

2. Networked user engagement

3. Combining different approaches

- Conclusions

○ Bibliography 
○ Mounia Lalmas, Visiting Principal Scientist, Yahoo! Labs

- Research interest: user engagement, social media, search

- Blog: http://labtomarket.wordpress.com

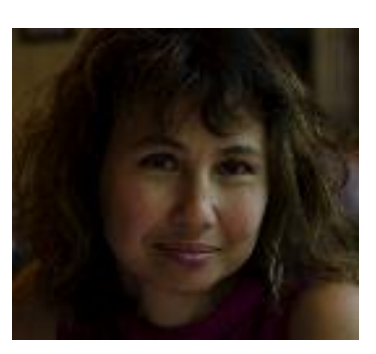

- Heather O’Brien, Assistant Professor, iSchool, University of British Columbia

- Research interests: theories of user engagement; selfreport and qualitative methods of evaluating user engagement

- Website: http://faculty.arts.ubc.ca/hobrien/

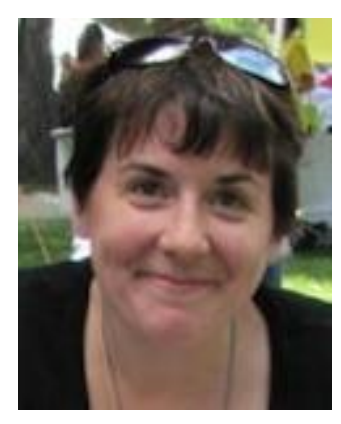

○ Elad Yom-Tov, Senior Researcher, Microsoft Research

- Research interests: learning from user behavior about actions in the physical world

- Website: http://research.microsoft.com/en-us/people/eladyt/

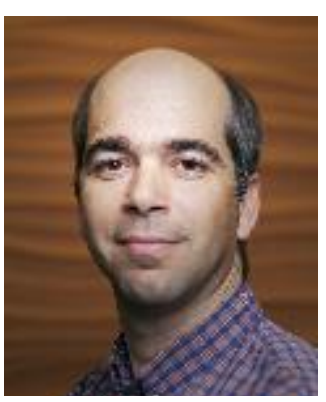



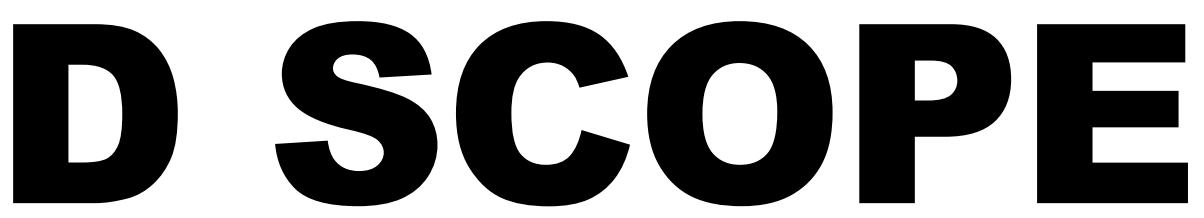


\section{ENGAGEMENT IS ON EVERYONE'S MIND}

\section{User Engagement}

Engaged Users spend $115 \%$ more time on sites and return

http://iactionable.com/user-engagement/

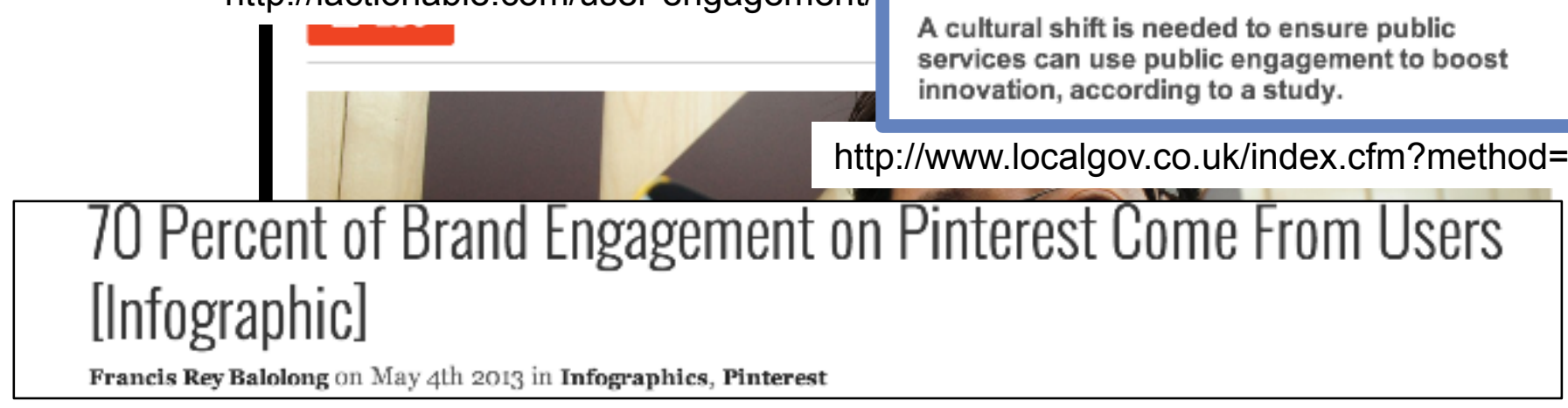

http://socialbarrel.com/70-percent-of-brand-engagement-on-pinterest-come-from-users/

510321

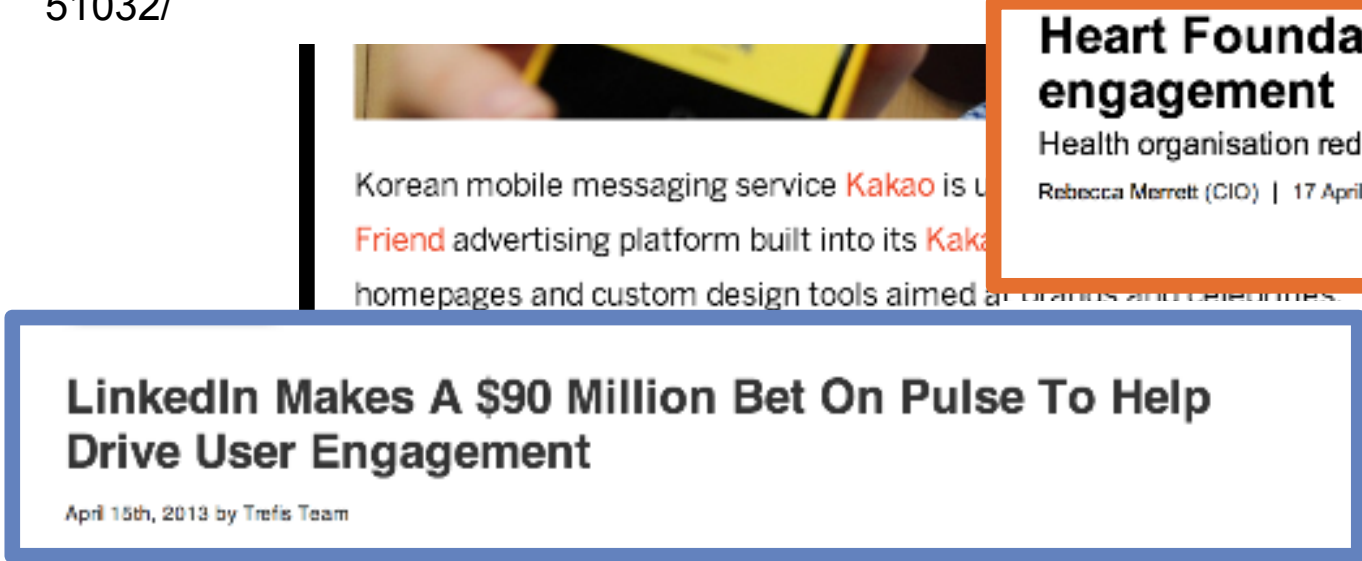

http://www.trefis.com/stock/Inkd/articles/179410/linkedin-makes-a-90-

million-bet-on-pulse-to-help-drive-user-engagement/2013-04-15

Korean mobile messaging service Kakao is

Friend advertising platform built into its Kak

homepages and custom design tools aimed artign

\section{Engagement}

\section{olls out Plus}

16 April 2013

Nesta: Public sector must 'catch up' on user engagement

Thomas Bridge

MOST READ

Bamet Council wins legal viclo 1.au/article/459294/

uses_gamification_drive_user_engagement/

$$
\text { 다 } 1 \text { Comment }
$$

013/05/03/kakao-talk-rolls-out-plus-friend-home-azt-users-with-their-favorite-brands/ 7 


\section{WHAT IS USER ENGAGEMENT (UE)? (I)}

- "The state of mind that we must attain in order to enjoy a representation of an action" so that we may experience computer worlds "directly, without mediation or distraction" (Laurel, 1993, pp. 112-113, 116).

- "Engagement is a user's response to an interaction that gains maintains, and encourages their attention, particularly when they are intrinsically motivated" (Jacques, 1996, p. 103).

$\circ$ A quality of user experience that depends on the aesthetic appeal, novelty, and usability of the system, the ability of the user to attend to and become involved in the experience, and the user's overall evaluation of the experience. Engagement depends on the depth of participation the user is able to achieve with respect to each experiential attribute (O'Brien \& Toms, 2008).

$\circ$ "...explain[s] how and why applications attract people to use them" (Sutcliffe, 2010, p. 3). 


\section{WHAT IS UE? (II)}

- User engagement is a quality of the user experience that emphasizes the positive aspects of interaction - in particular the fact of being captivated by the technology (Attfield et al, 2011).

user feelings: happy, sad, excited, ... user mental states: involved, lost, concentrated... user interactions: click, read comment, recommend, buy...
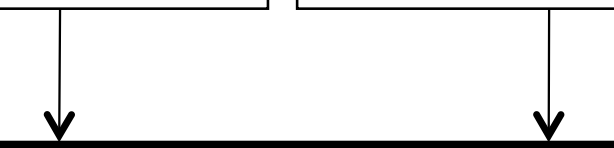

The emotional, cognitive and behavioural connection that exists, at any point in time and over time, between a user and a technological resource 


\section{INCREASED EMPHASIS ON MEASURING UE}

\section{Marketers exploiting secrets of the living brain}

By Kelly Crowe, CaC News Posted: Jan 1, 2013 8:15 AM ET | Last Updated: Jan 1, 2013 9:01 AM ET $\square 118$
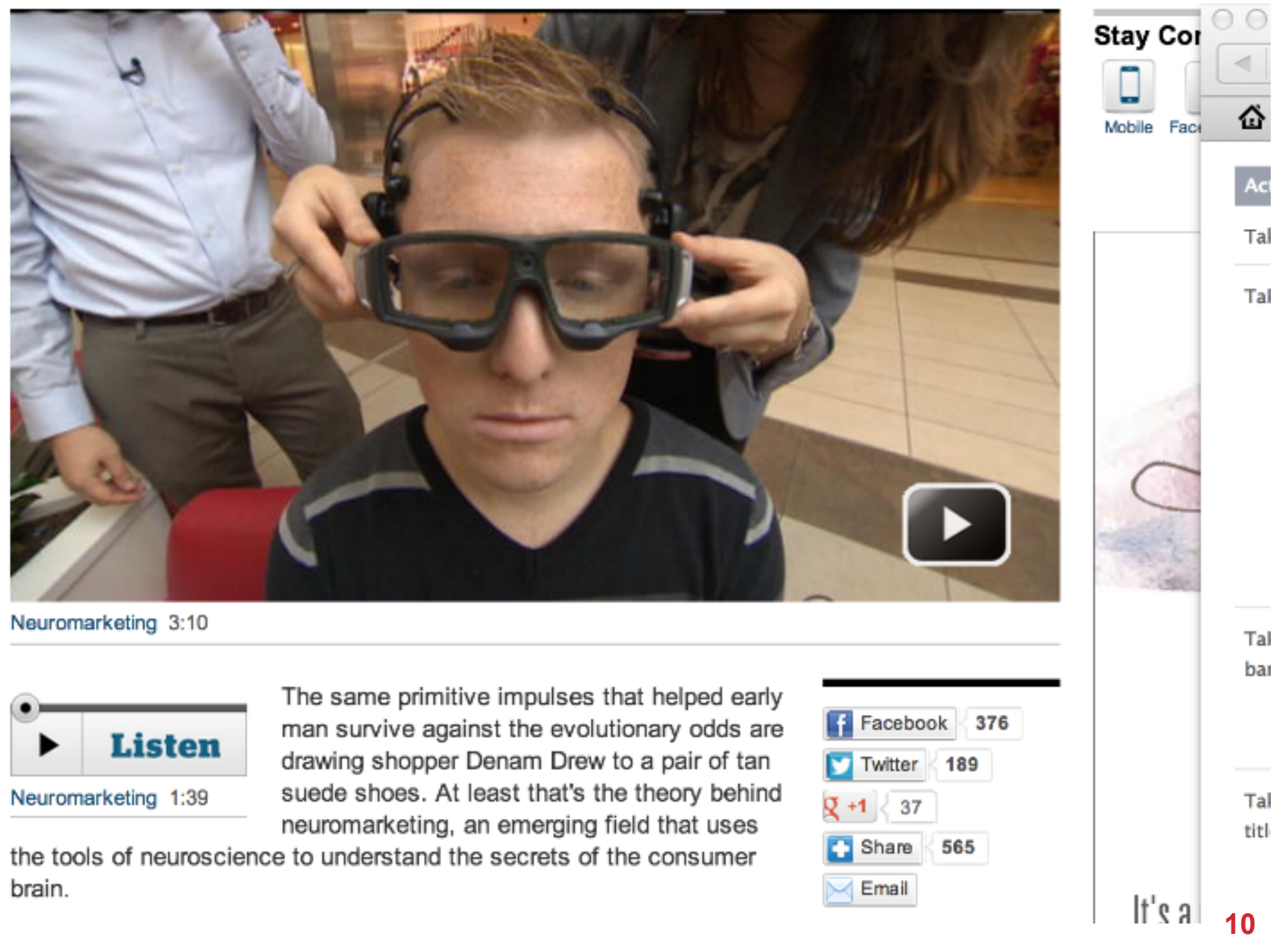

http://www.cbc.ca/news/health/story/2012/12/20/inside-your-brain-neuromarketing.html 


\section{TRACKING USER BEHAVIOR}

Google Analytics

\section{Gain insights that matter}

Google Analytics not only lets you measure sales and conversions, but also gives you fresh insights into how visitors use your site, how they arrived on your site, and how you can keep them coming back.

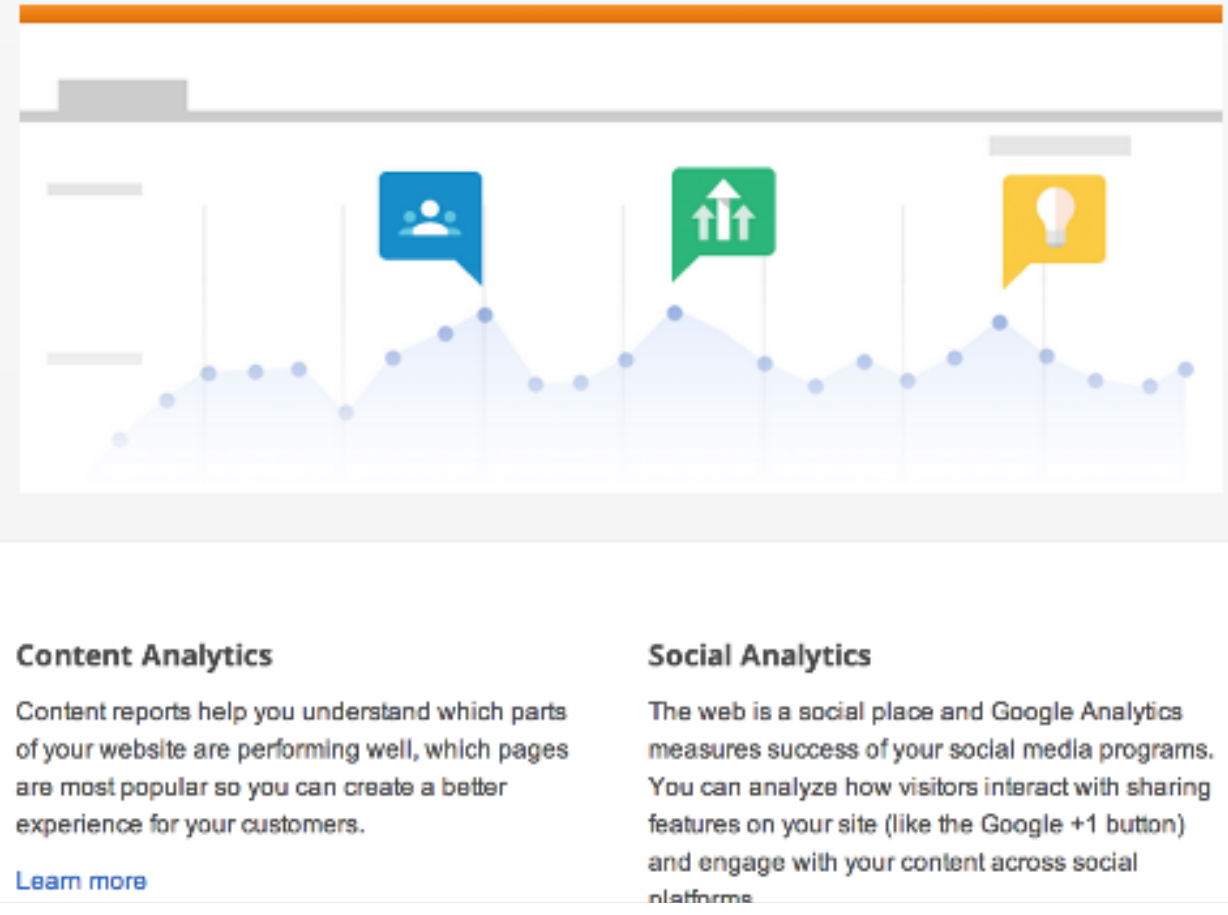

\section{Analysis Tools}

Google Analytics is built on a powerful, easy to use, reporting platform, so you can decide what data you want to view and customize your reports, with just a few clicks.

Learn more 


\section{HOW DO WE CAPTURE USER ENGAGEMENT?}

\section{Bloomberg Businessweek}

Technology

Global

Economics

Companies \&

Politics \& Policy Technology

f Like

$109 \mathrm{k}$

\section{GigaOm}

Why Measuring User Engagement Is Harder Than You

\section{Think}

\section{GIGAOM}

Posted on GigaOM

By Mathew Ingram on October 12, 2012

(7) in $8 . \square 0$ comments

\section{Related}

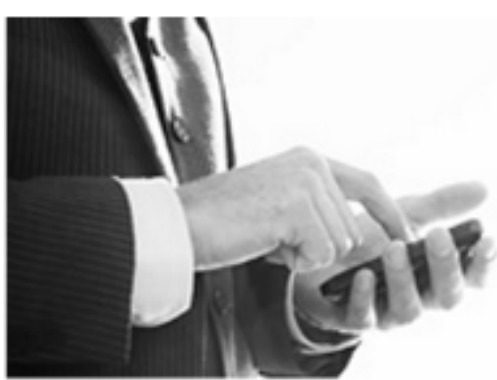

Data: $85 \%$ of Mobile Traffic But $39 \%$ of Revenue-What Gives?

If you've spent any time in a newsroom, traditional or otherwise, you know that publishers are obsessed with measuring where their Web traffic comes from. Whether it's Google (GOOG) Analytics or Chartbeat, or comScore, or Omniture, or any one of a dozen other providers, tracking where readers come from is a crucial part of online media-mostly because publishers need to know which channels are worth focusing on, since there are so many to choose from. Is Twitter your biggest source? Then you should tweet more and optimize your content for Twitter. Is Facebook (FB) a big referrer of 


\section{WHY IS MEASURING UE IMPORTANT?}

- User engagement is a complex construct

- Various approaches have been proposed for measuring engagement, but...

- Not enough emphasis on reliability and validity of individual measures, or triangulation of various approaches.

- Standardization of what user engagement is and how to measure it will benefit research, design, and users.
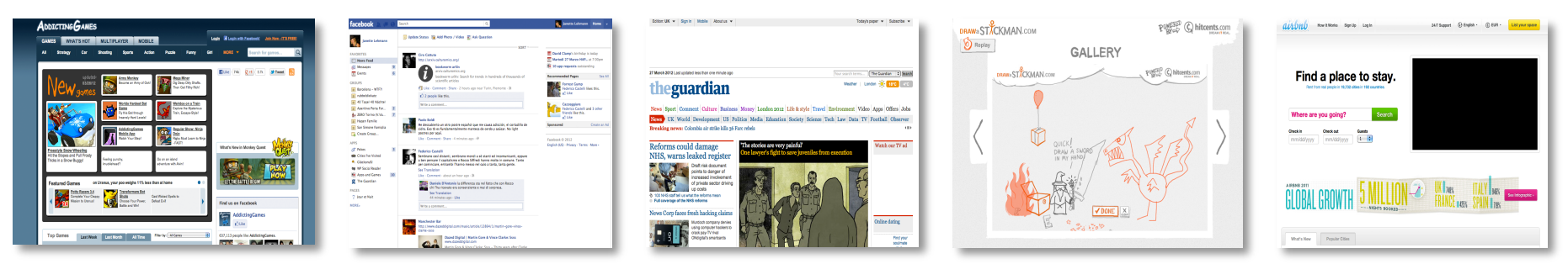


\section{CONSIDERATIONS IN THE MEASUREMENT \\ OF USER ENGAGEMENT}

- Short term (within session) and long term (across multiple sessions)

- Laboratory vs. field studies

- Subjective vs. objective measurement

- Large scale (e.g., dwell time of 100,000 people) vs. small scale (gaze patterns of 10 people)

○ UE as process vs. as product

One is not better than other; it depends on what is the aim.
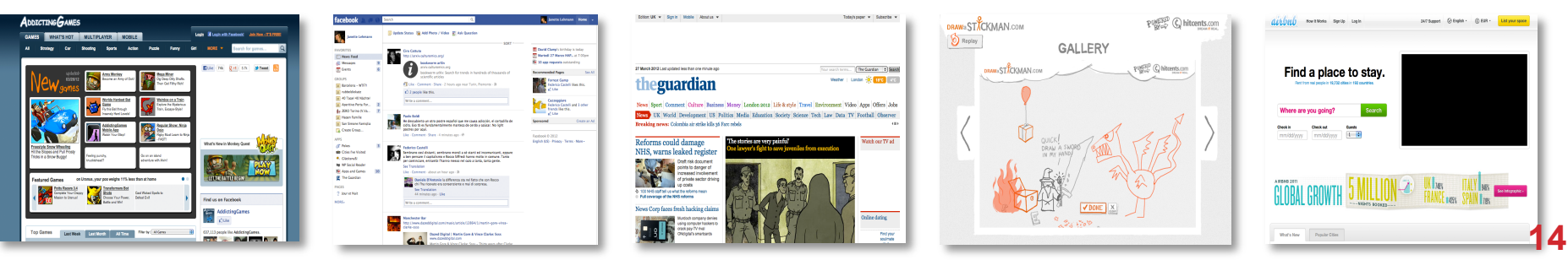


\section{SOME CAVEATS (I)}

- This tutorial assumes that web application are "properly designed"

- We do not look into how to design good web site (although some user engagement measurement may inform for an enhanced design).

- This tutorial is based on "published research" literature

- We do not know how each individual company and organization measure user engagement (although we guess some common baselines).

- This tutorial focuses on web applications that users "chose" to engage with

- A web tool that has to be used e.g. for work purpose, is totally different (users have no choice).

- This tutorial is not an "exhaustive" account of all existing works

- We focus on work that we came across and that has influenced us; if we have missed something important, let us know. 


\section{SOME CAVEATS (II)}

- This tutorial focuses on web applications that are widely used by "anybody" on a "large-scale"

- User engagement in the game industry or education have different characteristics.

- This tutorial does not focus on the effect of advertisements on user engagement

- We assume that web applications that display ads do so in a "normal" way so that to not annoy or frustrate users.

- This tutorial looks at user engagement at web application "level"

- Although we use examples and may refer to specific sites or types of applications, we do not focus on any particular applications.

- This tutorial is not about "how" to increase user engagement $($ ) 
- Introduction and Scope

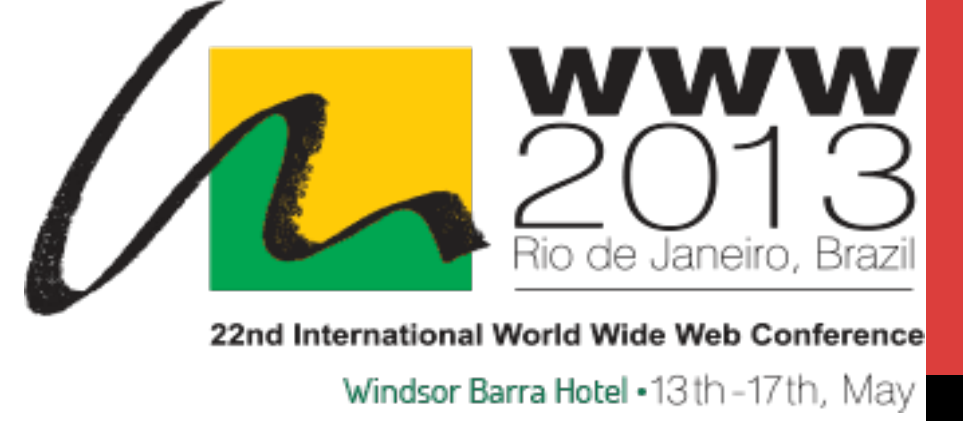

- Part I - Foundations

1. Approaches based on self-report measures

2. Approaches based on web analytics

3. Approaches based on physiological measures

- Part II - Advanced Aspects

1. Measuring user engagement in mobile information searching

2. Networked user engagement

3. Combining different approaches

- Conclusions

○ Bibliography 

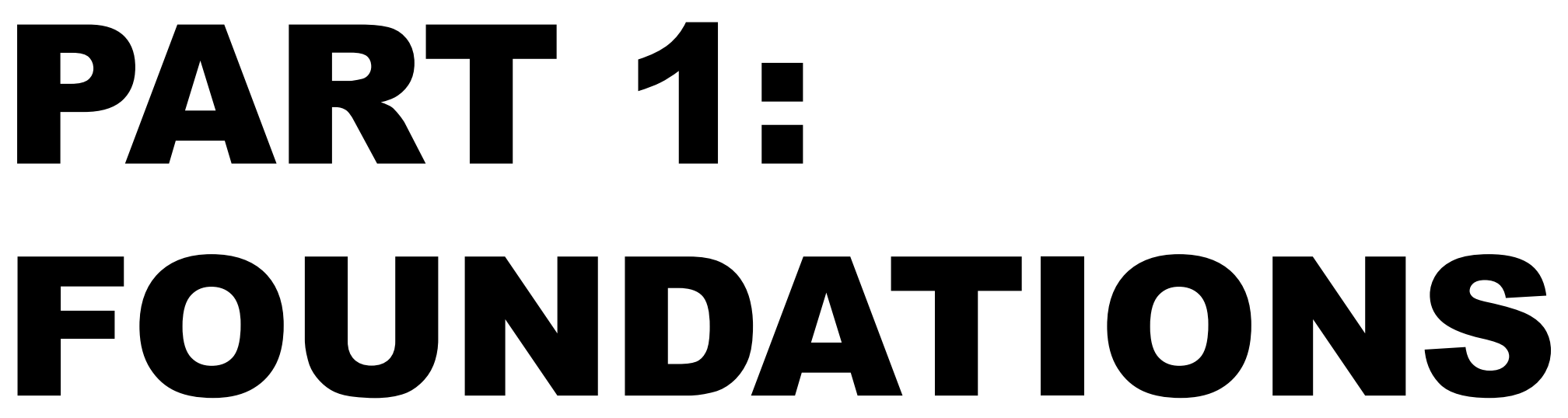


\section{CHARACTERISTICS OF USER ENGAGEMENT (I)}

Focused attention (Webster \& Ho, 1997; O'Brien, 2008)
- Users must be focused to be engaged

- Distortions in the subjective perception of time used to measure it
Positive Affect

(O'Brien \& Toms, 2008)
- Emotions experienced by user are intrinsically motivating - Initial affective "hook" can induce a desire for exploration, active discovery or participation

\section{Aesthetics}

(Jacques et al, 1995; O'Brien, 2008)
- Sensory, visual appeal of interface stimulates user \& promotes focused attention

- Linked to design principles (e.g. symmetry, balance, saliency)

\section{Endurability}

(Read, MacFarlane, \& Casey, 2002; O'Brien, 2008)
- People remember enjoyable, useful, engaging experiences and want to repeat them

- Reflected in e.g. the propensity of users to recommend an experience/a site/a product 


\section{CHARACTERISTICS OF USER ENGAGEMENT (II)}

\section{Novelty}

(Webster \& Ho, 1997; O’Brien, 2008)
- Novelty, surprise, unfamiliarity and the unexpected

- Appeal to users' curiosity; encourages inquisitive behavior and promotes repeated engagement
Richness and control (Jacques et al, 1995; Webster \& Ho, 1997)
- Richness captures the growth potential of an activity

- Control captures the extent to which a person is able to achieve this growth potential
Reputation, trust and expectation (Attfield et al, 2011)
- Trust is a necessary condition for user engagement

- Implicit contract among people and entities which is more than technological
Motivation, interests, incentives, and benefits (Jacques et al., 1995; O'Brien \& Toms, 2008)
- Difficulties in setting up "laboratory" style experiments

- Why should users engage? 


\section{FORRESTER RESEARCH - THE FOUR I'S}

\section{Involvement}

- Presence of a user

- Measured by e.g. number of visitors, time spent

\section{Interaction}

- Action of a user

- Measured by e.g. CTR, online transaction, uploaded photos or videos

Intimacy

- Affection or aversion of a user

- Measured by e.g. satisfaction rating, sentiment analysis in blogs, comments, surveys, questionnaires

\section{Influence}

- Likelihood a user advocates

- Measured by e.g. forwarded content, invitation to join 


\section{FLOW: THE THEORY OF OPTIMAL EXPERIENCE}

○ What is "Flow"

the state in which people are so involved in an activity that nothing else seems to matter; the experience itself is so enjoyable that people will do it even at great cost, for the sheer sake of doing it (Csikszentmihalyi, 1990, p. 4).

- Engagement has been called "flow without user control" and "a subset of flow"

(Webster \& Ahuja, 2004, p. 8) 


\section{ATTRIBUTES OF FLOW}

Enjoyment, Focused attention, Absorption, Time perception, Clear goals and feedback, Control

(Cskiszentmihalyi, 1990)

\section{FLOW IN HUMAN COMPUTER INTERACTION (HCI)}

- The "PAT" - Person, Artefact, Task Model

(Finneran \& Zhang, 2003)

- Attributes and predictors of flow with work-based systems (Webster, Trevino \& Ryan, 1993)

- Relationships between flow and the tasks being performed

- Ghani \& Deshpande, 1994: work tasks

- Pace, 2004: directed and exploratory search tasks 


\section{RELEVANCE OF FLOW TO ENGAGEMENT}

\section{Flow}

Feedback from an activity

Control during an interaction

Appropriate levels of challenge

Focused attention

Intrinsic motivation

Goal-directed behaviour

Emphasis on the individual and task variables

\section{Engagement}

Perceived usability vital for engagement to be sustained

Complete absorption not necessary; getting "sidetracked" may be acceptable and engaging

May be extrinsic; may be more fruitful to explore motivations as utilitarian and hedonic

Have fun, have an experience; see where the road takes me

Personal and task relevance important, but characteristics of system and content precipitate engagement 


\section{IN THE GAME INDUSTRY?}

\section{Engagement - Engrossment - Total immersion}

(Brown \& Cairns, 2004)

\begin{tabular}{|c|c|c|c|}
\hline Dimension & Category & Valence & Codes \\
\hline \multirow{2}{*}{ Challenge } & Hard & Struggle & Challenging, Hard \\
\hline & Easy & Cope & Easy, Repetitive-Simple \\
\hline \multirow{2}{*}{ Choice } & In-Control & Positive & In-Control, Interactive \\
\hline & Controlled & Negative & Controlled, No-Choice \\
\hline \multirow{2}{*}{ Engagement } & Interested & Positive & Attached, Anticipation, Curious, Interested, Immersed, In-Zone, Focused \\
\hline & Bored & Negative & Bored, Out-of-Game, Repetitive-Boredom, Break \\
\hline \multirow{2}{*}{ Knowledge } & Understand & Positive & Aware, Creative, Experimenting, Learning, Understanding \\
\hline & Confused & Negative & Confused, Don't-Know, Overloaded, Unaware, Unsure-Know \\
\hline \multirow{2}{*}{ Pleasure } & Satisfied & Positive & Cool, Enjoyment, Fun, Happy, Satisfied \\
\hline & Dissatisfied & Negative & Angry, Annoyed, Disappointed, Frustrated, Irritated \\
\hline \multirow{2}{*}{ Power } & Confident & Cope & Calm, Comfortable, Confident, Normal, OK, Powerful, Safe, Successful \\
\hline & Cautious & Struggle & Afraid, Cautious, Reserved, Scared, Stressed, Tense, Worried, Useless \\
\hline \multirow{2}{*}{ Purpose } & Purposeful & Positive & Determined \\
\hline & Aimless & Negative & Disoriented, Lost, No-Plan, No-Direction, Unsure-Plan \\
\hline
\end{tabular}

(Gow et al, 2010)

... not covered in this tutorial ... but should be aware of this line of work. 


\section{MEASURING USER ENGAGEMENT}

Measures

Self-reported Questionnaire, interview, report, engagement product reaction cards, think-aloud
Characteristics

Subjective

Short- and long-term

Lab and field

Small-scale

Product outcome

Cognitive Task-based methods (time spent, engagement follow-on task)

Objective

Short-term

Lab and field

Neurological measures (e.g. EEG) Small-scale and large-

scale

Physiological measures (e.g. eye tracking, mouse-tracking)

Interaction Web analytics engagement

metrics + models

Process outcome
Objective

Short- and long-term

Field

Large-scale

Process 


\section{Subjective perception}

of time (Baldauf, Burgarda \&

- Ask a user to make some estimation of the passage of time during an activity.

Wittmann, 2009)

\section{Physiological} measures

- Involuntary body responses

- Gaze behaviour, mouse gestures, biometrics (e.g., skin condunctance, body temperature, blood volume pulse), facial expression analysis

Follow-on task performance

(Jennett et al, 2008)

\section{Online behaviour}

- How well somebody performs on a task immediately following a period of engaged interaction

- An estimate of the degree and depth of visitor interaction against a clearly defined set of goals

- Based on web analytics (e.g. click-through rate, comments posted)

\section{Search (evaluation)}

- Relate system effectiveness and user satisfaction

- Designing user models is an important and active research area 
- Introduction and Scope

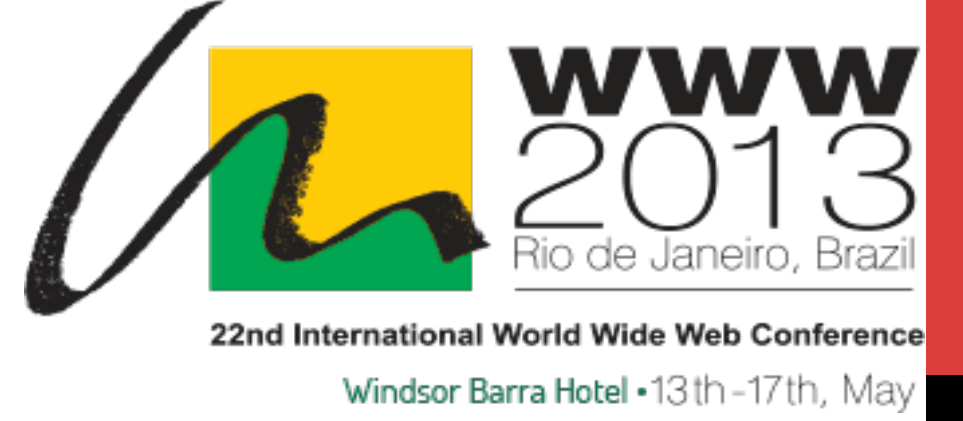

- Part I - Foundations

1. Approaches based on self-report measures

2. Approaches based on web analytics

3. Approaches based on physiological measures

- Part II - Advanced Aspects

1. Measuring user engagement in mobile information searching

2. Networked user engagement

3. Combining different approaches

- Conclusions

○ Bibliography 

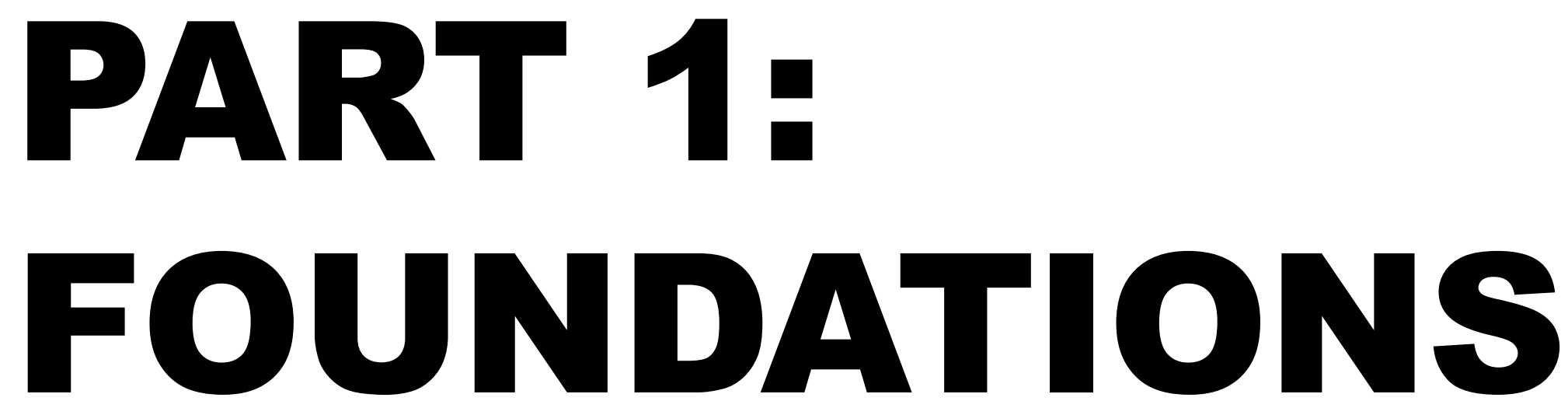

APPROACHES BASED ON SELF-REPORT MEASURES 


\section{INTRODUCTION TO SELF-REPORT MEASURES}

○ What are self-report measures?

- A type of method commonly used in social science where individuals express their attitudes, feelings, beliefs or knowledge about a subject or situation.

○ Why consider self-reports?

- Emphasize individuals' perceptions and subjective experiences of their engagement with technologies.

- Self-report methods may be discrete, dimensional, and free response. (Lopatovska \& Arapakis, 2011) 


\section{ADVANTAGES OF SELF-REPORT MEASURES}

- Flexibly applied in a variety of settings

- High internal consistency for well-constructed measures

- Convenient to administer

- Specificity in construct definition

- Quantitative self-report measures, i.e., questionnaires

- Enable statistical analysis and standardization

- Participant anonymity

- Administered to individuals or groups

- Paper-based or web-based

- Function well in large-sample research studies

(Fulmer \& Frijters, 2009)

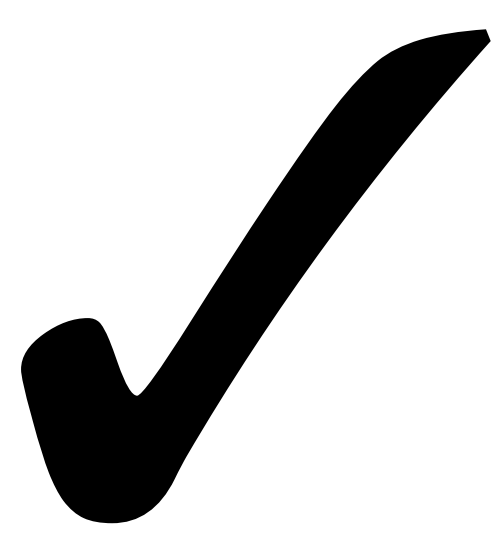




\section{DISADVANTAGES OF SELF-MEASURES}

- Information processing issues

- Interpretation of researchers' questions

- Developmental challenges associated with age or cognitive ability

- Communication issues

- Wording and response options

- Rapport between interviewer and interviewee

- Construct issues

$\circ$ Reliability and validity issues

- Participants' responses

- What does the "neutral" category mean?

- Over-estimate behavior frequency

- Reliance on recollection.

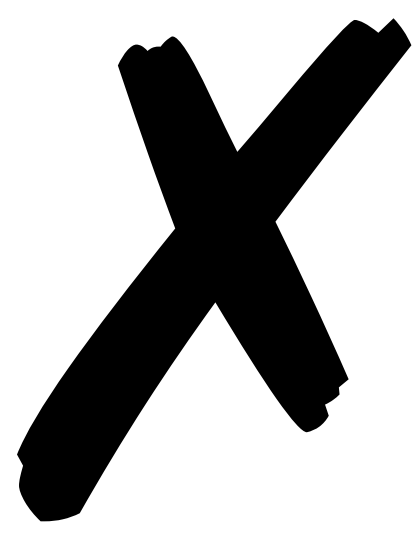

(Fulmer \& Frijters, 2009; Kobayashi \& Boase, 2012) 


\section{APPROACHES TO STUDYING USER ENGAGEMENT WITH SELF-REPORT MEASURES - OUTLINE}

○ Methods

- Interviews

- Think aloud/think after protocols

- Questionnaires

- Examples of employing each method to study engagement

- Examples of using self-report methods 


\section{INTERVIEWS}

○ May be structured, semi-structured or unstructured.

- The interview schedule.

○ May be one-on-one or one-to-many (focus groups).

- May focus on general or specific events, experiences, or timeframes.

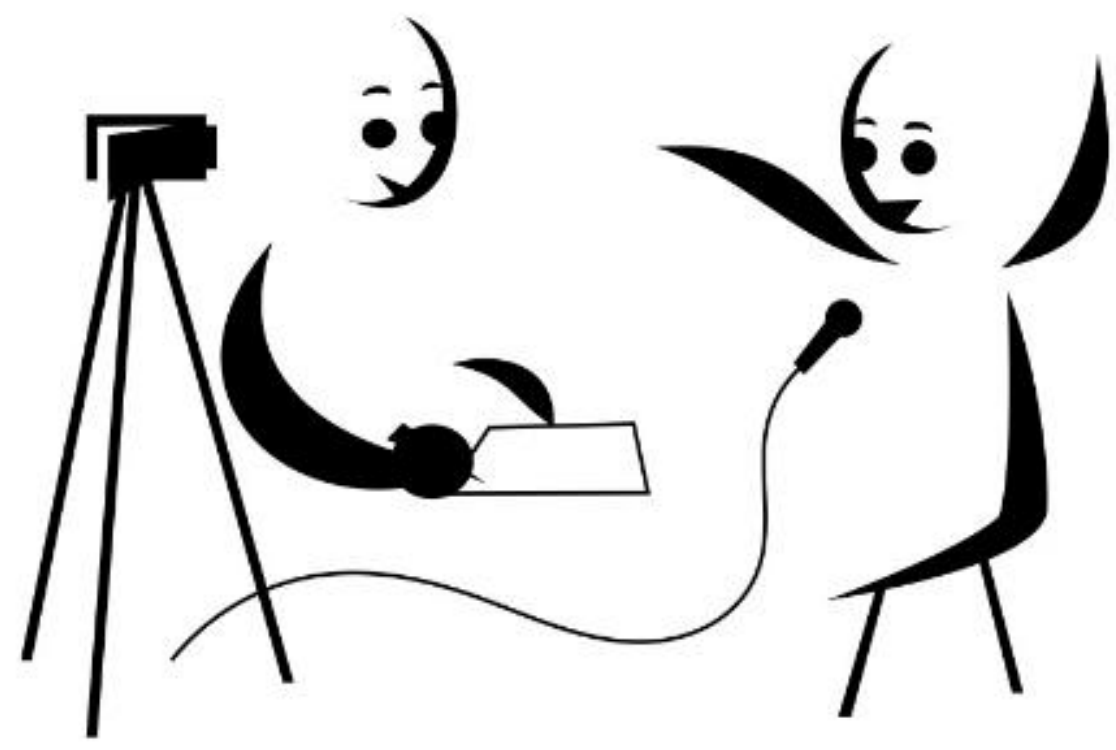

http://openclipart.org/detail/173434/interview-by-jammi-evil-173434 


\section{USING INTERVIEWS TO MEASURE USER ENGAGEMENT}

○ Objectives:

1. To develop an operational definition of engagement, and

2. To identify key attributes of engagement.

○ Who?

- 17 online searchers, gamers, learners and shoppers.

$\circ$ Why interviews?

- How were the questions formulated?

- Grounded in interdisciplinary literature review and theory

-What guided the analysis?

- Threads of Experience (McCarthy \& Wright, 2004)

(O'Brien \& Toms, 35008 ) 
USING INTERVIEWS TO MEASURE USER ENGAGEMENT: OUTCOMES

- Developed a process-based model of user engagement.

- Identified attributes of engagement:

- Aesthetic and sensory appeal, affect, feedback, control, interactivity, novelty, focused attention, motivation, interest.

$\circ$ Mapped attributes to stages in the process model.

$\circ$ Benefit of using interviews. 


\section{THINK ALOUD/THINK AFTER PROTOCOLS}

○ Think aloud

- Verbalization during the human-compute

○ Think after or simulated recall

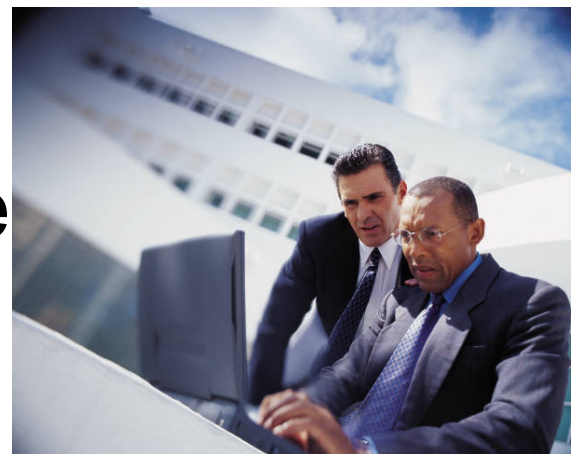

- Verbalization after the human-computer interaction

- Constructive interaction

- Involves two verbalizing their thoughts as they interact with each other

- Spontaneous and prompted self-report

- Participants provide feedback at fixed intervals or at other points defined by the researcher

(Branch, 2000; Ericson \& Simon, 1984; Kelly, 2009; Van den Haak, De Jong, \& Schellens, 2009) 
THINK ALOUD/THINK AFTER PROTOCOLS: CONSIDERATIONS

$\circ$ Automatic processes difficult to articulate.

$\circ$ Complex/highly visual interactions may be challenging to remember and/or verbalize.

$\circ$ Think aloud/spontaneous or prompted self-report

- Unnatural, interruptive

- Increased cognitive load

$\circ$ Think after or simulated recall:

- Relies on memory but attention is less divided

- Researcher can draw participants' attention to specific features of the interface, activities, etc.

(Branch, 2000; Ericson \& Simon, 1984; Kelly, 2009; Van den Haak, De Jong, \& Schellens, 2009) 


\section{USING THINK ALOUD TO STUDY USER}

ENGAGEMENT WITH EDUCATIONAL MULTIMEDIA

- Series of studies with educational multimedia and television advertisements

$\circ$ Think aloud component of the research:

- Identified salient aspects of engagement with content and media

- Content: Perceptions driven by personal interest

- Media: Focus on media preference, presentation, and affordances of control in navigation 


\section{QUESTIONNAIRES}

- Closed-ended (quantitative) and open-ended (qualitative).

○ Effect of mode (Kelly et al., 2008).

- Scale development and evaluation is a longitudinal process.

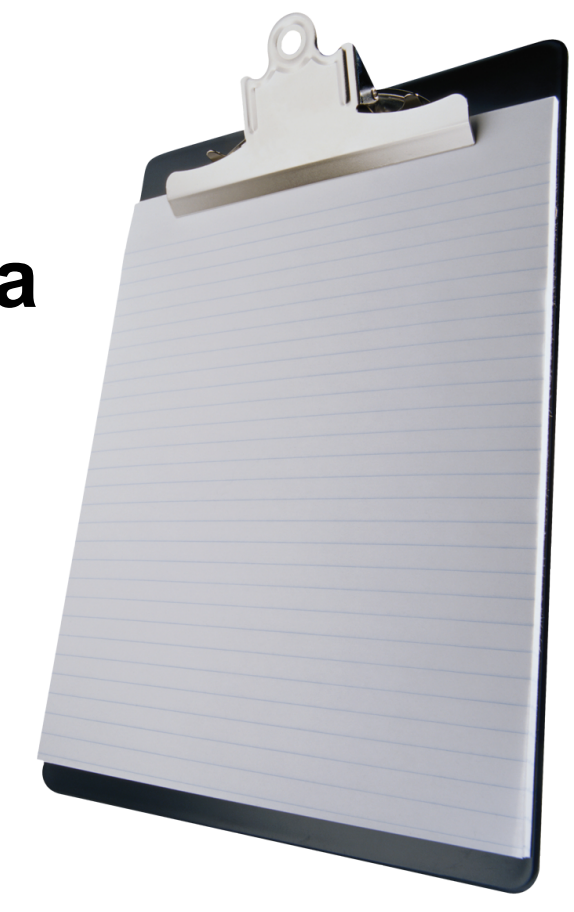




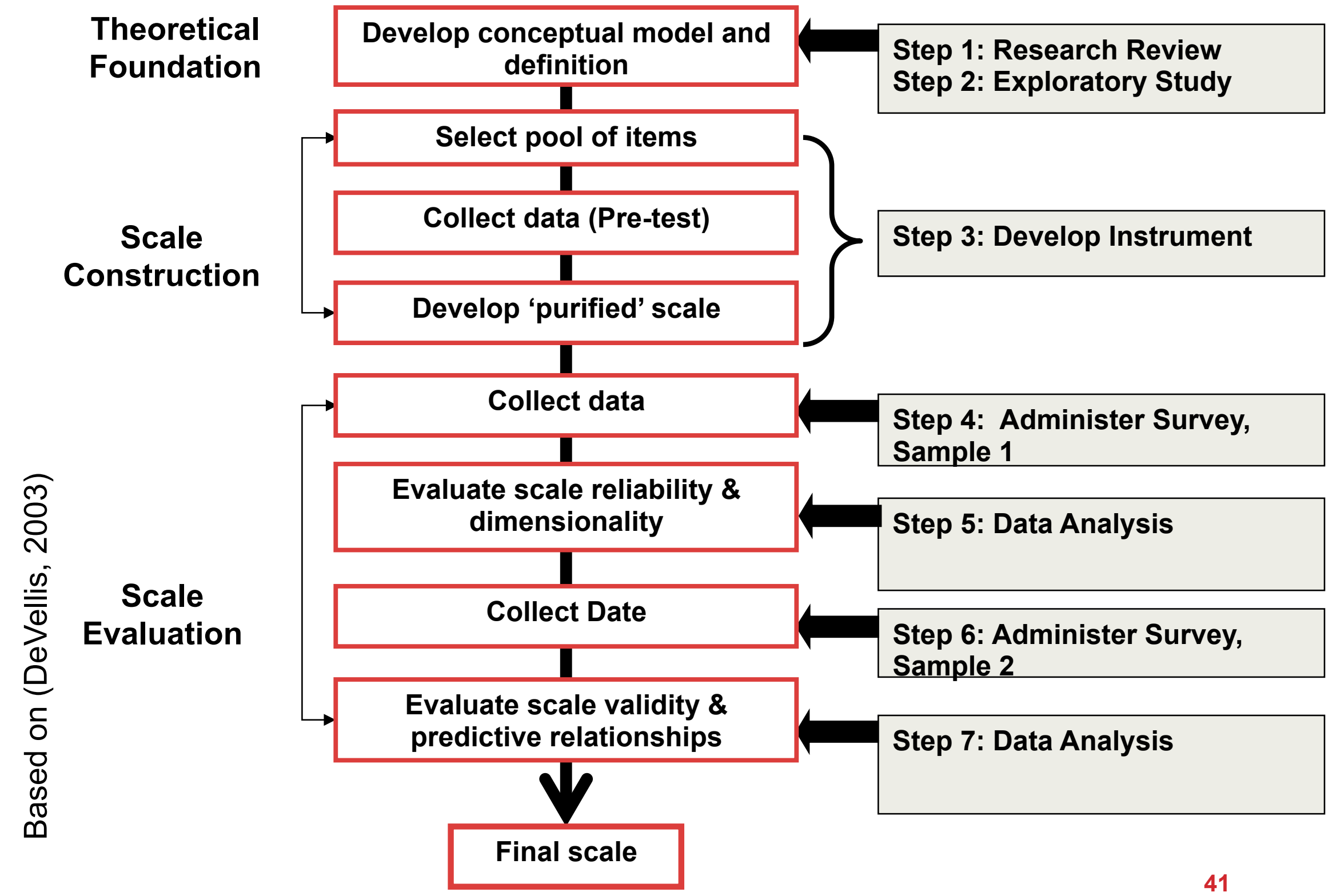




\section{ENGAGEMENT}

○ Jacques, 1996

- 13-items

- Attention, perceived time, motivation, needs, control, attitudes, and overall engagement

○ Webster \& Ho, 1997

- 15-items

- Influences on engagement: including challenge, feedback, control and variety, and

- Engagement, including attention focus, curiosity, intrinsic interest, and overall engagement.

O'Brien \& Toms, 2010 - User Engagement Scale (UES)

- 31-items

- Aesthetic appeal, novelty, felt involvement, focused attention, perceived usability, and endurability (overall experience) 
USING QUESTIONNAIRES TO STUDY ENGAGEMENT: ROLE OF MEDIA FORMAT: EXAMPLE I

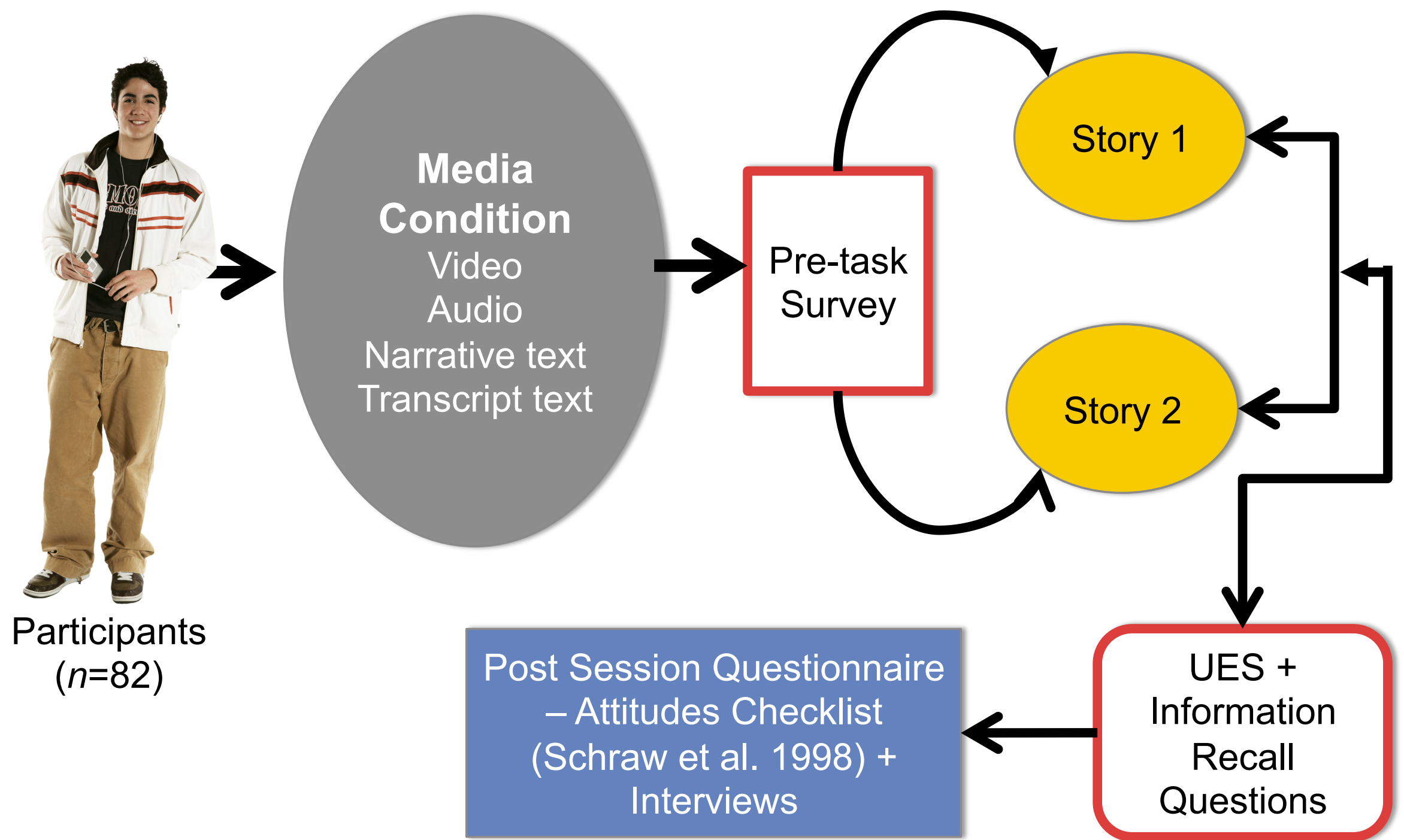

(O’Brien, 2013) 


\section{ROLE OF FORMAT IN MEDIA ENGAGEMENT: PREPARATION AND SCREENING OF UES}

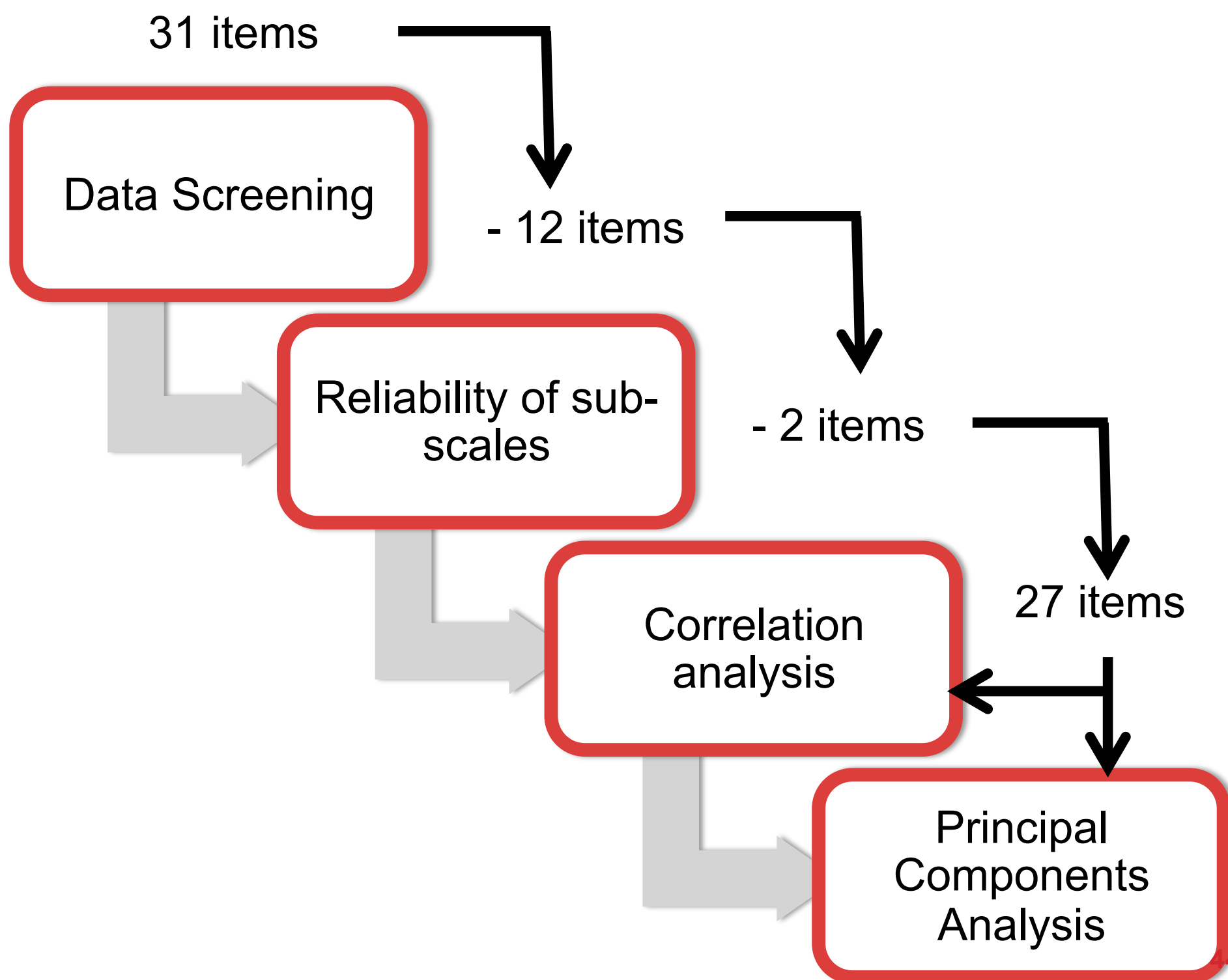


PRINCIPLE COMPONENTS ANALYSIS (PCA) OF REMAINING UES ITEMS

\begin{tabular}{|l|l|l|l|l|}
\hline Component & $\begin{array}{l}\text { Description } \\
\text { Items }\end{array}$ & $\begin{array}{c}\text { No. } \\
\text { Variance }\end{array}$ & $\begin{array}{c}\text { Cronbach's } \\
\text { alpha }\end{array}$ \\
\hline 1 & $\begin{array}{l}\text { Hedonic } \\
\text { Engagement }\end{array}$ & 12 & 47.9 & 0.95 \\
\hline 2 & $\begin{array}{l}\text { Focused } \\
\text { Attention }\end{array}$ & 4 & 11 & 0.87 \\
\hline 4 & $\begin{array}{l}\text { Affective } \\
\text { Usability }\end{array}$ & 4 & 5.9 & 0.75 \\
\hline $\begin{array}{l}\text { Cognitive } \\
\text { effort }\end{array}$ & 2 & 4.6 & 0.83 \\
\hline
\end{tabular}

Kaiser-Meyer-Olkin Measure of Sampling Adequacy $=0.89$ Bartlett's Test of Sphericity $=x^{2}=1621.12(231), p<0.001$ 


\section{FINDINGS FROM THE STUDY}

Relationship between Story and Engagement

\begin{tabular}{|l|c|c|}
\hline Component & Story 1: Farming M(SD) & Story 2: Mining M(SD) \\
\hline Hedonic Engagement & $4.06(1.3)$ & $5.06(1.05)$ \\
\hline Focused Attention & $3.3(1.4)$ & $3.93(1.3)$ \\
\hline Affective Usability & $4.69(1.3)$ & $5.6(0.9)$ \\
\hline Cognitive Effort & $4.19(1.5)$ & $5.29(1.3)$
\end{tabular}

Relationship between Media Condition and Engagement

\begin{tabular}{|l|c|c|c|c|}
\hline Component & $\begin{array}{c}\text { Audio } \\
M(S D)\end{array}$ & $\begin{array}{c}\text { Video } \\
M(S D)\end{array}$ & $\begin{array}{c}\text { Transcript } \\
M(S D)\end{array}$ & $\begin{array}{c}\text { Narrative } \\
M(S D)\end{array}$ \\
\hline $\begin{array}{l}\text { Hedonic } \\
\text { Engagement }\end{array}$ & $4.7(1.2)$ & $5(1.1)$ & $3.9(1.4)$ & $4.5(1.2)$ \\
\hline Focused Attention & $3.6(1.4)$ & $3.8(1.4)$ & $3.5(1.4)$ & $3.5(1.5)$ \\
\hline Affective Usability & $5(1.2)$ & $5.4(1.1)$ & $4.9(1.3)$ & $5(1.2)$ \\
\hline Cognitive Effort & $4.5(1.6)$ & $5.5(1.1)$ & $4.1(1.5)$ & $4.8(1.4)$ \\
\hline
\end{tabular}




\section{FINDINGS FROM THE STUDY (CONTINUED)}

Multivariate Tests for Story and Condition

\begin{tabular}{|l|c|c|c|c|c|}
\hline Effect & $\wedge$ & $F$ & $\operatorname{dif}(1)$ & $\operatorname{dif}(2)$ & $p$ \\
\hline Story & 0.8 & 05.45 & 1 & 98 & .001 \\
\hline Condition & 0.78 & 1.81 & 3 & 98 & .04 \\
\hline Story x Condition & 0.92 & 0.54 & 3 & 98 & .88 \\
\hline
\end{tabular}

Significant F-tests for Univariate Follow-up

\begin{tabular}{|l|c|c|c|c|c|c|}
\hline UES Component & Effect & MS & $F$ & $\operatorname{dif}(\mathbf{1})$ & $\operatorname{dif}(\mathbf{2})$ & $p$ \\
\hline Hedonic Engagement & Story & 14.05 & 9.95 & 1 & 98 & .002 \\
\hline Focused Attention & Story & 10.32 & 4.78 & 1 & 98 & .031 \\
\hline Affective Usability & Story & 23.76 & 17.71 & 1 & 98 & .000 \\
\hline Cognitive Effort & Story & 20.02 & 11.4 & 1 & 98 & .000 \\
\hline Cognitive Effort & Condition & 7.23 & 4.11 & 3 & 98 & .009 \\
\hline
\end{tabular}


- Next steps in data analysis.

- Value of screening and examining the reliability and principal component structure of the UES items.

- Why performance measures would not be significant in this controlled study.

-What was learned about users' perceived engagement in this study. 
EMPLOYING MULTIPLE SELF-REPORT METHODS:

EXAMPLE II

- How the visual catchiness (saliency) of "relevant" information impacts user engagement metrics such as focused attention and emotion (affect)

- focused attention refers to the exclusion of other things

- affect relates to the emotions experienced during the interaction

- Saliency model of visual attention developed by (Itti \& Koch, 2000) 


\section{MANIPULATING SALIENCY}
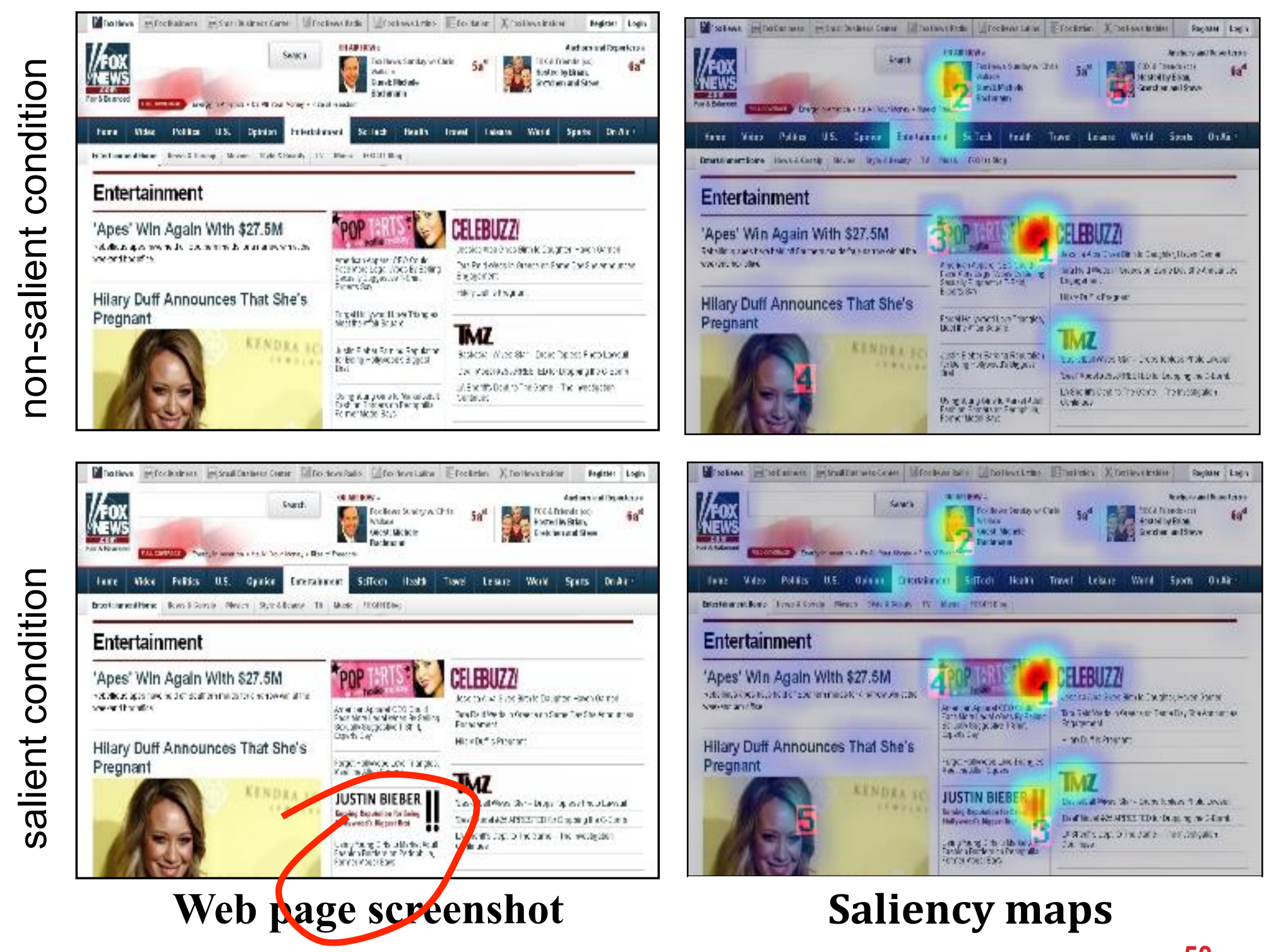

\section{Saliency maps}

(McCay-Peet et al, 2012) 


\section{STUDY DESIGN}

- 8 tasks $=$ finding latest news or headline on celebrity or entertainment topic

- Affect measured pre- and post- task using the Positive e.g. "determined", "attentive" and Negative e.g. "hostile", "afraid" Affect Schedule (PANAS)

- Focused attention measured with 7-item focused attention subscale e.g. "I was so involved in my news tasks that I lost track of time", "I blocked things out around me when I was completing the news tasks" and perceived time

- Interest level in topics (pre-task) and questionnaire (posttask) e.g. "I was interested in the content of the web pages", "I wanted to find out more about the topics that I encountered on the web pages"

- $189(90+99)$ participants from Amazon Mechanical Turk 
PANAS (10 POSITIVE ITEMS AND 10 NEGATIVE ITEMS)

- You feel this way right now, that is, at the present moment

[1 = very slightly or not at all; 2 = a little; 3 = moderately;

4 = quite a bit; 5 = extremely]

[randomize items]

distressed, upset, guilty, scared, hostile, irritable, ashamed, nervous, jittery, afraid interested, excited, strong, enthusiastic, proud, alert, inspired, determined, attentive, active

(Watson, Clark \& Tellegen, 1988) 
7-ITEM FOCUSED ATTENTION SUBSCALE (PART OF THE 31ITEM USER ENGAGEMENT SCALE)

5-POINT SCALE (STRONG DISAGREE TO STRONG AGREE)

1. I lost myself in this news tasks experience

2. I was so involved in my news tasks that I lost track of time

3. I blocked things out around me when I was completing the news tasks

4. When I was performing these news tasks, I lost track of the world around me

5. The time I spent performing these news tasks just slipped away

6. I was absorbed in my news tasks

7. During the news tasks experience I let myself go 
$\circ$ When headlines are visually non-salient

- users are slow at finding them, report more distraction due to web page features, and show a drop in affect

$\circ$ When headlines are visually catchy or salient

- user find them faster, report that it is easy to focus, and maintain positive affect

o Saliency is helpful in task performance, focusing/avoiding distraction and in maintaining positive affect 


\section{SALIENCY AND FOCUSED ATTENTION}

- Adapted focused attention subscale from the online shopping domain to entertainment news domain

- Users reported "easier to focus in the salient condition" BUT no significant improvement in the focused attention subscale or differences in perceived time spent on tasks

o User interest in web page content is a good predictor of focused attention, which in turn is a good predictor of positive affect 


\section{SELF-REPORTING, CROWDSOURCING, SALIENCY AND USER ENGAGEMENT}

- Interaction of saliency, focused attention, and affect, together with user interest, is complex.

$\circ$ Using crowdsourcing worked!

$\circ$ What next?

- include web page content as a quality of user engagement in focused attention scale

- more "realistic" user (interactive) reading experience

- other measurements: mouse-tracking, eye-tracking, facial expression analysis, etc. 
CONSIDERATIONS WHEN EMPLOYING SELF-REPORT MEASURES

$\circ$ What is the research question?

$\circ$ What is the most suitable self report method?

$\circ$ How might we use self-report in studies of user engagement?

- Gather data explicitly about engagement

- Other self-report measures may predict, validate, or enrich other measures of engagement

$\circ$ Why do self-reports get a bad rap? 

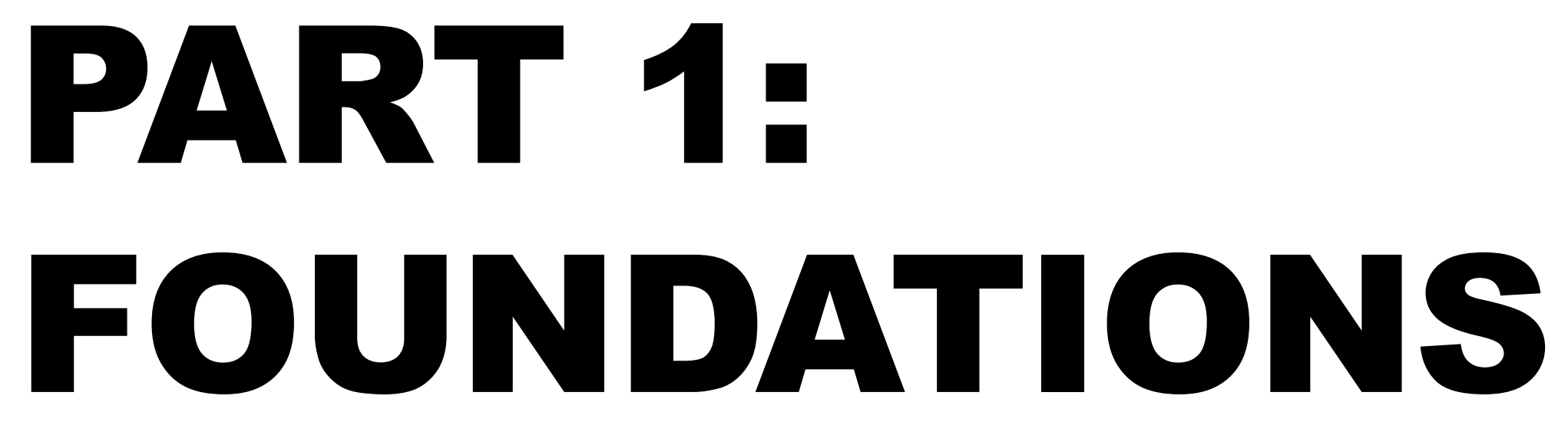

APPROACHES BASED ON WEB ANALYTICS 


\section{WEB ANALYTICS}

\section{Revenue}

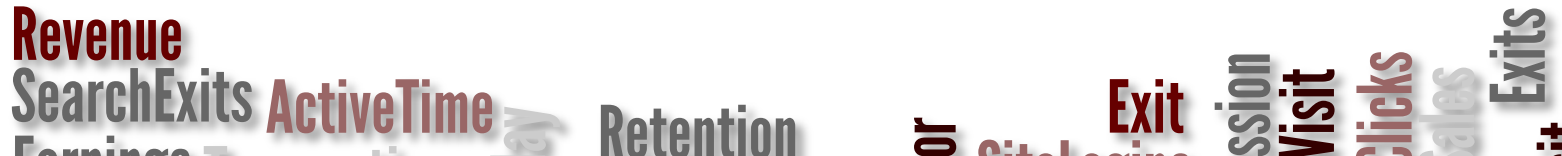

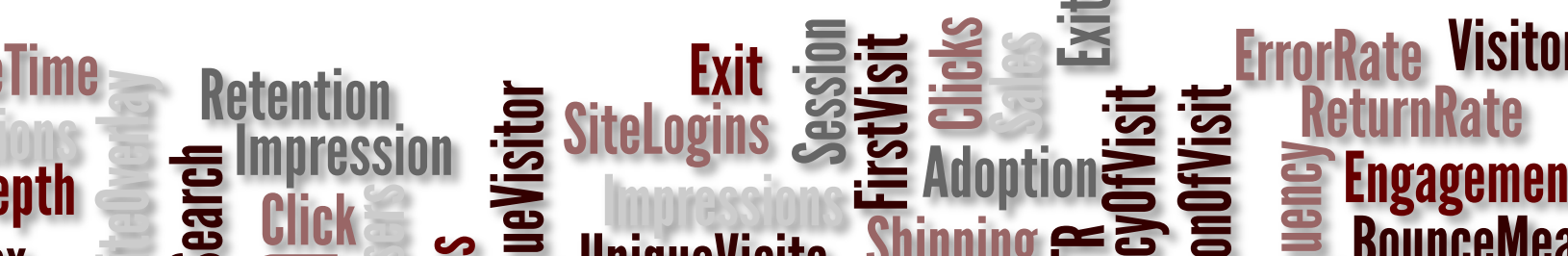

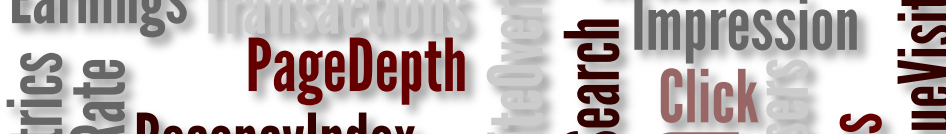
를 畗言 Recentnessofvisit 를 -

\section{PàgeViews b

SessionPerUnique NavigationPaths CPM
GoalitoAValue

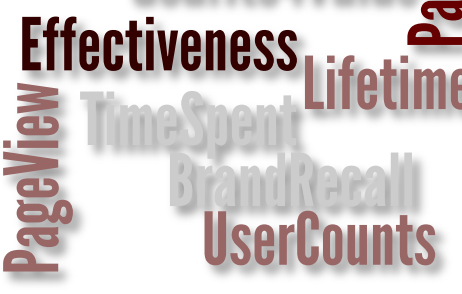

SAdoption
를 Engagement

BounceMeasure . VisibilityTime:

a

흐르를 UniqueVisits Shipping 등흘

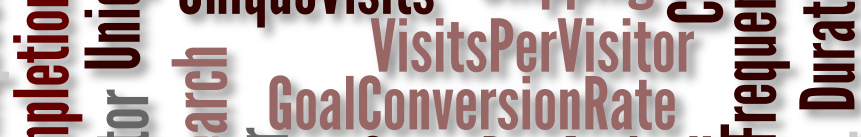

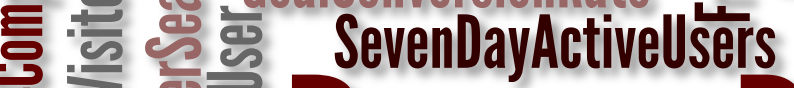
Happiness ConversionRate Goal Conversions De Durationlindex :

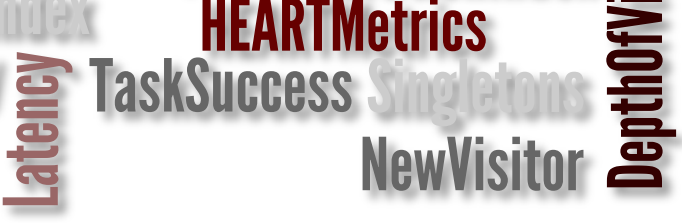


○ Click Depth Index: page views

○ Duration Index: time spent

- Recency Index: rate at which users return over time

- Loyalty Index: level of long-term interaction the user has with the site or product (frequency)

- Brand Index: apparent awareness of the user of the brand, site, or product (search terms)

- Feedback Index: qualitative information including propensity to solicit additional information or supply direct feedback

- Interaction Index: user interaction with site or product (click, upload, transaction)

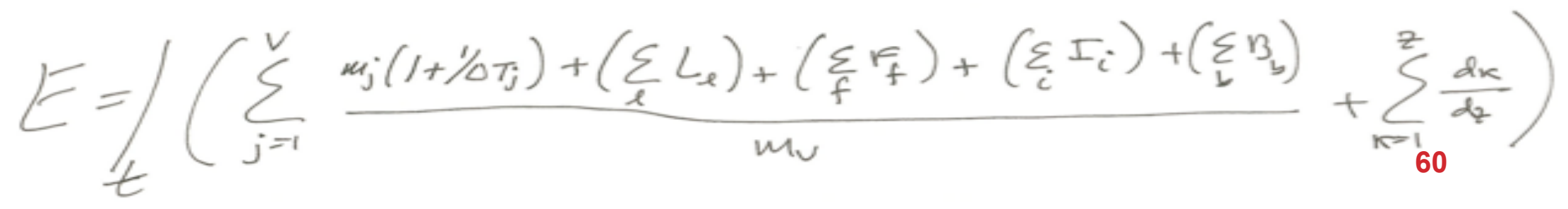


- Intra-session engagement measures our success in attracting the user to remain on our site for as long as possible

- "Long-term engagement can be defined as the degree of voluntary use of a system along a wide period of time..." (Febretti and Garazotto, 2009)

- Inter-session engagement can be measured directly or, for commercial sites, by observing lifetime customer value (CTR, etc.).

- Some studies (Lehmann et al, 2011) report some correlation between inter- and intra-session measures, for example, dwell time and number of active days $(\varrho=-0.66)$ 
WHY NOT USE INTRA-SESSION MEASURES

EXCLUSIVELY?

- We seek to have users return to the site again and again, and to perceive the site as beneficial to them

- Intra-session measures can easily mislead, especially in for a short time (Kohavi et al, 2012):

- Consider a very poor ranking function introduced into a search engine by mistake

- Therefore, bucket testing may provide erroneous results if intra-session measures are used

$\circ$ Hence inter-session (long-term) engagement is the preferred measure 


\section{DEPENDENCY ON USER TYPE}

(Lehmann et al, 2012) observed that different users engage with sites differently.

Users were defined according to the number of days per month that a site is used:

- Tourists: 1 day

- Interested: 2-4 days

- Average: 5-8 days

- Active: 9-15 days

- VIP: more than 16 days

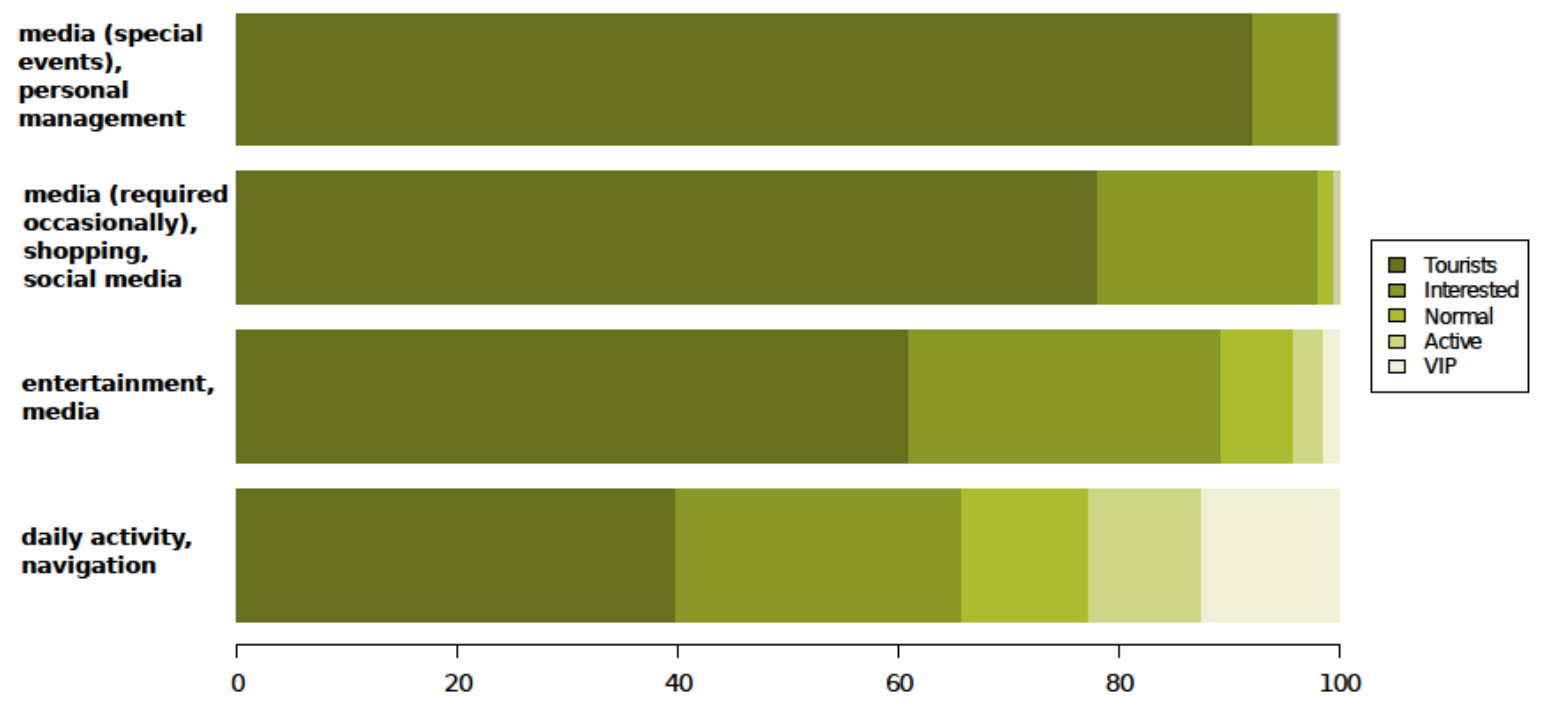

Sites from the Yahoo! network were clustered according to the proportion of users from each group.

The figure shows that different sites receive different user types and corresponding usage. 


\section{DEPENDENCY ON TASK AND WEBSITE}

$\circ$ Engagement varies by task. For example, a user who accesses a website to check for emails (a goal-specific task) has different engagement patterns from one who is browsing for leisure.

- In one study (Yom-Tov et al, 2013), sessions in which $\mathbf{5 0 \%}$ or more of the visited sites belonged to the five most common sites (for each user) were classified as goal-specific.

- Goal-specific sessions accounted for $38 \%$ of sessions

- Most users (92\%) have both goal-specific and non-goal-specific sessions.

- The average downstream engagement (more later) in goal-specific sessions was 0.16 . This is to be contrasted with 0.2 during non-goalspecific sessions.

- Dependence on website is clear: news site will see different engagement patterns that online shopping sites. 


\begin{tabular}{|c|c|c|}
\hline & Intra-session measures & Inter-session measures \\
\hline Single site & $\begin{array}{ll}\text { - } & \text { Dwell time I session } \\
\text { - } & \text { Plaration } \\
\text { - } & \text { Click through rate (CTR) } \\
\text { - } & \text { Mouse movement } \\
\text { - } & \text { Number of pages viewed } \\
\text { (click depth) } \\
\text { - Conversion rate (mostly } \\
\text { for e-commerce) }\end{array}$ & $\begin{array}{l}\text { - } \text { Fraction of return visits } \\
\text { - } \text { Time between visits (inter- } \\
\text { - } \text { session time, absence time) } \\
\text { - } \quad \text { Total view time per month (video) } \\
\text { - Lifetime value } \\
\text { - Number of sessions per unit of } \\
\text { time } \\
\text { - Total usage time per unit of time } \\
\text { - Number of friends on site (Social } \\
\text { networks) }\end{array}$ \\
\hline
\end{tabular}

Multiple sites - Downstream engagement

- Revisits 


\section{ANOTHER CATEGORIZATION OF MEASURES}

- (Lehmann et al, 2012) used a different categorization of measures:

- Popularity: Total number of users to a site, number of visits, and number of clicks

- Activity: Number of page views per visit, time per visit (dwell time)

- Loyalty: Number of days a user visits a site, number of times visited, total time spent

- Each of these categories captures a different facet of engagement, and are therefore not highly correlated

... more about this later
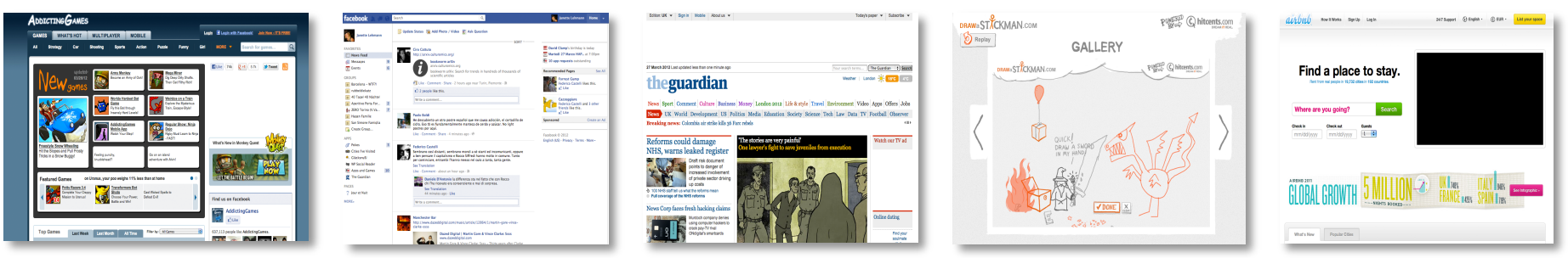


\section{DWELL TIME AND OTHER SIMILAR MEASURES}

- Definition

The contiguous time spent site or web page

- Similar measures

Play time (for video sites)

$\circ$ Cons

Not clear that the user was actually looking at the site while there

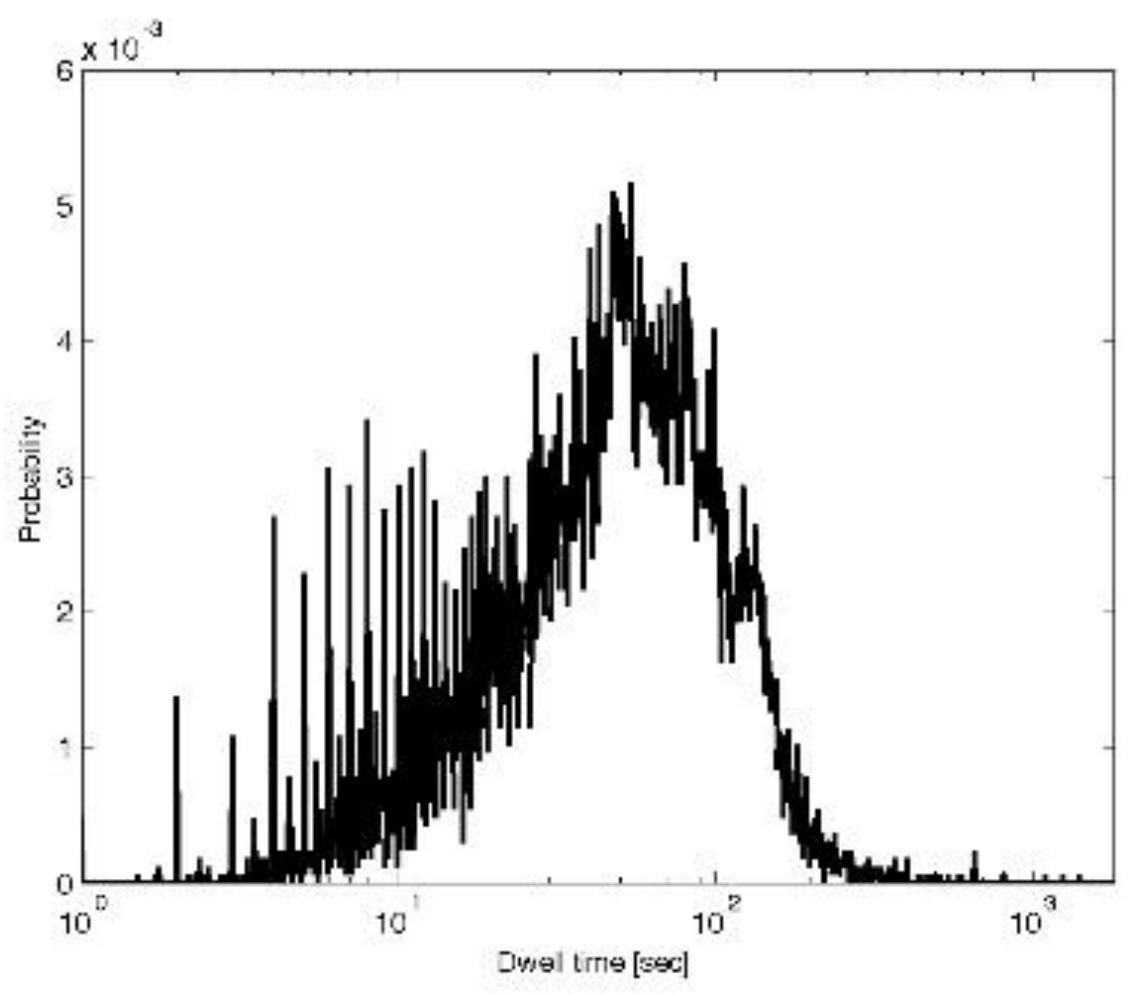

Distribution of dwell times on 50 Yahoo! websites 


\section{DISTRIBUTION OF DWELL TIMES ON 50 YAHOO! SITES}

- Dwell time varies by site type: leisure sites tend to have longer dwell times than news, ecommerce, etc.

- Dwell time has a relatively large variance even for the same site

(recall tourists, VIP, active ... users)

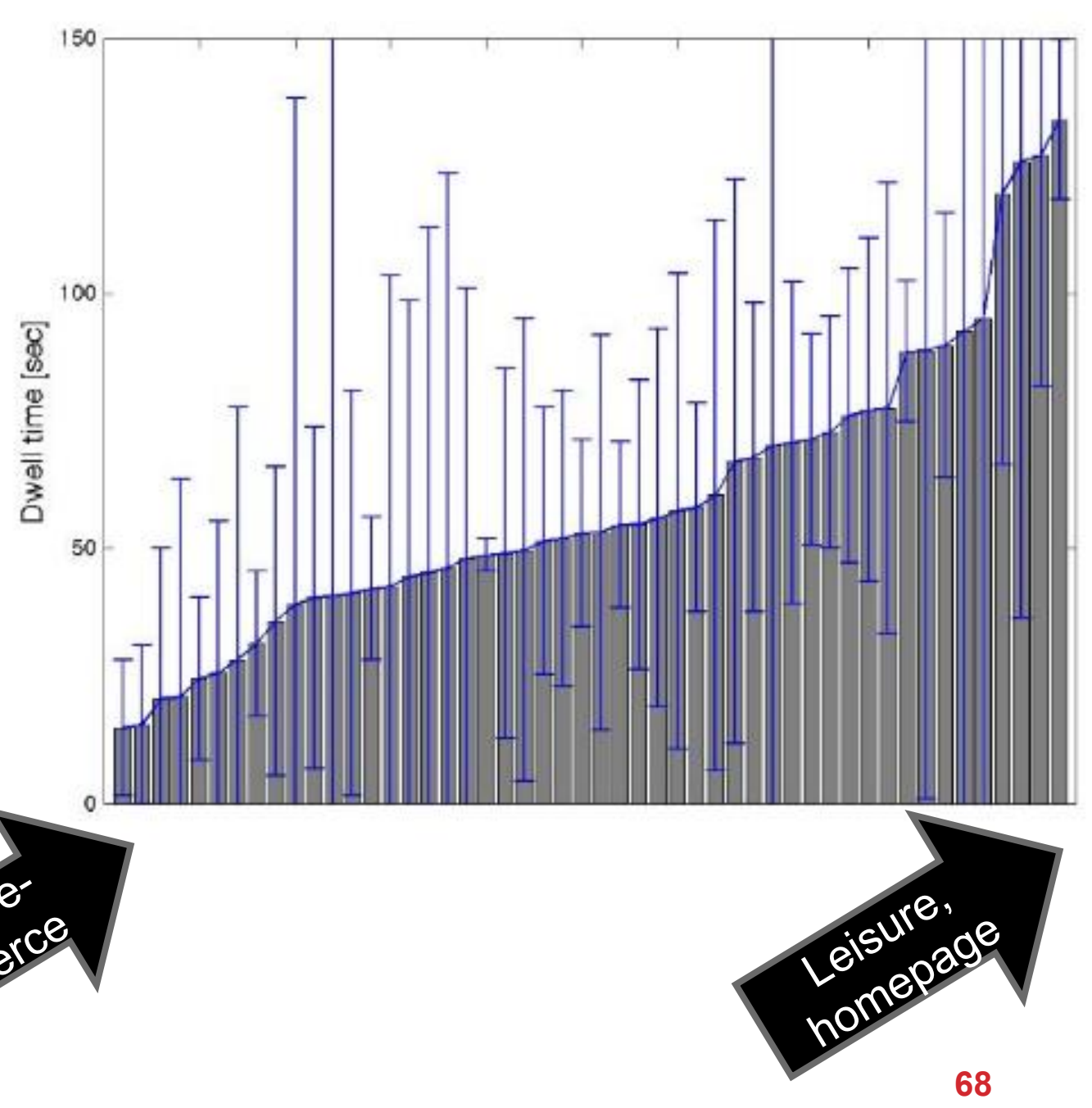




\section{DISTRIBUTION OF USER REVISITS TO A LIST OF YAHOO! SITES (WITHIN SESSION)}

- User revisits are common in sites which may be browser homepages, or contain content which is of regular interest to users.

- Goal-oriented sites (e.g., e-commerce) have lower revisits in the time range observed, meaning that revisit horizon should be adjusted by site.

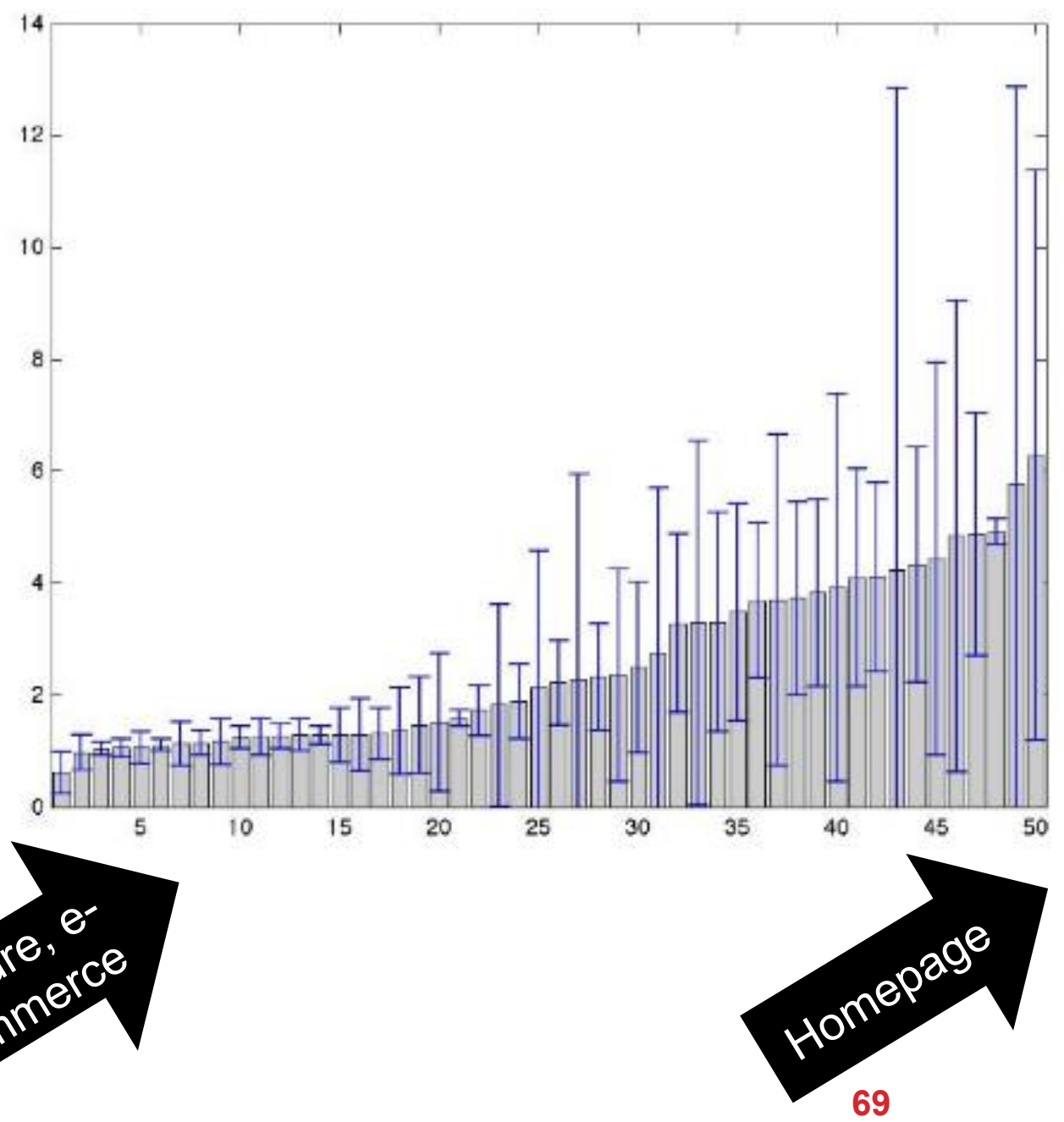




\section{OTHER INTRA-SESSION MEASURES}

- Clickthrough rate (CTR): number of clicks (e.g., on an ad) divided by the number of times it was shown.

$\circ$ Number of pages viewed (click depth): average number of contiguous pages viewed within a site

- Can be problematic if the website is ill-designed.

- Number of returns to the website within a session

- Useful for websites such as news aggregators, where returns indicate that the user believes there may be more information to glean from the site.

- Conversion rate (mostly for e-commerce): fraction of sessions which end in a desired user action (e.g., purchase)

- Not all sessions are expected to result in a conversion, so this measure not always informative. However, it has the advantage of being closer to a website manager's goal. 


\section{INTER-SESSION ENGAGEMENT MEASURES}

\section{In general, these are the preferred measures of engagement}

- Direct value measurement:

- Lifetime value, as measured by ads clicked, monetization, etc.

○ Return-rate measurements:

- Fraction of return visits: How many users return for another visit?

- Time between visits (inter-session time, absence time)

- Number of distinct views (video)

- Total use measurements:

- Total usage time per unit of time

- Number of sessions per unit of time

- Total view time per month (video)

- Number of friends on site (social networks) 


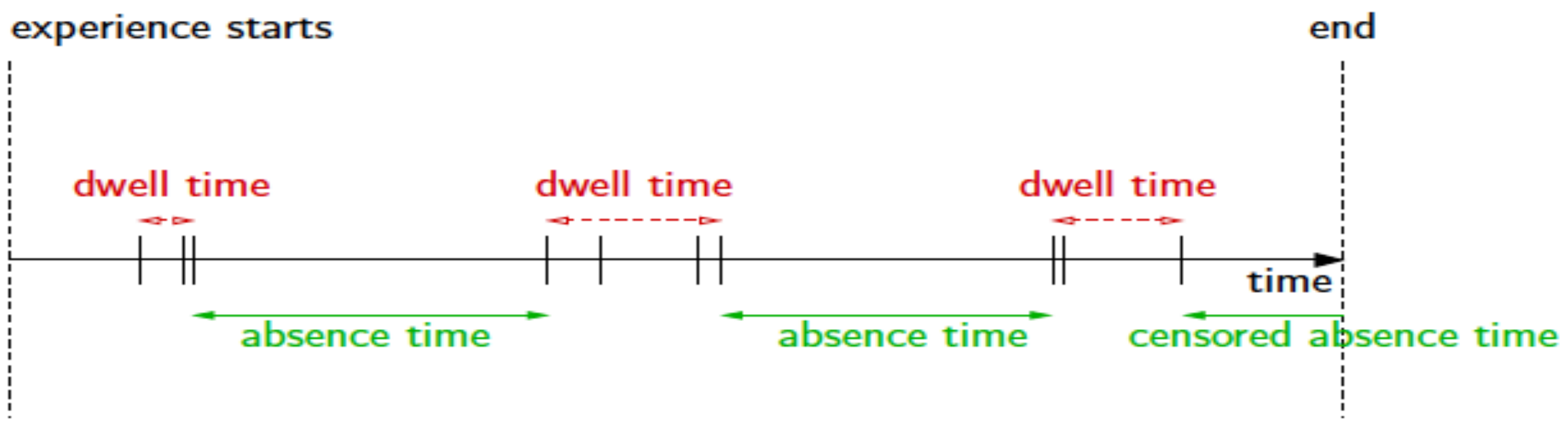

Yahoo! Japan (Answers search)

$$
h(t)=h_{0}(t) \exp \left(\beta_{i} \mathbb{1}_{\text {nclicks }}=\mathbf{i}\right)
$$

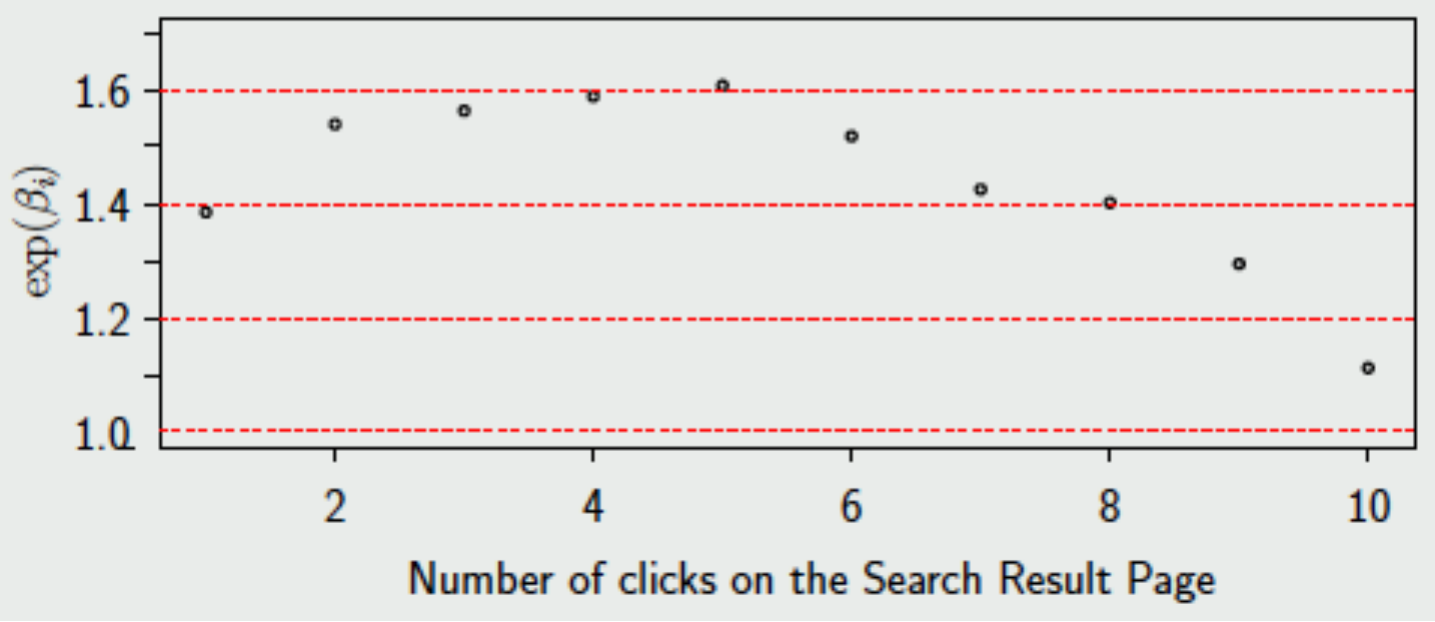

Easy to implement and interpret

Can compare many things in one go

No need to estimate baselines

But need lots of data to account for noise 
MODELS OF USER ENGAGEMENT BASED ON WEB ANALYTICS
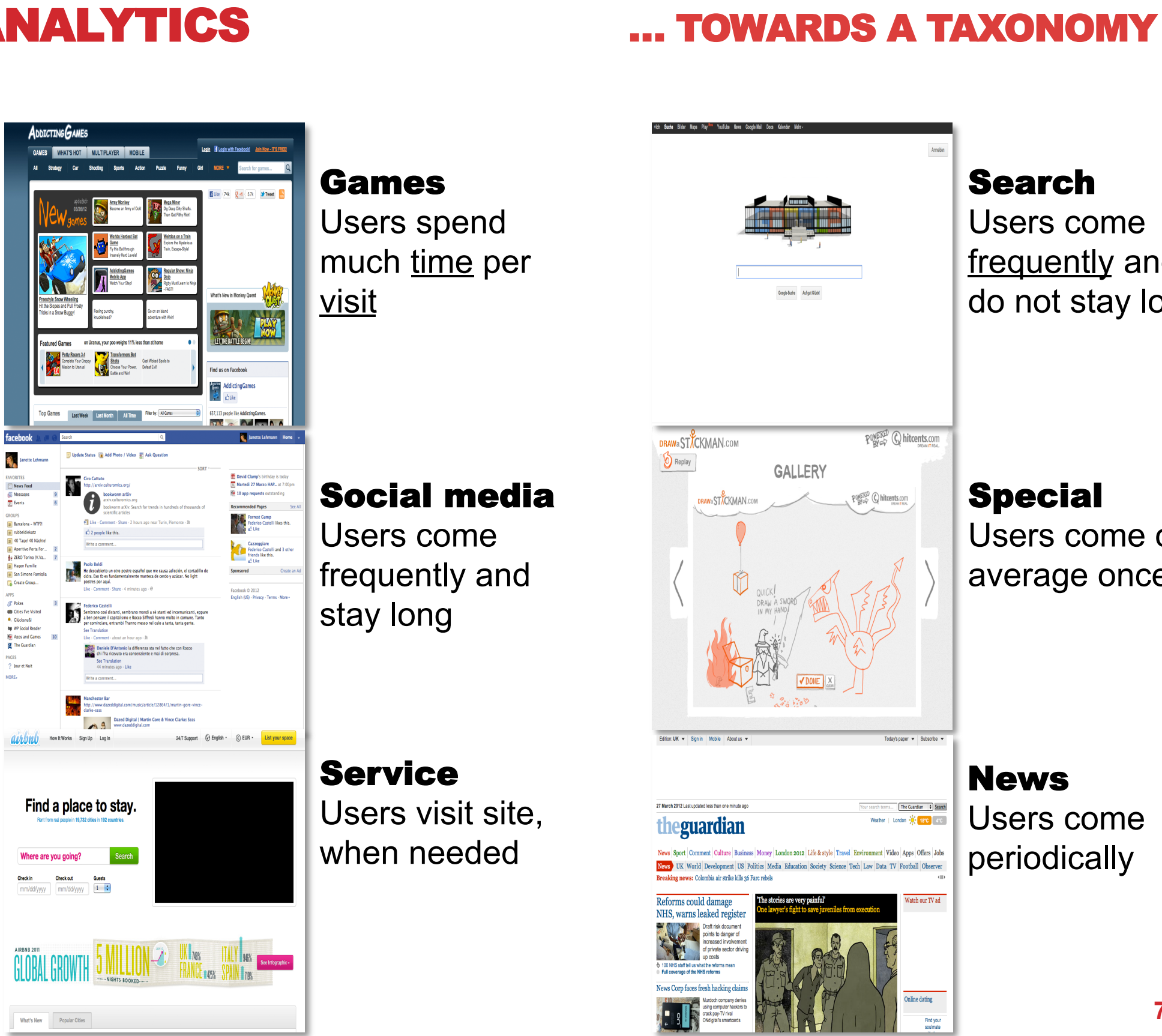

\section{Games}

Users spend much time per

visit

Social media

Users come

frequently and

stay long

\section{Service}

Users visit site, when needed

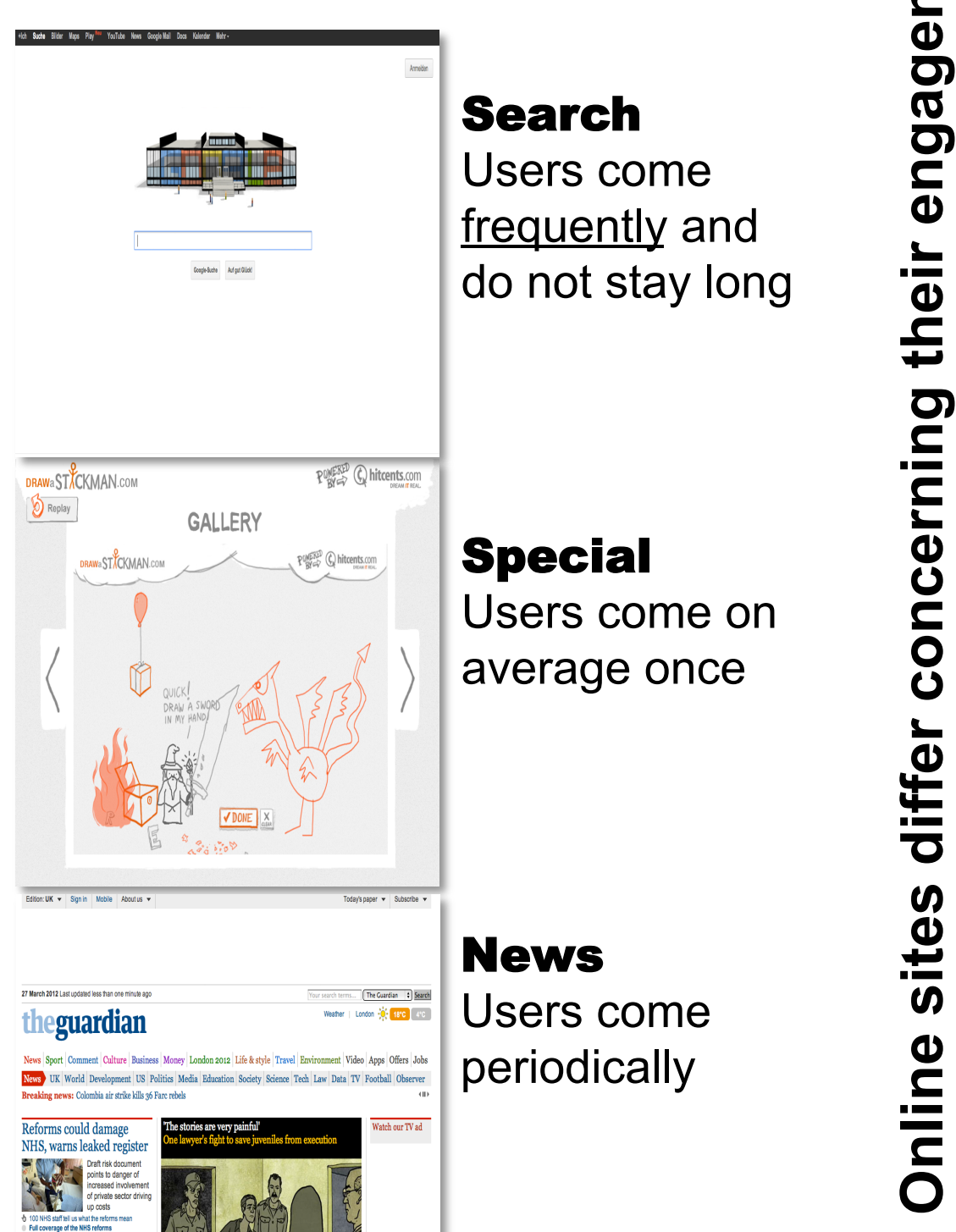




\section{Interaction data, $2 \mathrm{M}$ users, July 2011, 80 US sites}

\begin{tabular}{lll}
\hline Popularity & \#Users & Number of distinct users \\
& \#Visits & Number of visits \\
\#Clicks & Number of clicks \\
\hline Activity & ClickDepth & Average number of page views per visit. \\
& DwellTimeA & Average time per visit \\
\hline Loyalty & ActiveDays & Number of days a user visited the site \\
& ReturnRate & Number of times a user visited the site \\
& DwellTimeL & Average time a user spend on the site.
\end{tabular}




\section{METHODOLOGY}

\section{General models}

Dimensions

8 measures

\section{Time-based models}

weekdays, weekend

8 metrics per time span

\#Dimensions

8

16

Kernel k-means with

Kendall tau rank correlation kernel

$\mathrm{Nb}$ of clusters based on eigenvalue distribution of kernel matrix

Significant metric values with Kruskal-Wallis/Bonferonni

\#Clusters

(Models)
6

5

Analysing cluster centroids $=$ models 


\section{MODELS OF USER ENGAGEMENT \\ [6 GENERAL]}

- Popularity, activity and loyalty are independent from each other

- Popularity and loyalty are influenced by external and internal factors

e.g. frequency of publishing new information, events, personal interests

$\circ$ Activity depends on the structure of the site

\section{interest-specific}

\begin{tabular}{|c|c|c|c|c|c|}
\hline $\begin{array}{l}\text { periodic } \\
\text { media }\end{array}$ & & popularity & $\begin{array}{c}\text { activity } \\
\text { [ClickDepth] }\end{array}$ & $\begin{array}{c}\text { activity } \\
\text { [DwellTime] }\end{array}$ & loyalty \\
\hline e-comme & $\begin{array}{l}\text { model } \mathrm{m}_{\mathrm{g} 6} \\
\text { modelel } \mathrm{m}_{\mathrm{g} 5} \\
\text { model } \mathrm{m}_{\mathrm{g}}\end{array}$ & -- & $\ddot{-}$ & +- & $\begin{array}{l}++ \\
--\end{array}$ \\
\hline \multirow{2}{*}{$\begin{array}{l}\text { media (daily) } \\
\text { search }\end{array}$} & $\Rightarrow$ model $\mathrm{m}_{\mathrm{g} 1}$ & ++ & & & \\
\hline & & & lerage ++ high & - - low & \\
\hline
\end{tabular}




\section{TIME-BASED [5 MODELS]}

Models based on engagement over weekdays and weekend

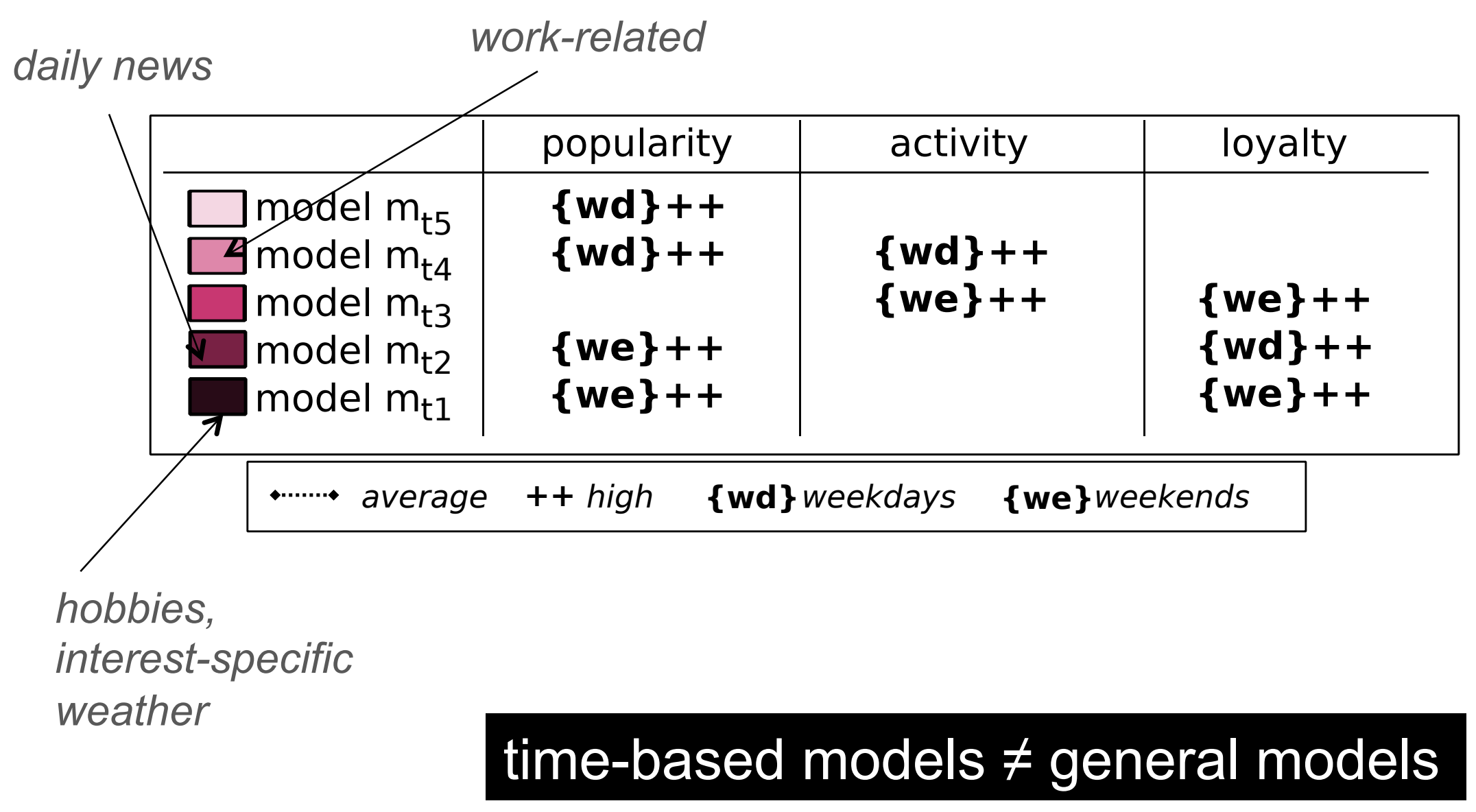




\section{MODELS OF USER ENGAGEMENT}

- User engagement is complex and standard metrics capture only a part of it

- User engagement depends on time (and users)

- First step towards a taxonomy of models of user engagement ... and associated measures

$\circ$ What next?

- More sites, more models, more measures

- User demographics, time of the day, geo-location, etc.

- Online multi-tasking 


\section{ONLINE MULTI-TASKING}

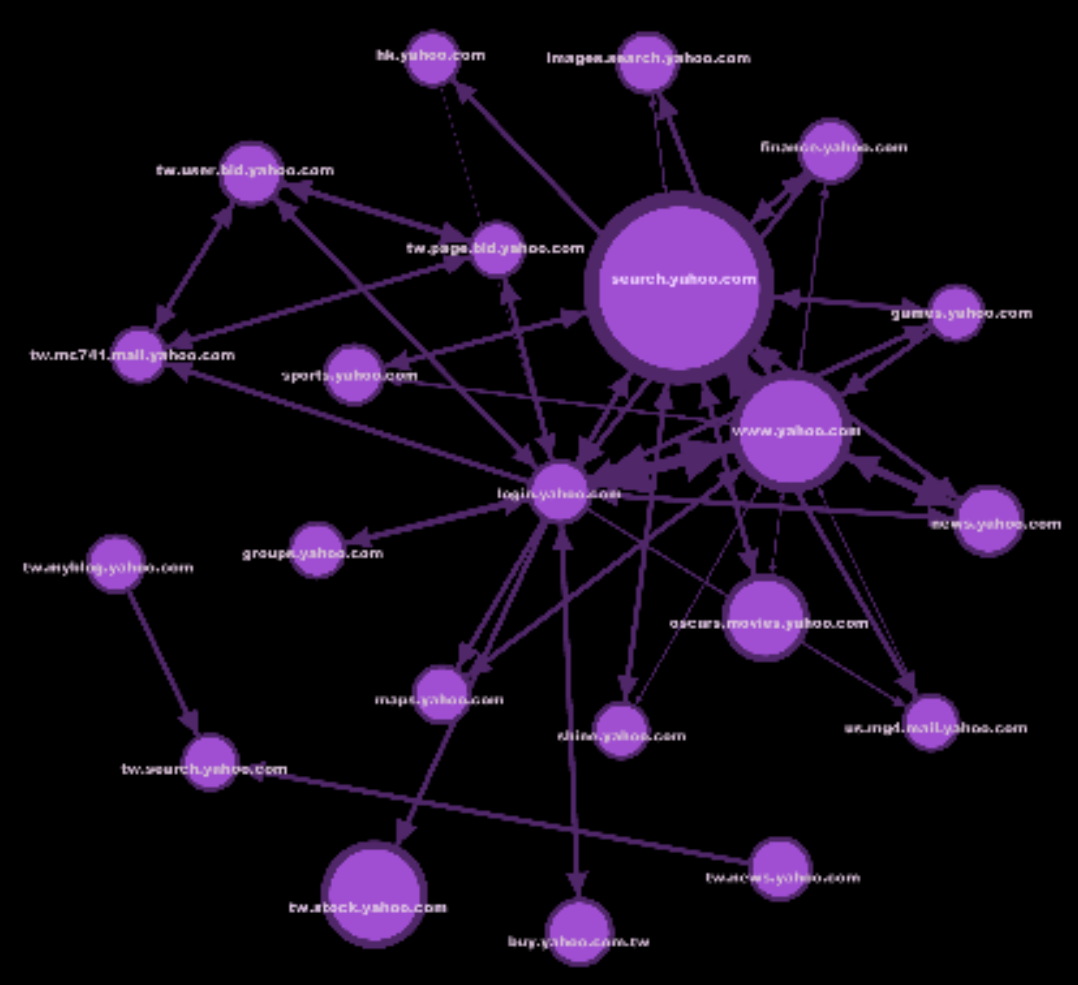

$181 \mathrm{~K}$ users, 2 months browser data, 600 sites, $4.8 \mathrm{M}$ sessions

-only $40 \%$ of the sessions have no site revisitation

-hyperlinking, backpaging and teleporting

\section{leaving a site is not a "bad thing!"}

(fictitious navigation between sites within an online session)

users spend more and more of their online session multi-tasking, e.g. emailing, reading news, searching for information $\rightarrow$ ONLINE MULTI-TASKING navigating between sites, using browser tabs, bookmarks, etc seamless integration of social networks platforms into many services 


\section{HEART FRAMEWORK: PUTTING IT ALL TOGETHER}

- Happiness

- Satisfaction

○ Engagement

- Adoption

○ Retention

○ Task success

- Efficiency and effectiveness

- Based on experience in working with usercentered products

- Not all measures appropriate to all products

HEART framework are "more" about user experience 
$\circ$ Page views

- Increase may mean increase of popularity or getting lost

○ Uptime

- Outage is bad

○ Latency

- Slow is bad

- Seven-day active users

- Number of users who used the application at least once a week

- Does not differentiate between new and returning users

$\circ$ Earnings

- Two many steps in purchasing flow is bad

- Short-term vs. long-term 


\section{HAPPINESS}

- Subjective aspects

- satisfaction, visual appeal, likelihood to recommend, perceived ease of use

$\circ$ Survey

- Possibility to track over time

iGoogle (personalised home page)

weekly in-product survey

major redesign $\rightarrow$ satisfaction decreases (1...7)

over time $\Rightarrow$ measure recovers

(sign of change aveirsion) 


\section{ENGAGEMENT}

- Level of involvement

- Behavioral proxies

- Frequency, intensity, depth of interaction over a time period

$\circ$ Reported as an average and not in total

GMAIL example
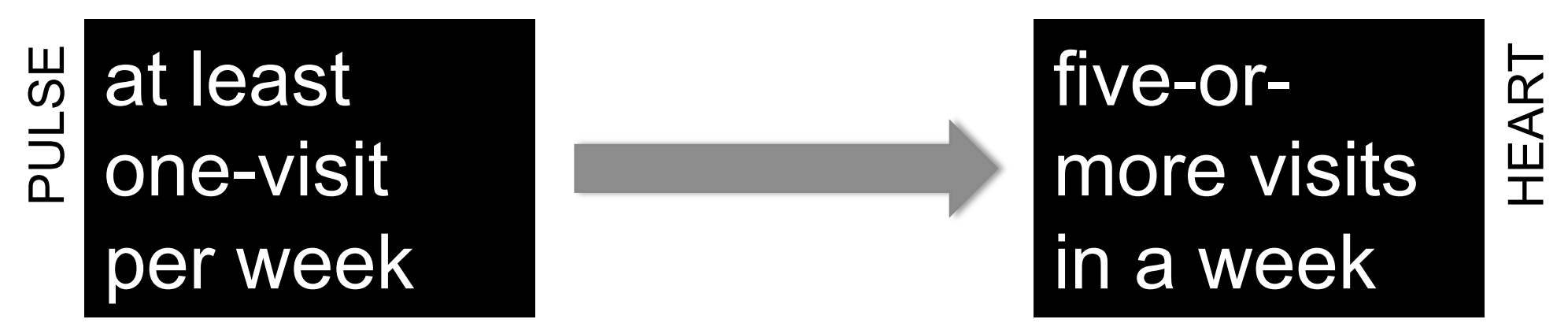

strong predictor of long-term retention 


\section{ADOPTION AND RETENTION}

- Adoption: how many new users for a given period

- Retention: percentage of users still active after some given period

- Useful for new applications or those undergoing change

- Should account for seasonal changes and external events

Google Finance (stock market meltdown 2008)

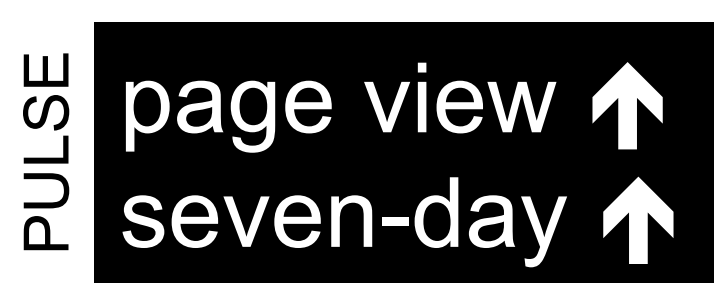

new users interested in the crisis?? current users panicking?

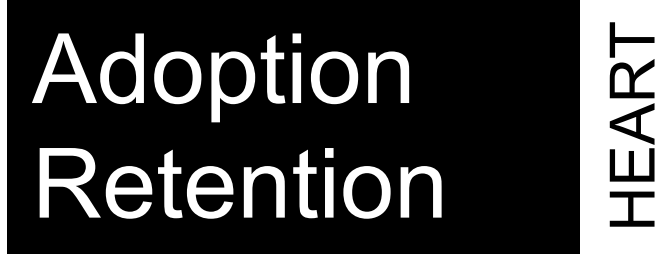

new users staying?

better understanding of event-driven traffic spikes 


\section{TASK SUCCESS}

- Behavioral measures of user experience

- efficiency (e.g. time to complete a task); effectiveness (e.g. percent of task completed); error rate

- Remote usability on a large scale

- Difficult with standard log data unless an optimal path exists for a type of task

Google map

dual box for search

- what

- where

A/B testing

Error rates

\section{single search box}




\section{GOALS - SIGNALS - MEASURES}

$\circ$ Measures

- should relate to one or several goals of the application/product

- Used to track progress towards that goal

1. articulate the goal(s) of an application/feature

2. identify signals that indicate success

3. build/chose corresponding measures to track 


\section{GOALS - SOME TIPS}

- What are the goals of the product/features in terms of user experience (user engagement)?

- What tasks users need to accomplish?

- What is the redesign cycle trying to achieve?

- Retention or adoption:

- Is it more important to acquire new users or to keep existing ones more engaged?

- Goal associated with a feature is not the same as goal of the whole product

- Measures (to be used or developed) should not be used to solely drive the goals 


\section{SIGNALS - SOME TIPS}

- What is success? What is failure?

- What feelings and perceptions correlate with success and failure?

- What actions indicate that goals are met?

- Data sources

- logs, surveys, panel of judges

○ Sensitive and specific signals

- need to observe some reaction when user experience is better or worse

- failure often easier to identify than success

- undo event, abandonment, frustration 


\section{MEASURES - SOME TIPS}

$\circ$ Raw counts need to normalised

$\circ$ Ratios, percentages, and average per users often more useful

$\circ$ Accuracy of metrics

- bots, all important actions recovered

- Keep comparing measures with "conventional" ones (e.g. comscore matters) 

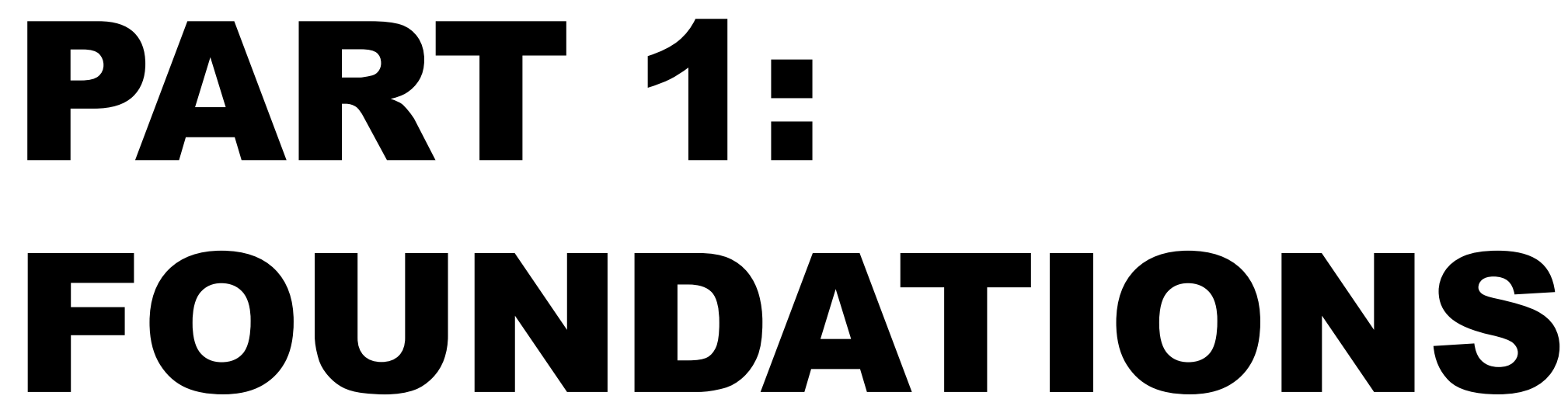

APPROACHES BASED ON PHYSIOLOGICAL MEASURES 
PHYSIOLOGICAL MEASURES

$\circ$ Eye tracking

- Mouse movement

- Face expression

- Psychophysiological measures

Respiration, Pulse rate Temperature, Brain wave, Skin conductance, ...
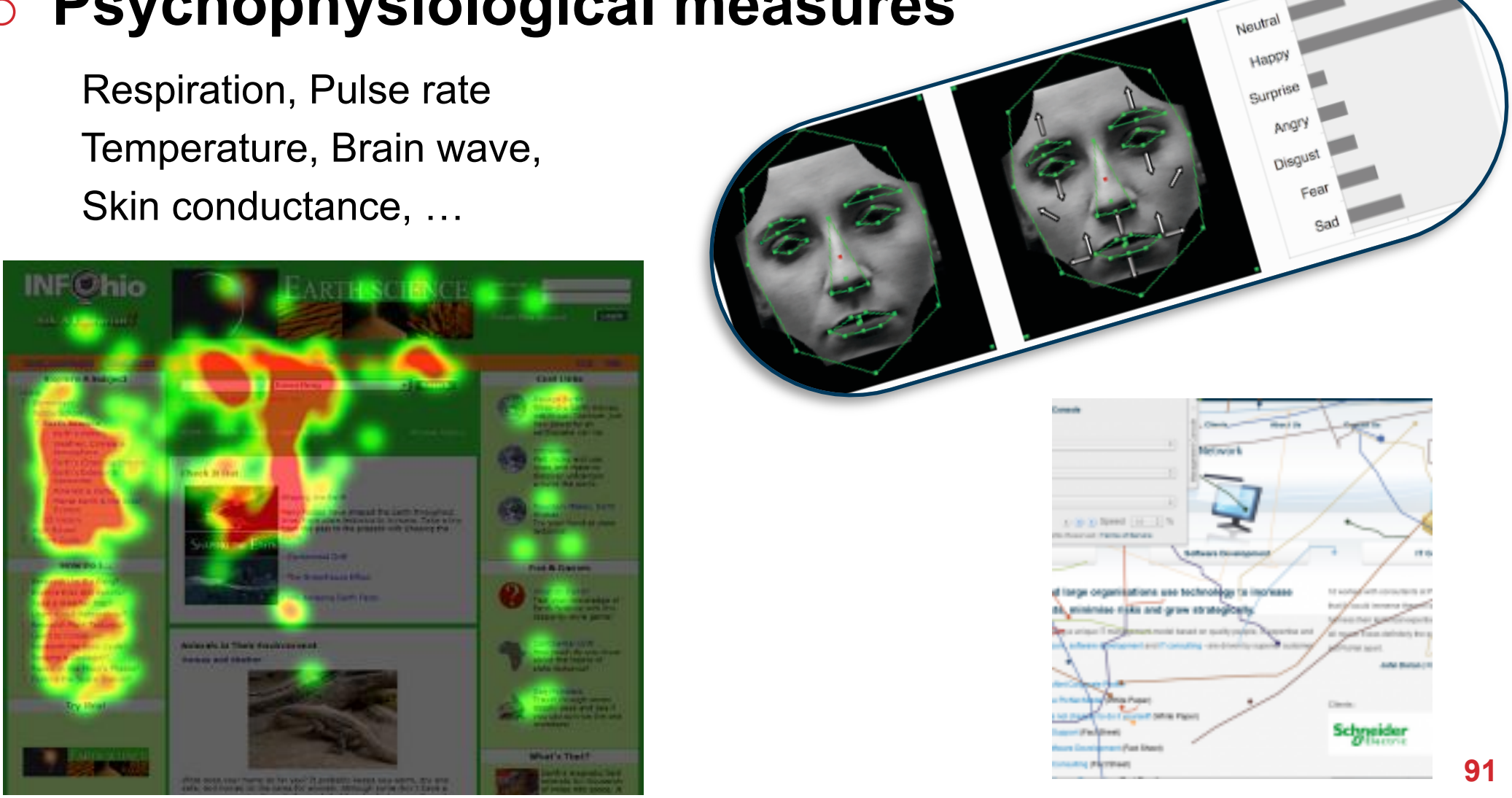


\section{WHAT IS PSYCHOPHYSIOLOGY?}

- The branch of physiology dealing with the relationship between physiological processes and thoughts, emotions, and behavior.

Reaction to The body responds to psychological processes.

we exercise $\rightarrow$ we sweat

we get embarrassed $\rightarrow$ our cheeks get red and warm

- Examples of measurements

- Electroencephalography (EEG) - measures the electrical activity of the brain through the scalp.

- Cardiovascular measures - heart rate, HR; beats per minute, BPM; heart rate variability, HRV; vasomotor activity

- Respiratory sensors - monitors oxygen intake and carbon dioxide output.

- Electromyographic (EMG) sensors - measures electrical activity in muscles

- Electrogastrogram (EGG) - measures changes in pupil diameter with thought and emotion (pupillometry) and eye movements

- Galvanic skin response (GSR) sensors - monitors perspiration/sweat gland activity (also called Skin Conductance Level - SCL)

- Temperature sensors - measures changes in blood flow and body temperature

- Functional magnetic resonance imaging (fMRI) - measures brain activity by detecting associated changes in blood flow 


\section{PSYCHOPHYSIOLOGY - PROS AND CONS}

\section{Pros}

- More objective data (not dependent on language and memory)

- Can be performed continuously during message/task processing

- Can provide information on emotional and attentional responses not available to conscious awareness

\section{Cons}

- Equipment expensive and can be cumbersome, and obtrusive

- Rarely a one-to-one correspondence between specific behaviors and physiological responses

- Difficult to operationalize and isolate a psychological construct

- Not applicable to large-scale

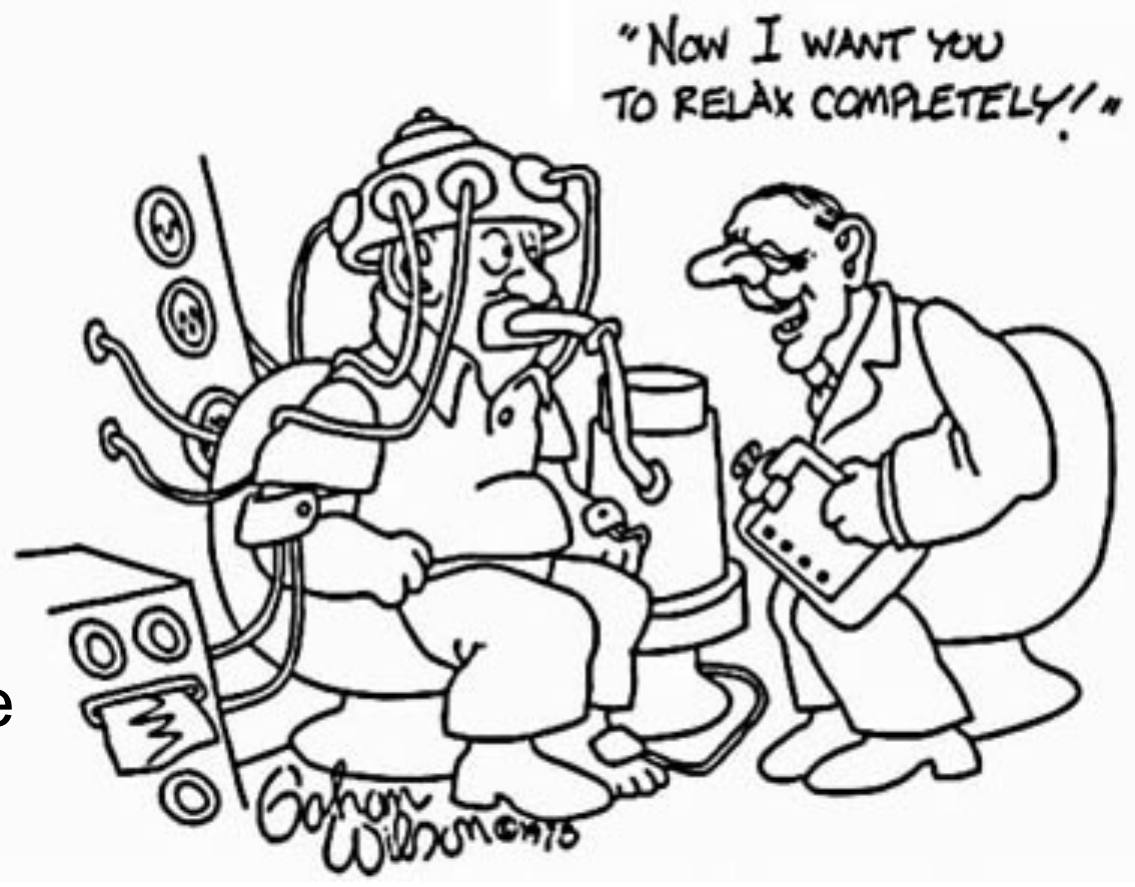

http://flavor.monell.org/ jlundstrom/research\%20behavior.html 


\section{WHAT IS EYE TRACKING?}

$\circ$ Process of measuring either the point of gaze (where one is looking) or the motion of an eye relative to the head.

$\circ$ Eye tracker is a device for measuring eye positions and eye movement.

- Used in research on the visual system, in psychology, in cognitive linguistics and in product design.

\section{Examples of measures:}

Time to First Fixation

Fixations Before

First Fixation Duration

Fixation Duration

Total Fixation Duration

Fixation Count

Visit Duration

Visit Count

whole screen or AOI (area of interest)

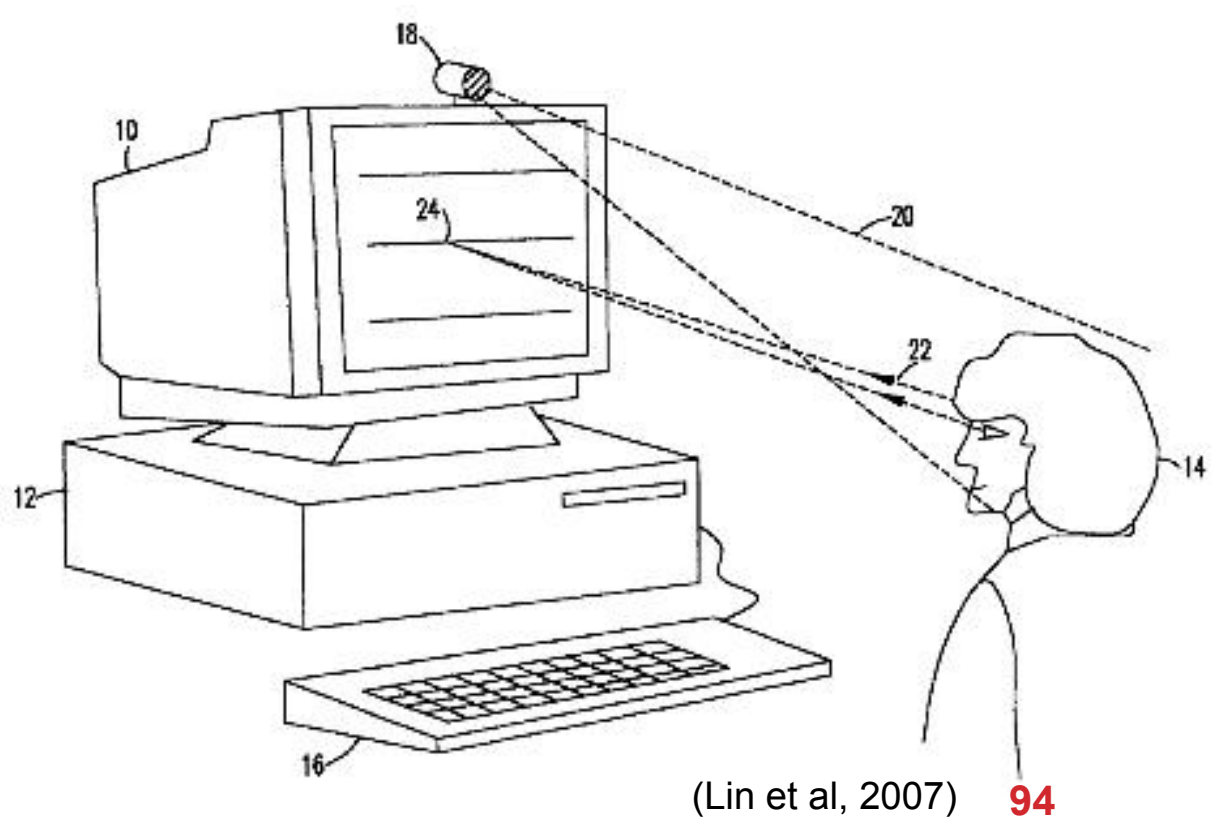




\section{EYE TRACKING - ATTENTION AND SELECTION}

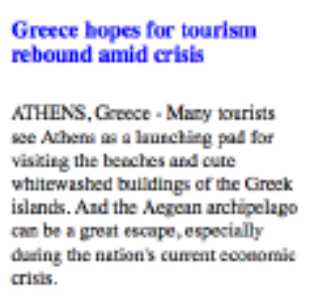

Writer Harper Lee denies taking part in memoir

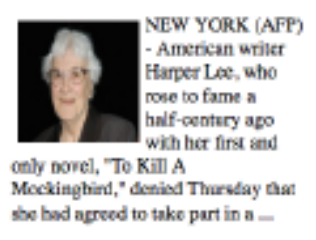

Thousands protest budget cuts at Calif. colleges

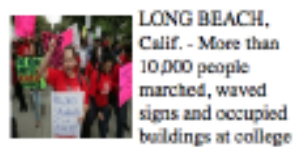
campuses across Celiformie at to stase budpot cuts of opposition

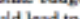

Apple updates software to fix tracking glitch

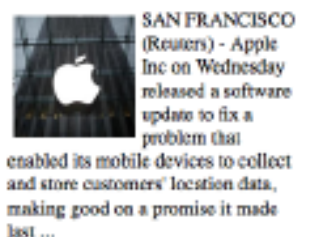

Colln Powell: Obama blew away the birthers

ORANGFBURG.S.C. . Colin Powell wodd gmaluster of South Carolians permier hishorically bleak university that they were graduaring dering a unultuons time that saw a ryal wedding, a poge's bestification Osama bin Laden, the warst persen on earts

Kvitova upsets Azarenka to take Madrid tennis titile

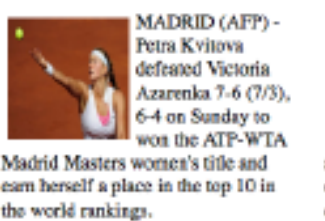

Obamas attend baptist church on Easter Suaday

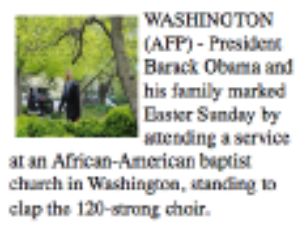

18 users, 16 tasks each (chose one story and rate it)

eye movement recorded

\section{Attention (gaze)} interest has no role position > saliency

\section{Selection}

mainly driven by interest position > attention

(Navalpakkam et al., 2012) 


\section{EYE TRACKING - PROS AND CONS}

- Pros

- Lots of details (fine-grained data/resolution)

- Offers direct measure of user attention +

what they are looking at

- Offers insights into how people consume \& browse web pages + why they fail at clicking on something

$\circ$ Cons

- Not scalable

- Slow and expensive

- Not natural environment (e.g. at home)

- Behavior ARE can be different in a lab setting

\section{Can mouse movement act as a (weak) proxy of gaze?}


- Using software (JavaScript) to collect user mouse cursor positions on computer/web interface

- Aim to provide information about what people are doing, typically to improve the design of an interface

- How does gaze is measured by an eye tracker relates to mouse movement as recorde

- Studies and applications

- Attention on web pages

- Relevance of search results

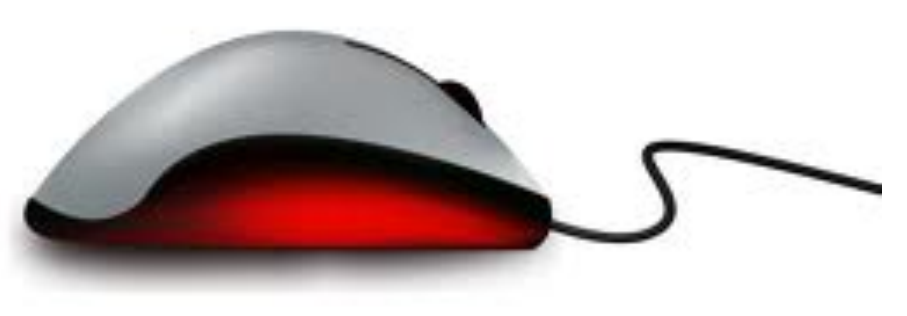

- As a proxy of relevance

- As additional and complimentary signal 


\section{MOUSE VS GAZE - ATTENTION ON WEB PAGES}

90 users on 6 Yahoo! Finance articles - rich media content

- 3 treatments:

- ad always on top; ad top right + random; random (6 positions)

$\circ$ Reading tasks + post-questionnaires

ad avoidance

similar patterns

more at top position

and longer dwell

left better than right similar patterns

shift of attention from top-left to right as ad position change similar patterns

visit ad sooner \& more time to process content when ad position moves

Similar patterns between gaze and mouse in terms of user attention when manipulating conditions (here ads) Interesting results for "ads" 


\section{RELEVANCE IN MULTIMEDIA SEARCH}

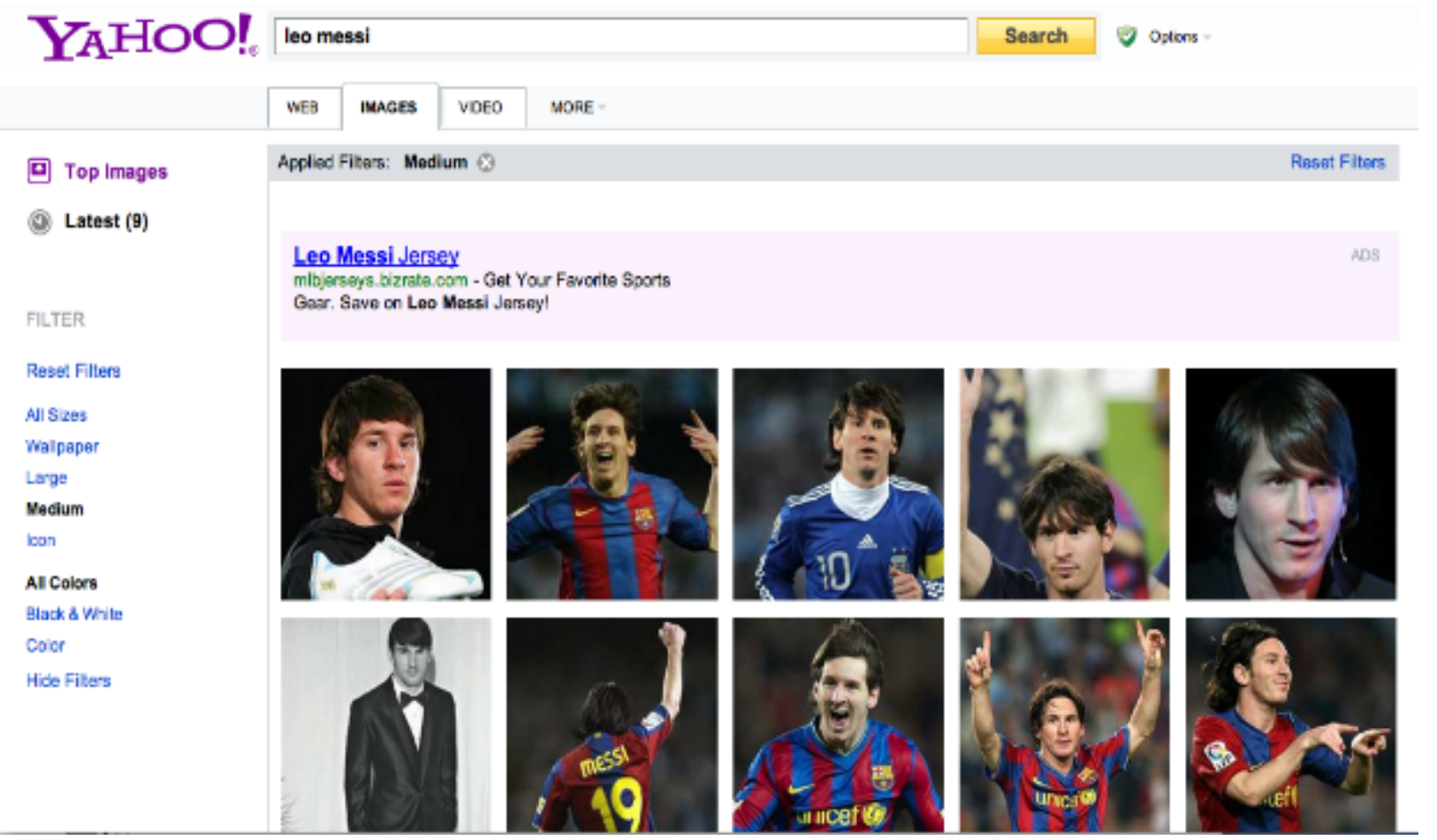

PEOPLE WHO SEARCHED FOR LEO MESSI ALSO SEARCHED FOR
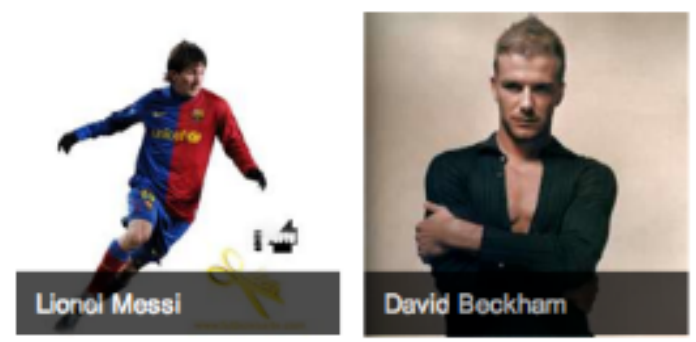

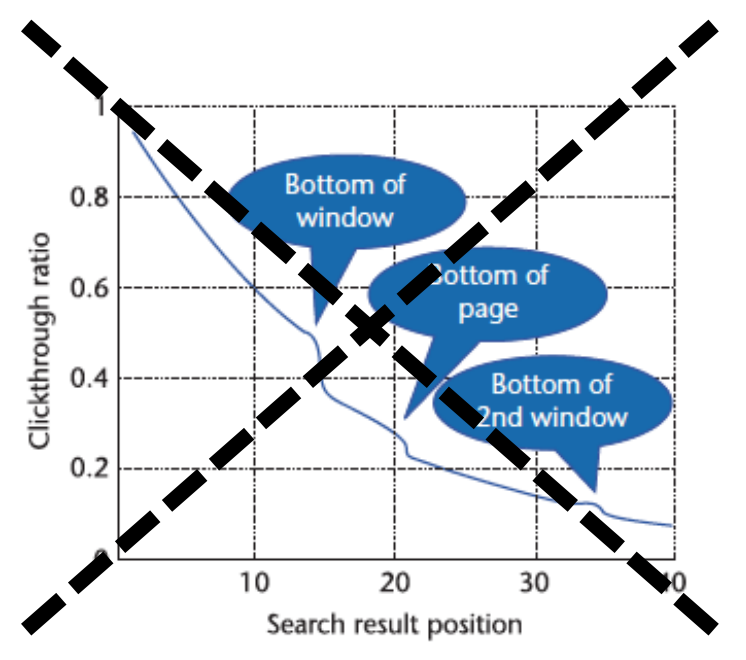

Multimedia search activities often driven by entertainment needs, not by information needs

(Slaney, 2011) 


\section{CLICK-THROUGH RATE AS PROXY OF RELEVANCE}

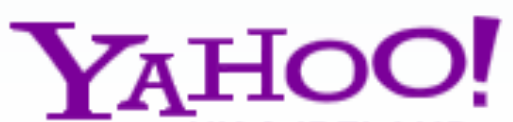

UK \& IRELAND

\section{Angel Lane surgery Dunmow}

Search

3,110 results

\begin{tabular}{|l|l|l|l|l|l}
\hline WEB & IMAGES & VIDEO & NEWS & SHOPPING & MORE \\
\hline
\end{tabular}

Search: $\odot$ the Web $\bigcirc$ only in UK $\bigcirc$ only in Ireland

\section{FILTER BY TIME}

Anytime

Past day

Past week

Past month

\section{Angel Lane Surgery - Essex}

Welcome to Angel Lane Surgery. We aim to provide you and your family with the best possible healthcare. Angel Lane Surgery Angel Lane Great Dunmow Essex CM6 1AQ www.angellanesurgery.co.uk - Cached

\section{Useful Contacts - Angel Lane Surgery - Essex}

Angel Lane Surgery: Appointments/Enquiries: 01371872 122: Hospitals ... Registrar of

Births, Deaths and Marriages (Dunmow)

www.angellanesurgery.co.uk/useful.asp - fached

Overview - Angel Lane Surgery - NHS Cholces

Angel Lane Surgery. Telephone: 01371872122 Address: Angel Lane, Great Dunmow,

Dunmow, Essex, CM6 1AQ Website: Website address not added

www.nhs.uk/Services/gp/Overv/ew/DefaultView.aspx?id=6F... - Cached

More results from nhs.uk "

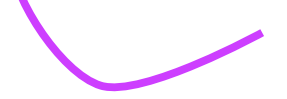


Small difference on part of page user attends to (5 users)

- Better correlation when cursor moves and when there is lots of movement (23 users + reading instructions)

(Chen et al, 2011; Hauger et al, 2011)

- Search result page

- Correlate more along the $y$-axis than $x$-axis

Correlate more when cursor placed over search results (32 users -16 search tasks; 10 users and 20 search tasks)

(Rodden et al, 2008; Guo \& Agichtein, 2010)

BUT

1. Search result page and result page

2. Some factor? 


\section{GAZE VS MOUSE - DISTANCE}

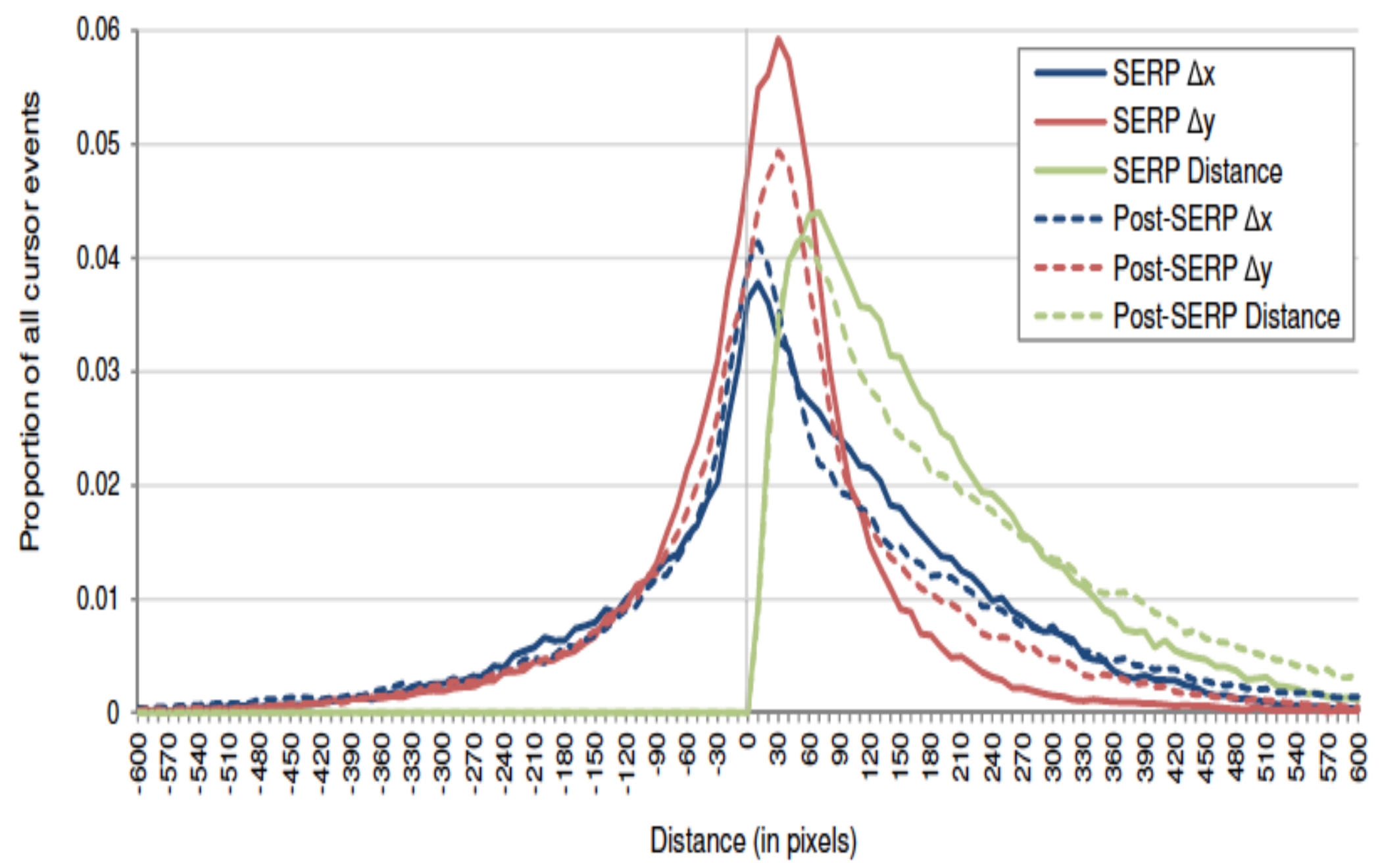

(Huang, White \& Dumais, 2011) 
○ $\mathbf{3 8}$ users and $\mathbf{3 2}$ search tasks (navigational + informational)

- Age or gender does not seem to be a factor

- Task does not seem to be a factor (others found the opposite)

(using click entropy to classify a a query)

- User individual behavior seem to matter more

- Gaze leads the cursor

- Stronger alignment when search result page loads

- Cursor behaviors: alignment increases

inactive < examining < reading < action < click

$$
58.8 \% \quad 31.9 \% \quad 2.5 \% \quad 5.7 \%
$$

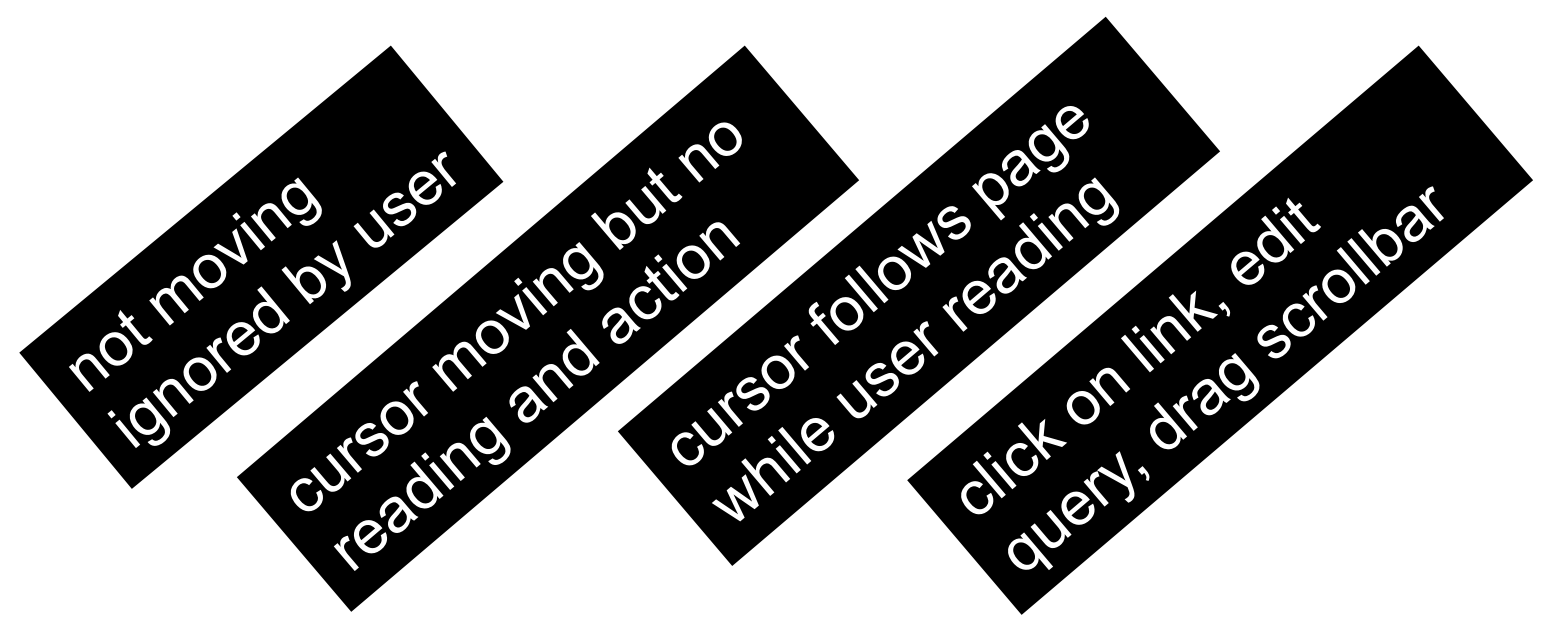

classification (heuristicbased) informed by watching replay of user interactions 


\section{CAN WE PREDICT GAZE?}

better prediction when accounting for cursor behaviors and time in addition to cursor only

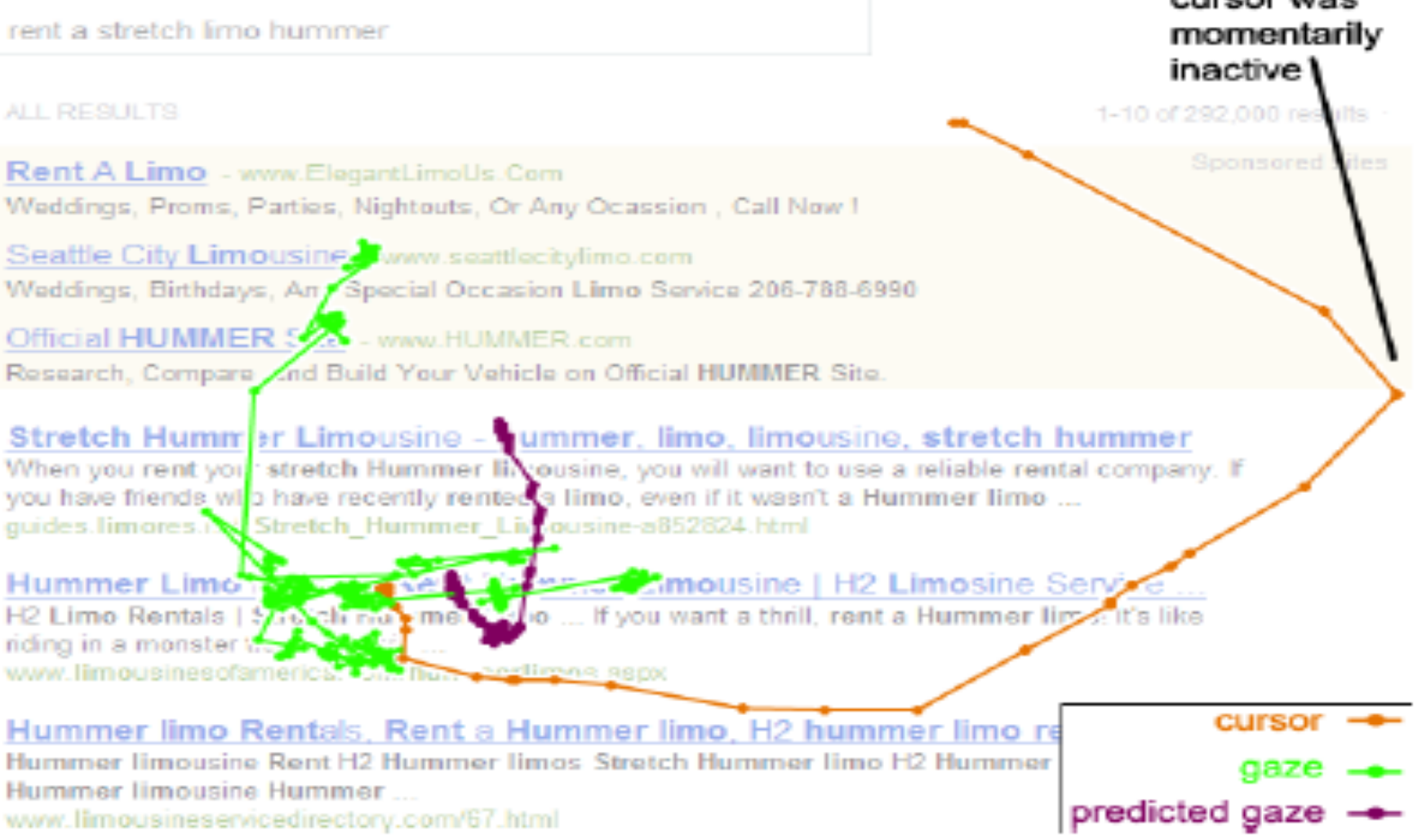

Figure 6. The cursor position (orange), the gaze position predicted by the linear regression model (purple), and the gaze position as determined by the eye-tracker (green) are drawn over the SERP presented to the subject following the query "rent a stretch limo hummer" from our study. The figure omits the right and left columns of the SERP. 


\section{CLICK VS CURSOR - HEATMAP}

○ Estimate search result relevance

\section{the role of hovering?}

(Bing - Microsoft employees - 366,473 queries; 21,936 unique cookies; $7,500,429$ cursor move or click)

Click positions

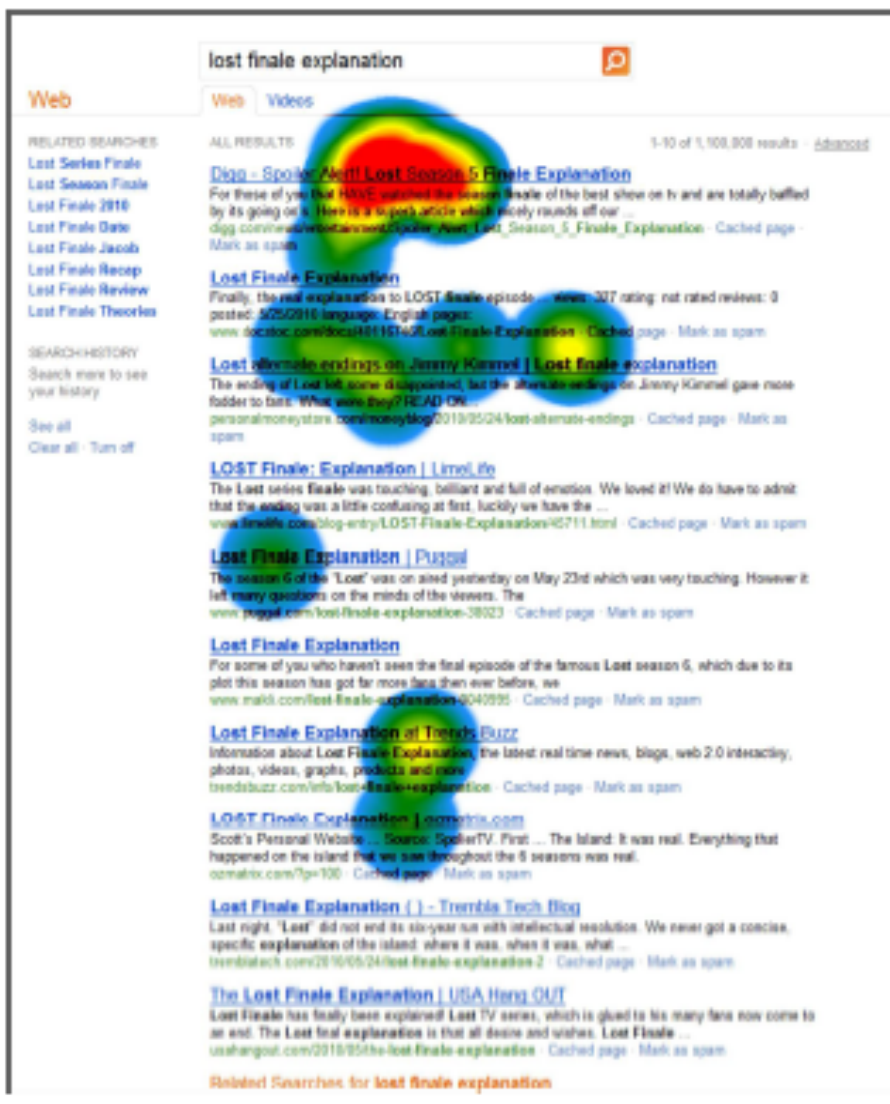

Cursor movement positions

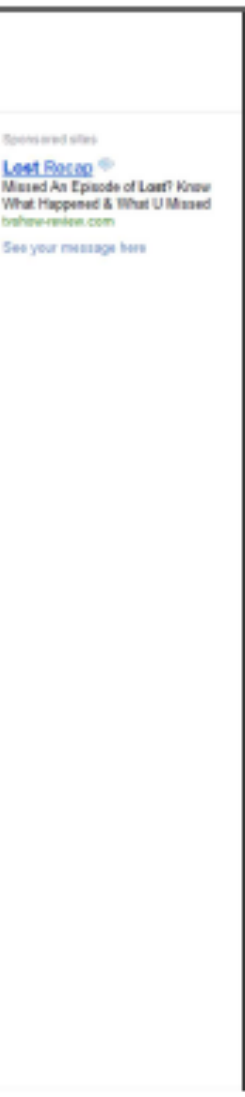

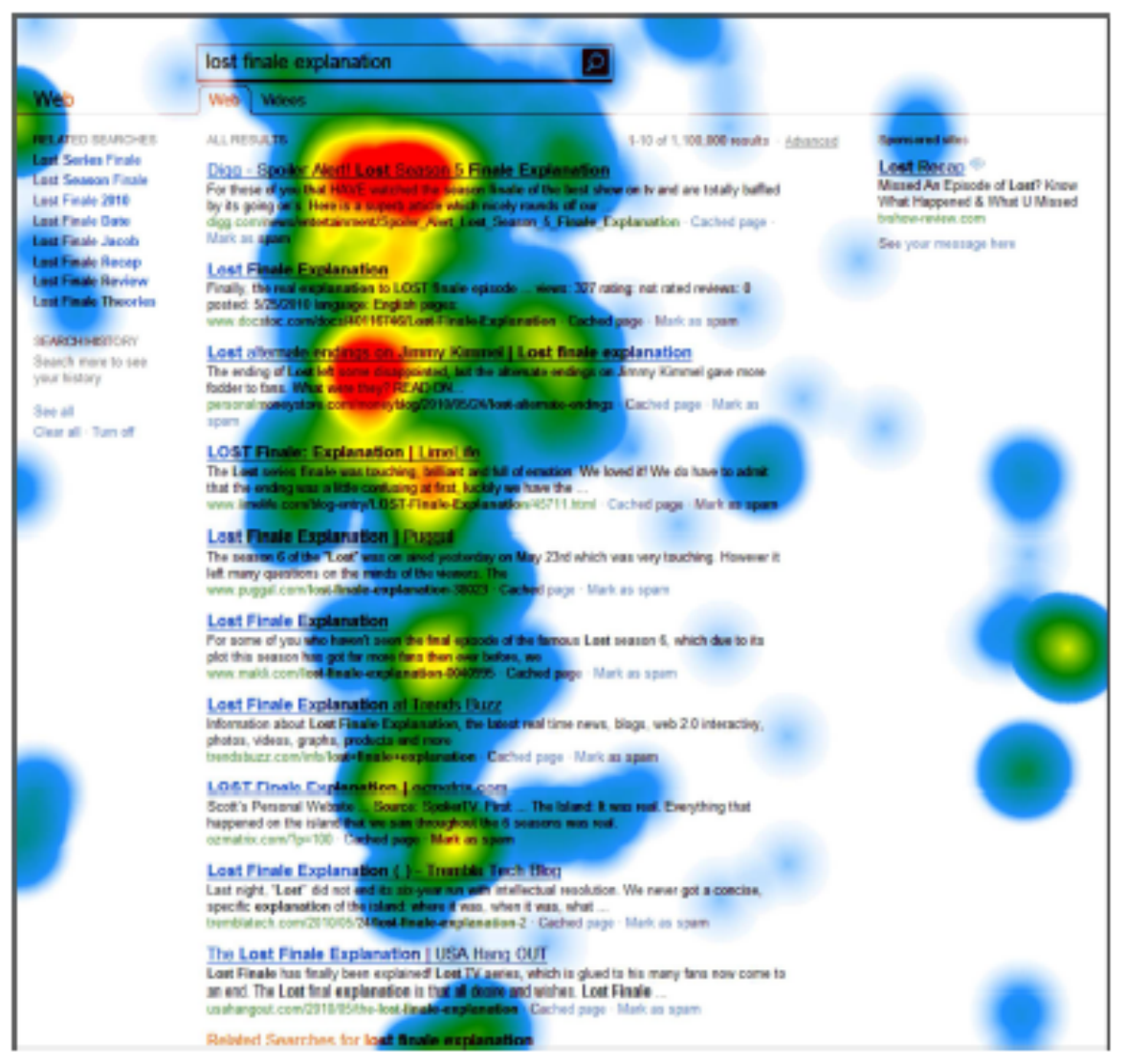

Figure 2. Heatmaps of all click positions (left) and recorded cursor positions (right) for the query [lost finale explanation].

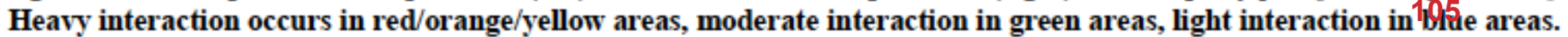




\section{MOUSE MOVEMENT - WHAT CAN HOVERING TELL ABOUT RELEVANCE?}

Table 3. Correlations between click and hover features and relevance judgments for queries with and without clicks.

\begin{tabular}{|c|c|c|}
\hline $\begin{array}{l}\text { Result } \\
\text { clicks or } \\
\text { no clicks }\end{array}$ & Feature source & $\begin{array}{l}\text { Correlation with } \\
\text { human relevance } \\
\text { judgments }\end{array}$ \\
\hline \multirow{5}{*}{$\begin{array}{l}\text { Clicks } \\
(\mathrm{N}=1194)\end{array}$} & Clickthrough rate (c) & 0.42 \\
\hline & Hover rate $(\mathrm{h})$ & 0.46 \\
\hline & Unclicked hovers (u) & -0.26 \\
\hline & Max hover time (d) & -0.15 \\
\hline & Combined $^{1}$ & 0.49 \\
\hline \multirow{4}{*}{$\begin{array}{c}\text { No clicks } \\
(\mathrm{N}=96)\end{array}$} & Hover rate & 0.23 \\
\hline & Unclicked hovers & 0.06 \\
\hline & Max hover time & 0.17 \\
\hline & Combined $^{2}$ & 0.28 \\
\hline
\end{tabular}

Cickthrough rate:

$\%$ of clicks when URL

Shown (per query)

Hover rate:

$\%$ hover over URL (per query)

Unclicked hover:

Media time user hovers over URL but no click (per query)

Max hover time:

Maximum time user hover Over a result (per SERP) 
- Abandonment (a engagement metric in search) is when there is no click on the search result page

- User is dissatisfied (bad abandonment)

- User found result(s) on the search result page (good abandonment)

○ 858 queries ( $21 \%$ good vs. $79 \%$ abandonment manually examined)

- Cursor trail length

- Total distance (pixel) traveled by cursor on SERP

- Shorter for good abandonment

○ Movement time

- Total time (second) cursor moved on SERP

- Slower when answers in snippet (good abandonment)

- Cursor speed

- Average cursor speed (pixel/second)

- Slower when answers in snippet (good abandonment) 
○ Clickthrough rate (CTR) - in a search result

- Ranking bias

- Various way to deal with it such as "interleaving"

- Presentation bias

- Perceived relevance from reading the snippet

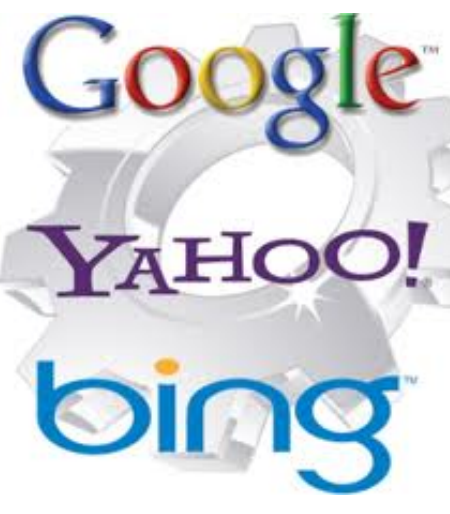

$\bigcirc$ Dwell time - on landing page (post search result)

- Although a good indicator of user interest/relevance, not reliable on its own

- Time spending reading a document (result) has shown to improve search quality

- Short dwell time a good indication of non-relevance

- BUT

- Interpreting long dwell-time not so straight-forward (user spends a long time localising the relevant part in long document!) 


\section{RELEVANCE \& CURSOR}

(Guo \& Agichtein, 2012)

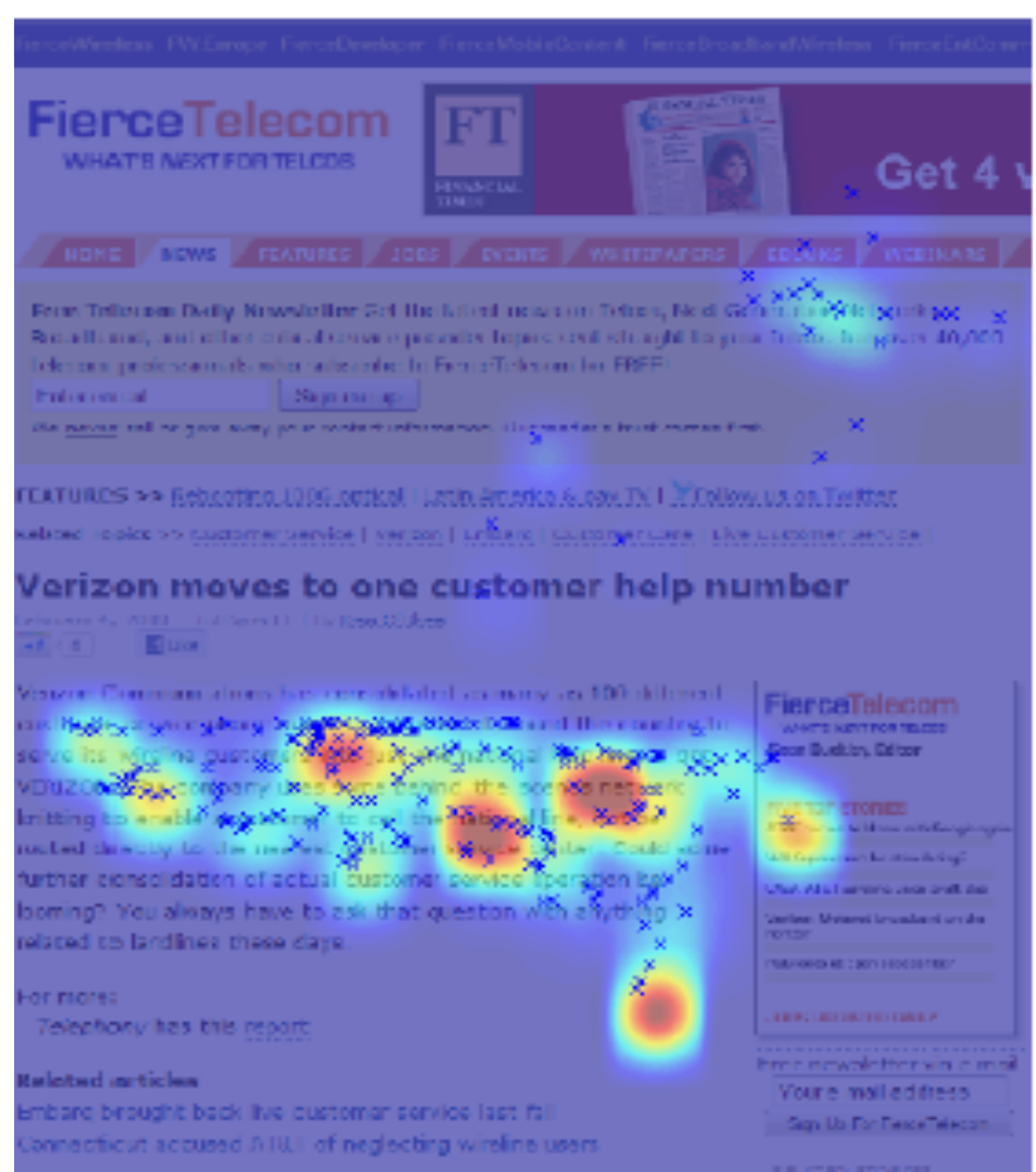

(a) relevant (dwell time: 30 s)

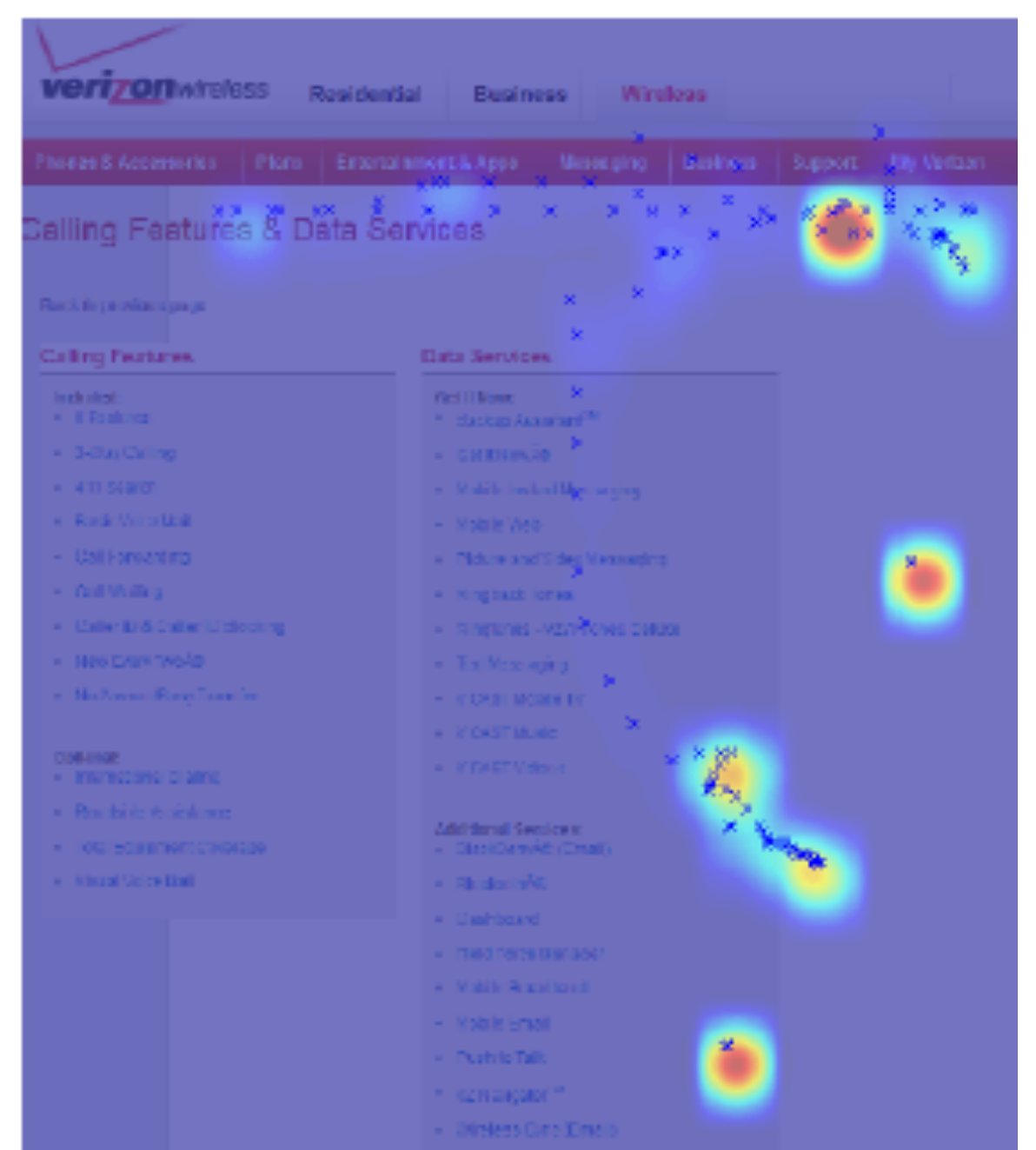

(b) non-relevant (dwell time: $30 s$ )

"reading" cursor heatmap of relevant document vs "scanning" cursor heatmap of non-relevant document (both dwell time of 30s) 


\section{RELEVANCE \& CURSOR}

(Guo \& Agichtein, 2012)

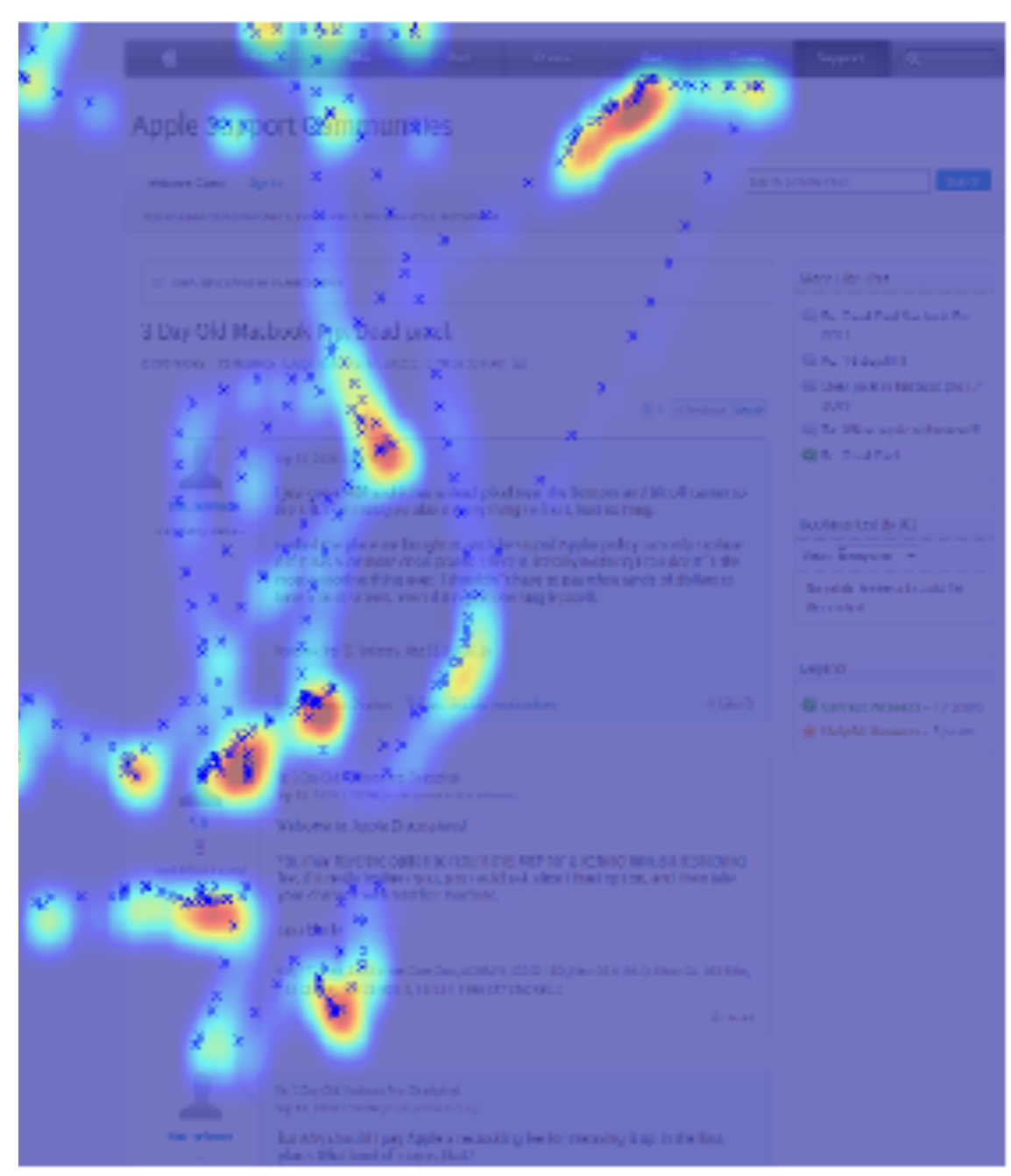

(a) relevant (dwell time: 70 s)

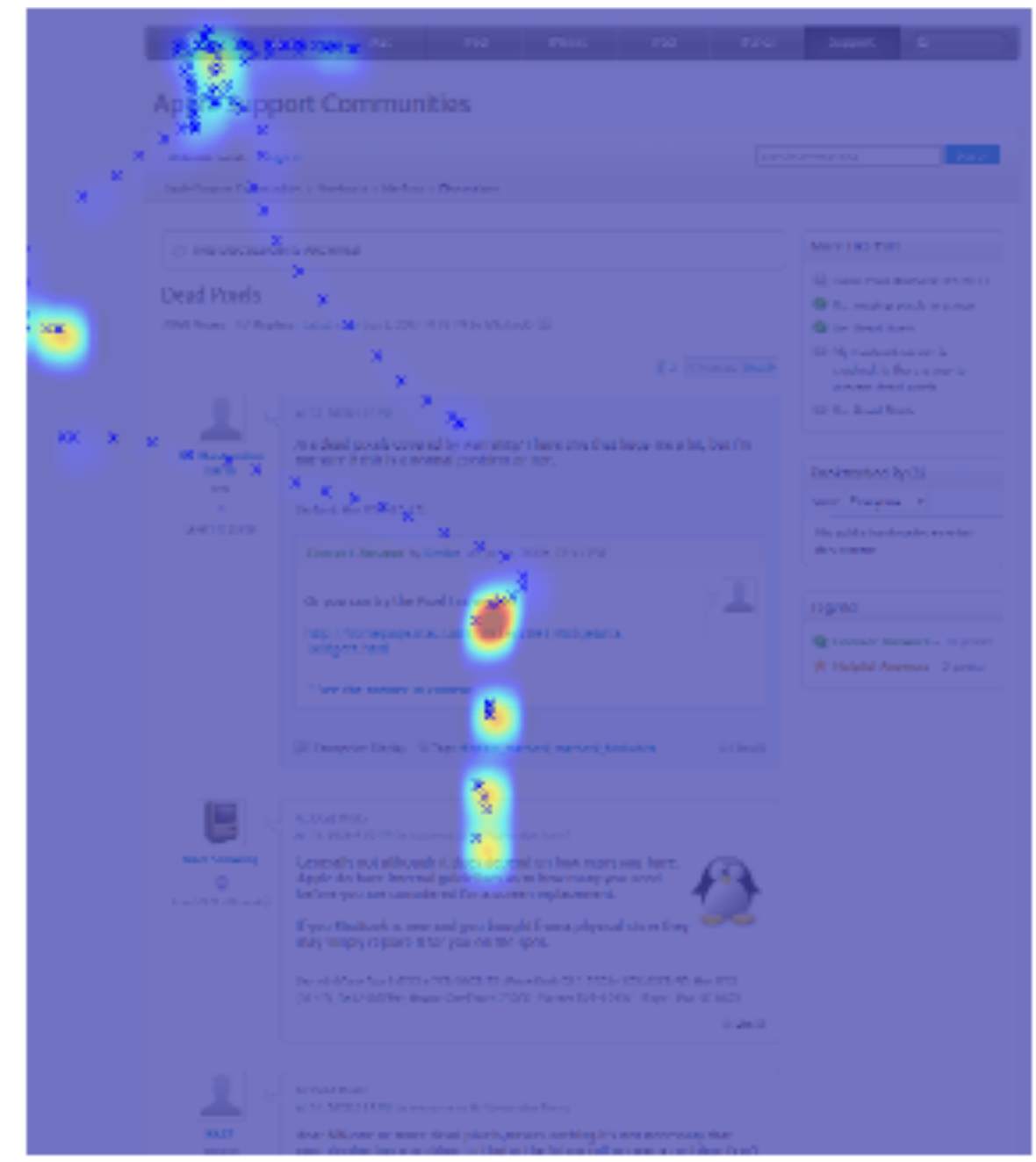

(b) non-relevant (dwell time: $80 \mathrm{~s}$ )

"reading" a relevant long document vs "scanning" a long non-relevant document 


\section{WHAT WORKS? - PREDICTING RELEVANCE}

... learning a model with:

- Dwell time

- Cursor movement

- number, total distance traveled (and $x$ - and y-axis), speed (-), maximal coordinate

- Scroll

- frequency (-) and speed (-)

- Predefined areas of interest (AOI)

- Where main content lies

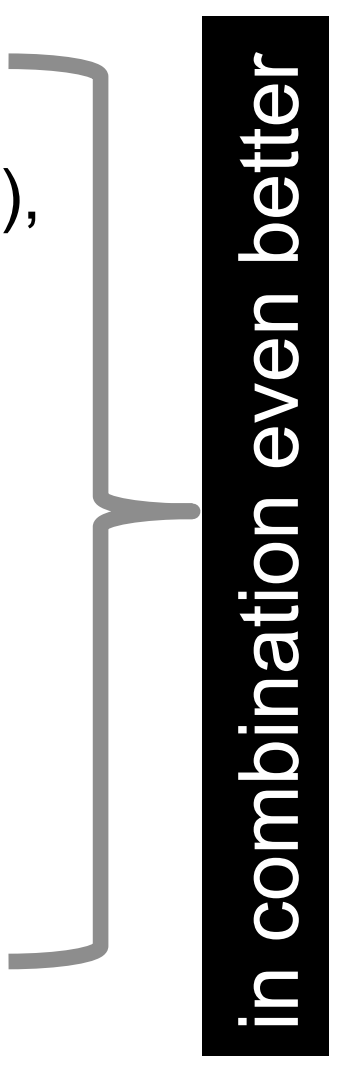

- Actual rank way less informative 


\section{FACIAL EXPRESSION AND SEARCH}
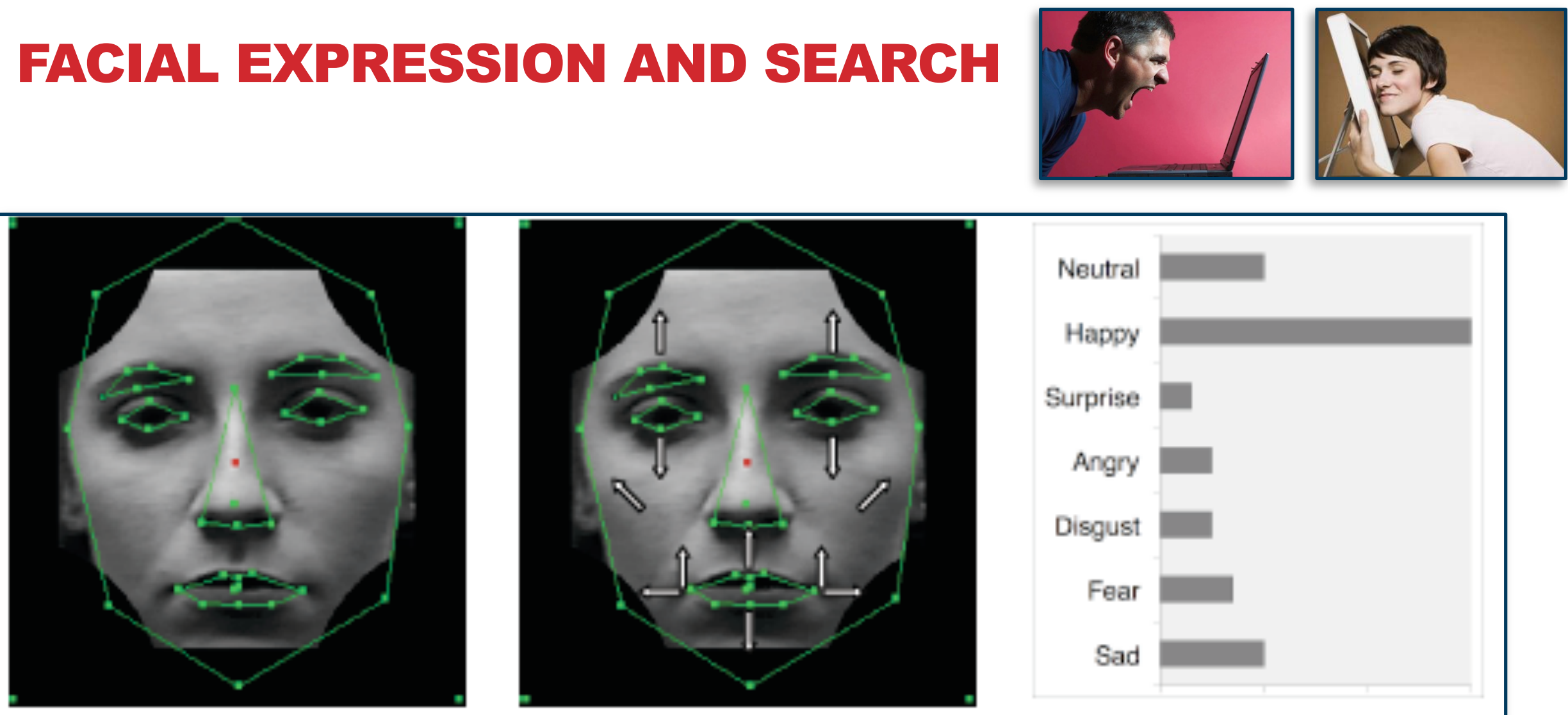

\section{Neutral}

Happy

Surprise

Angry

Disgust

Fear

Sad

16 subjects, facial expressions recorded while performing search tasks of various levels of difficultly.

learned model (based on support vector machine) shows that facial expressions provide good cues on topical relevance.

Potential application: personalised relevance feedback based on implicit cues.

$\left(\right.$ Arapakis et al, 2010) ${ }^{112}$ 


\section{FACEBOOK AND EMOTIONAL ENGAGEMENT (FLOW)}

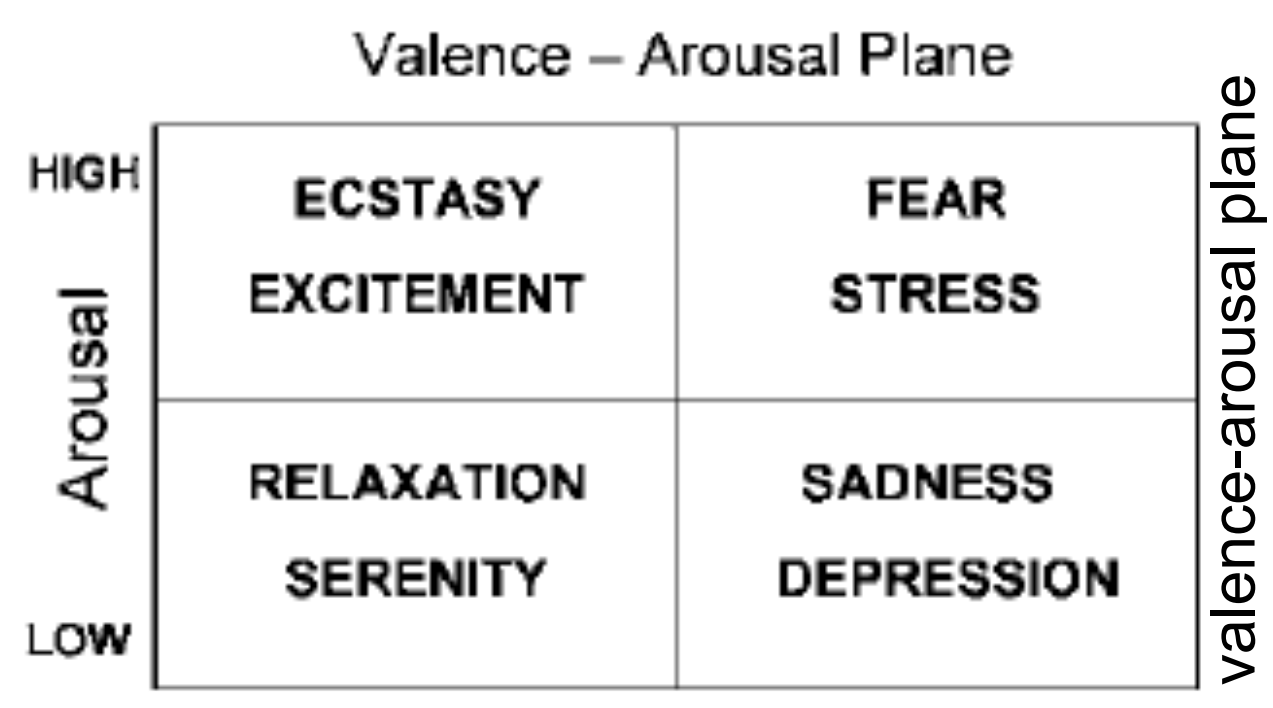

\section{facebook}

positive Valence negative

relaxation ( $3 \mathrm{mn}$, panorama pictures) $\rightarrow$ Facebook (3mn, free navigation) $\rightarrow$ stress (4mn, arithmetic tasks)

\section{0 students}

(Lang, 1995; Mauri et al, 2011)

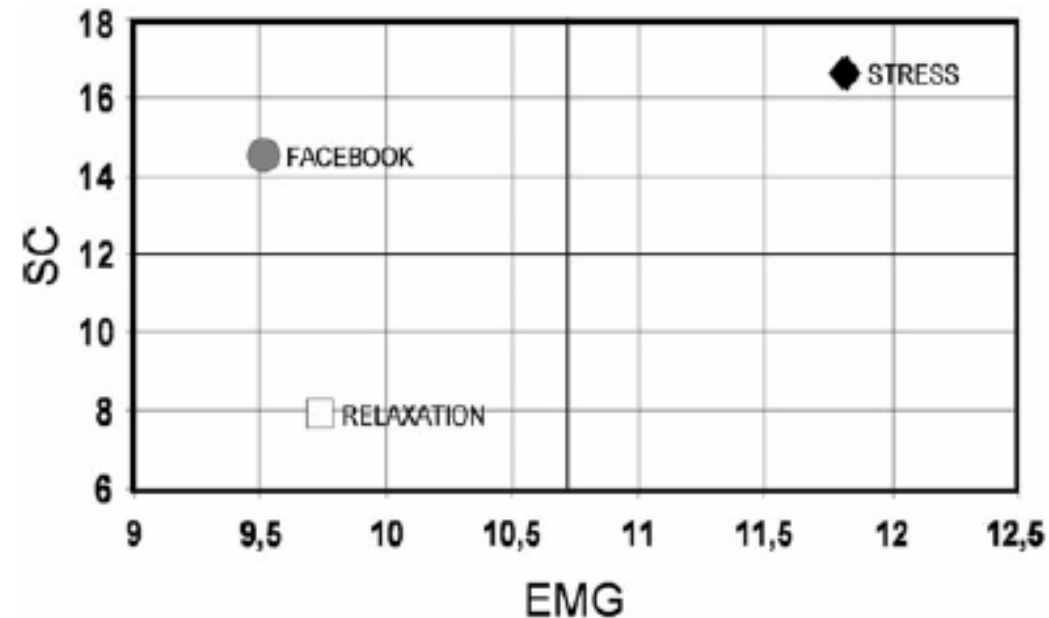

FIG. 9. The averaged data from all subjects for each epoch (relaxation, Facebook use, and stress) are plotted distributing the SC values along the Arousal axe (Y axe), and the EMG of $\mathrm{CS}$ along the Valence axe (X axe). 
- Introduction and Scope

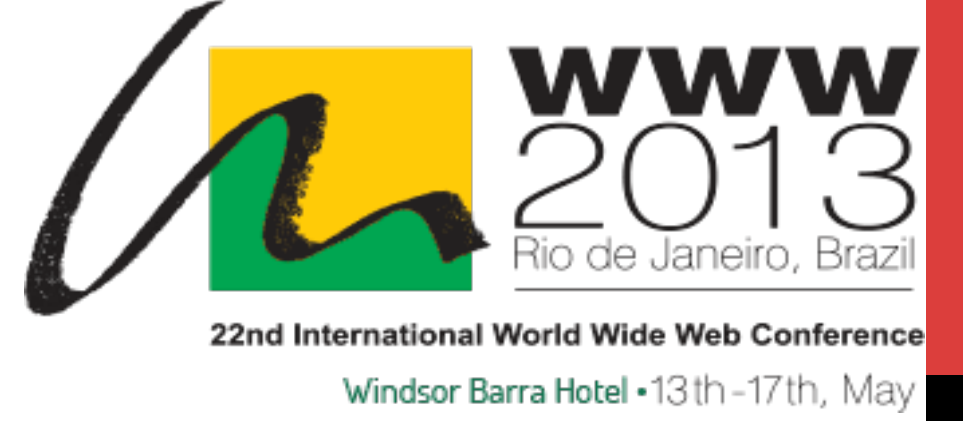

- Part I - Foundations

1. Approaches based on self-report measures

2. Approaches based on web analytics

3. Approaches based on physiological measures

- Part II - Advanced Aspects

1. Measuring user engagement in mobile information searching

2. Networked user engagement

3. Combining different approaches

- Conclusions

○ Bibliography 

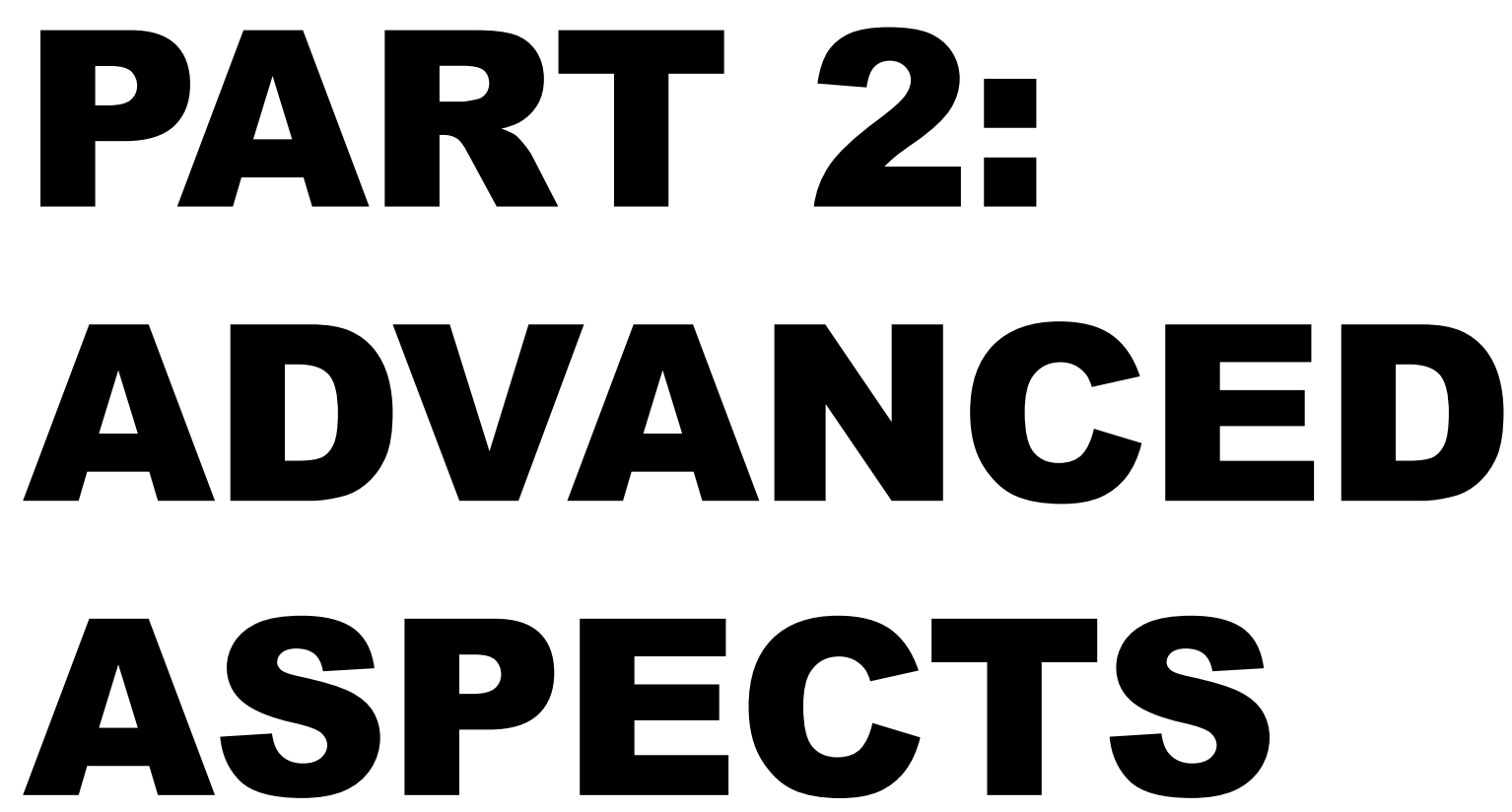

MOBILE INFORMATION SEEKING 


\section{MOBILE USER ENGAGEMENT}

$\circ$ Mobile devices are changing the ways in which we are learning, working, and communicating.

- The role of device has not been considered in (published) studies of user engagement.

$\circ$ However ... related work has been done in the UX literature.

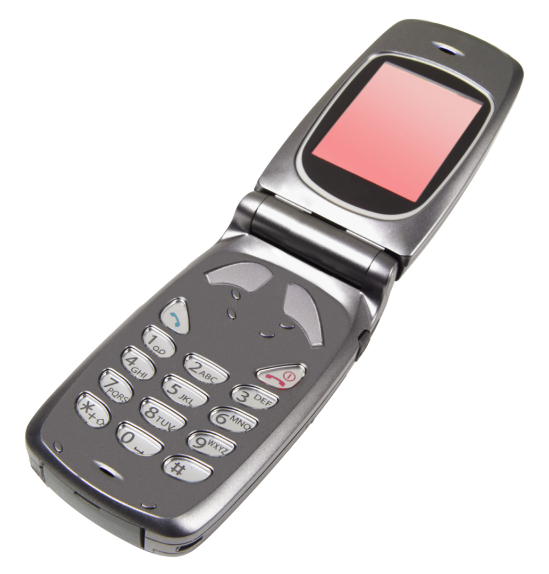




\section{DIARY STUDIES}

1. Komaki et al, 2012

- Context heavily influenced search behavior

2. Nylander et al, 2009

- General preference for using mobile, even when an alternative was available (51\% of instances)

- Mobile use influenced by: technical ease and functionality, and convenience, laziness, and integration with social life and daily activities

3. Church \& Smythe, 2009; Church \& Oliver, 2011

- Emphasized location and time as key factors in mobile use 


\section{FIELD STUDIES}

- Oulasvirta et al, 2005

- Attention shifting between the mobile device and the external environment

○ Gökera \& Myrhaugb, 2008

- Context closely tied to perceived relevance and value of information

○ Battarbee \& Koskinen, 2005

- Emotional response of information sharing and communication with friends in everyday life 


\section{BUILDING A MODEL OF ENGAGEMENT BASED ON UX LITERATURE}

○ User experience (UX) literature suggests that:

- Users must focus attention on the mobile task and the external environment (Oulasvirta et al., 2005).

- $63 \%$ of mobile searches were social in nature (Teevan et al. 2011).

- Mobile devices with constant connectivity are often 'habitforming' (Oulasvirta et al., 2012)

- Time motivates mobile phone use (Tojib \& Tsarenko, 2012).

Therefore ... 


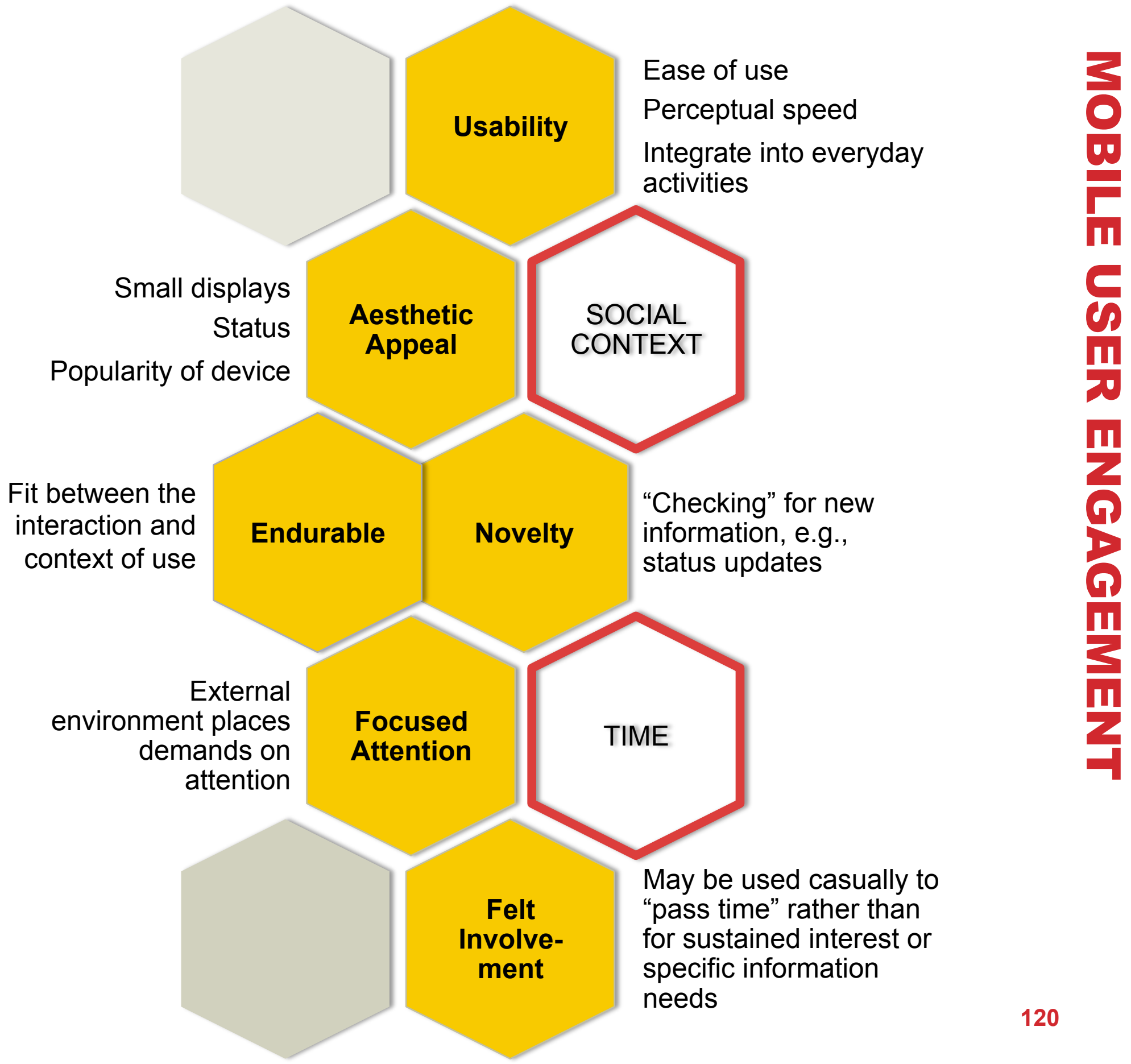


MOBILE USER ENGAGEMENT: EXPLORATORY STUDY METHODS

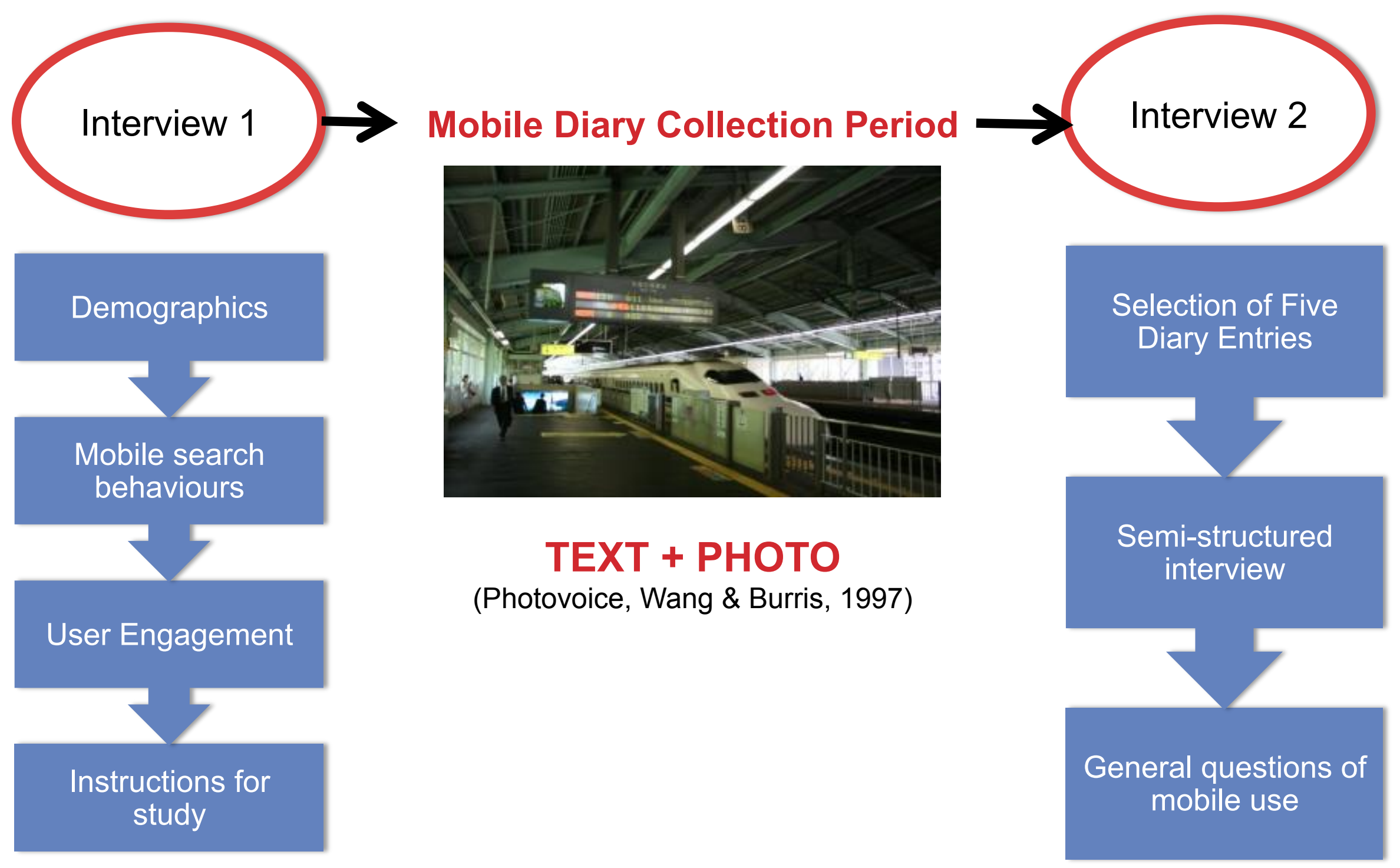




\section{ENGAGEMENT WITH MOBILE APPS}

- Focused on branded mobile apps, interactive marketing tools

- Methodology: identification and analysis of branded apps

- 2010 Interbrand Top 100 Global Brands + iTunes app store

- Analysis of features and content on the branded app according to: vividness, novelty, motivation, control, customization, feedback, and multiplatforming

- Distinguished product and service branded apps

- Almost all apps incorporated at least one of the seven engagement attributes:

- control (97.2\%), customization (85.8\%), vividness (78.3\%: entire app, $86.8 \%$ : entry page), multiplatforming $(70.8 \%)$, motivation $(62.3 \%)$, feedback (55.7\%), and novelty (11.3\%).

(Kim, Lin \& Sung, 2013) 

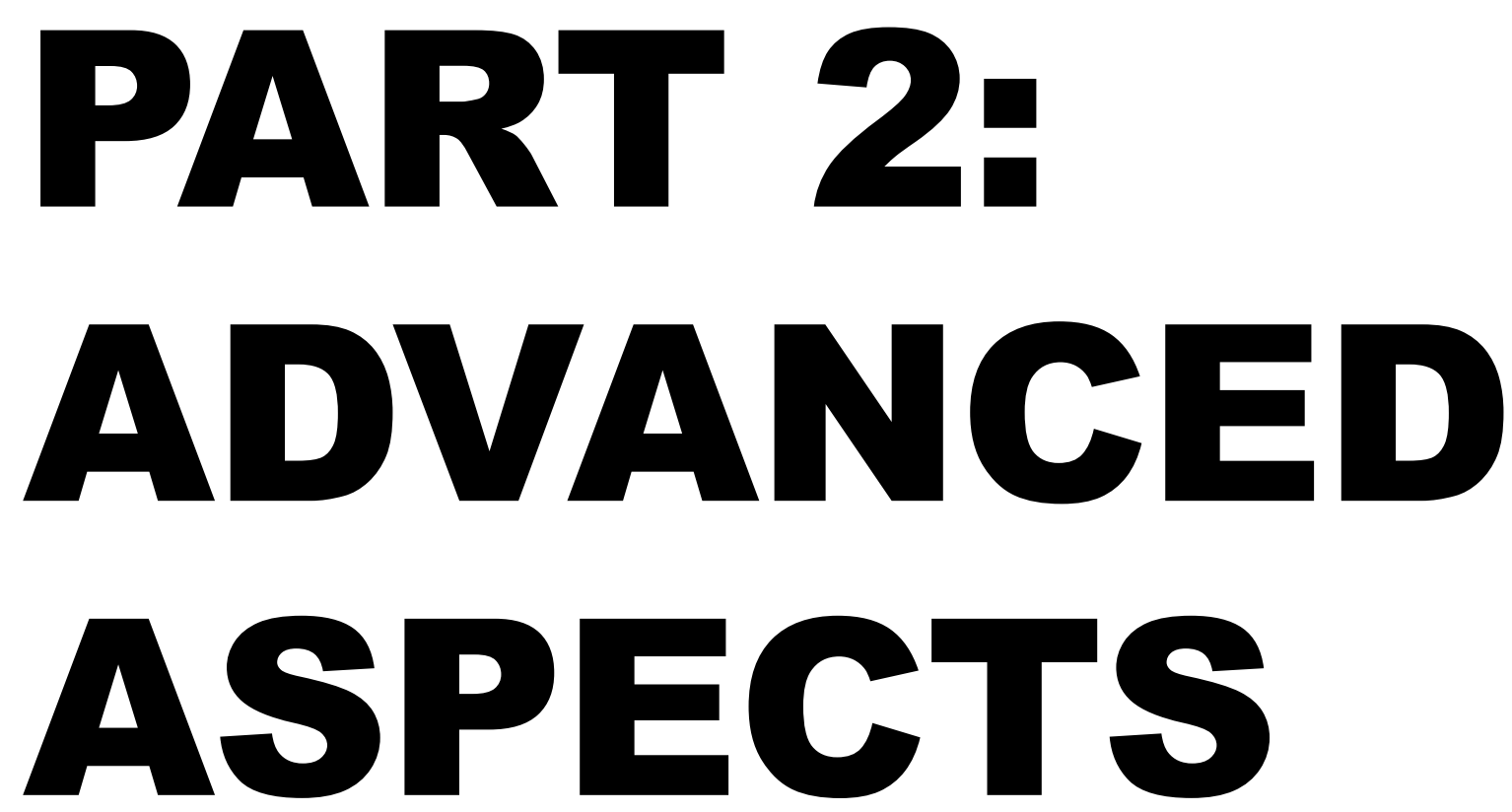

NETWORKED USER ENGAGEMENT 
DOWNSTREAM ENGAGEMENT

NO MAN IS AN ISLAND, ENTIRE OF ITSELF

- Basic premises:

- The success of a web site depends not only on itself, but also on its environment.

- This is particularly relevant for companies running networks of properties or services 


\section{USER BEHAVIOR WITHIN A NETWORK OF SITES}

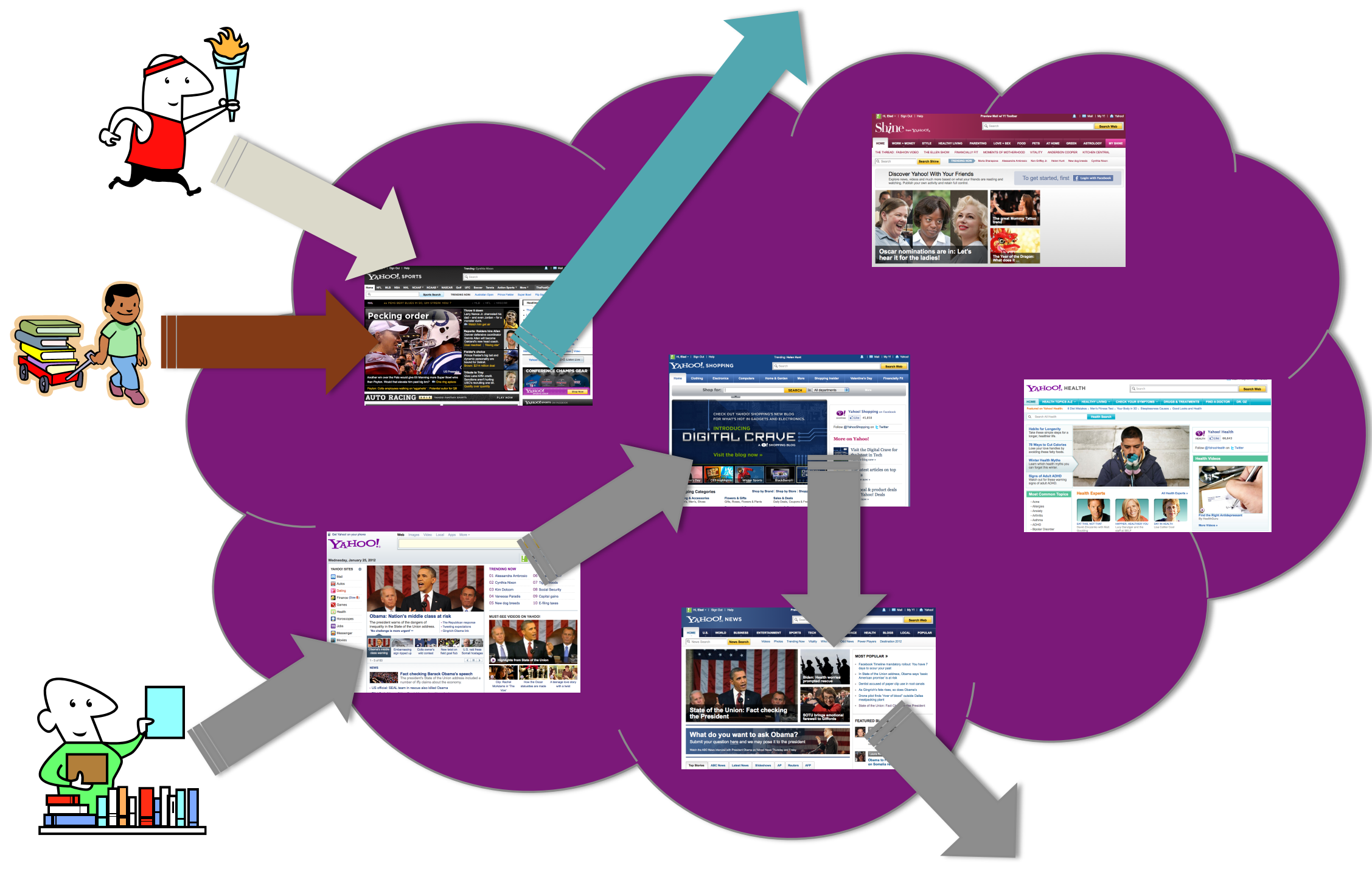




\section{NETWORKED USER ENGAGEMENT:}

\section{ENGAGEMENT ACROSS A NETWORK OF SITES}

$\bigcirc$ Large online providers (AOL, Google, Yahoo!, etc.) offer not one service (site), but a network of sites

Each service is usually optimized individually, with some effort to direct users between them

Success of a service depends on itself, but also on how it is reached from other services (user traffic)

$\bigcirc$ Users switch between sites within an online session, several sites are visited and the same site is visited several times (online multi-tasking) 


\section{MEASURING DOWNSTREAM ENGAGEMENT}

Downstream engagement for site A

(\% remaining session time)

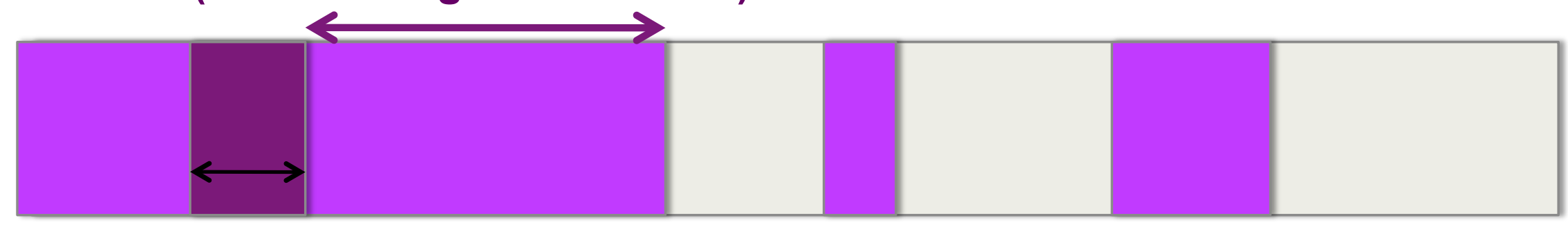

Site A
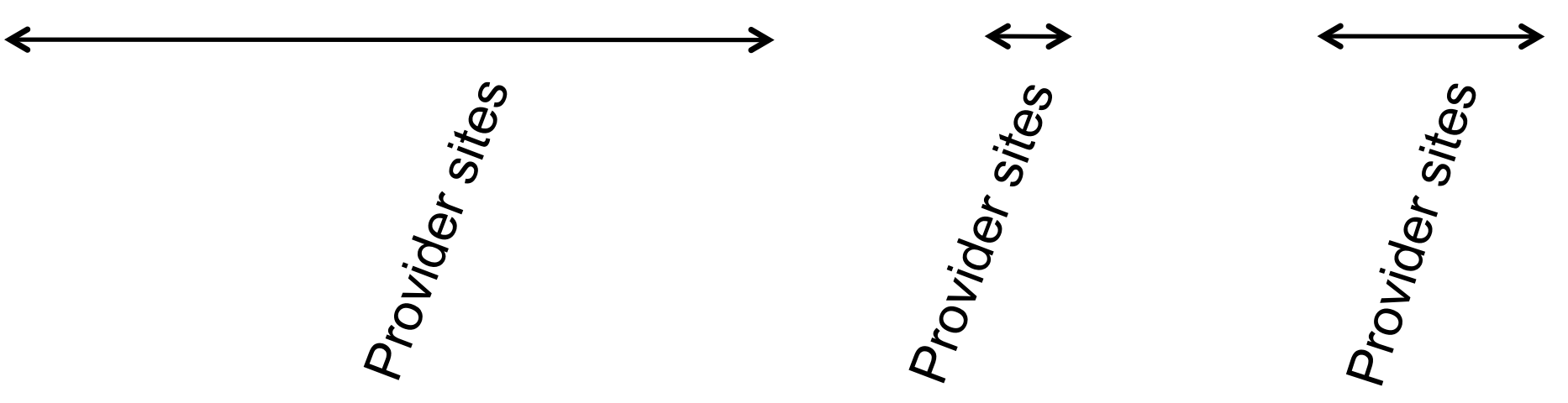

User session 


\section{DOWNSTREAM ENGAGEMENT}

- Varies significantly across sites

- Exhibits different distributions according to site type

- Is not highly correlated with other engagement measures such as dwell time

- Optimizing downstream engagement will have little effect on user engagement within that site

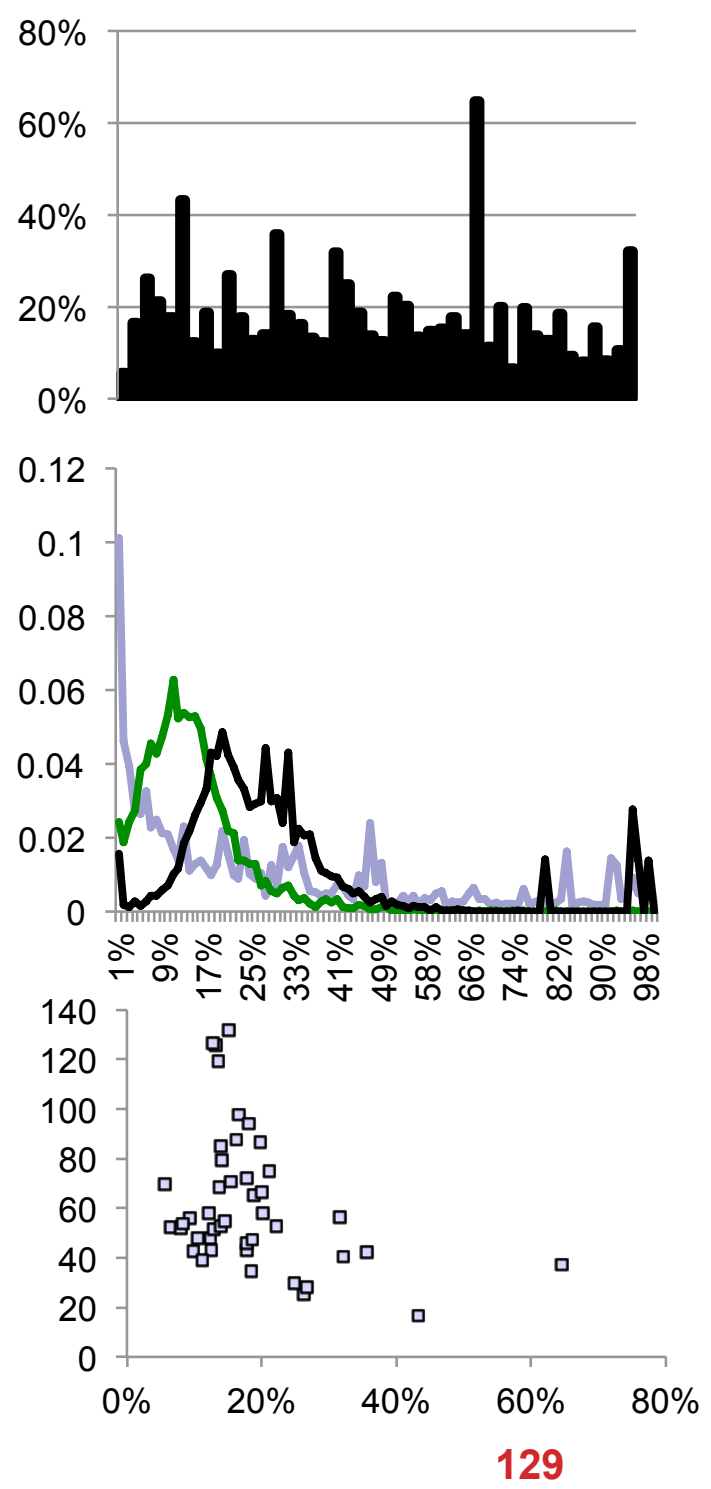




\section{DISTRIBUTION OF DOWNSTREAM ENGAGEMENT SCORES}

○ Downstream

engagement is not highly correlated with intra-site measures of engagement such as dwell time $(\varrho=$ $\left.-0.05, p<10^{(-5)}\right)$.

- Downstream engagement is negatively correlated with inter-session measures such as revisits $(\varrho=-0.26$, $\left.p<10^{(-5)}\right)$.

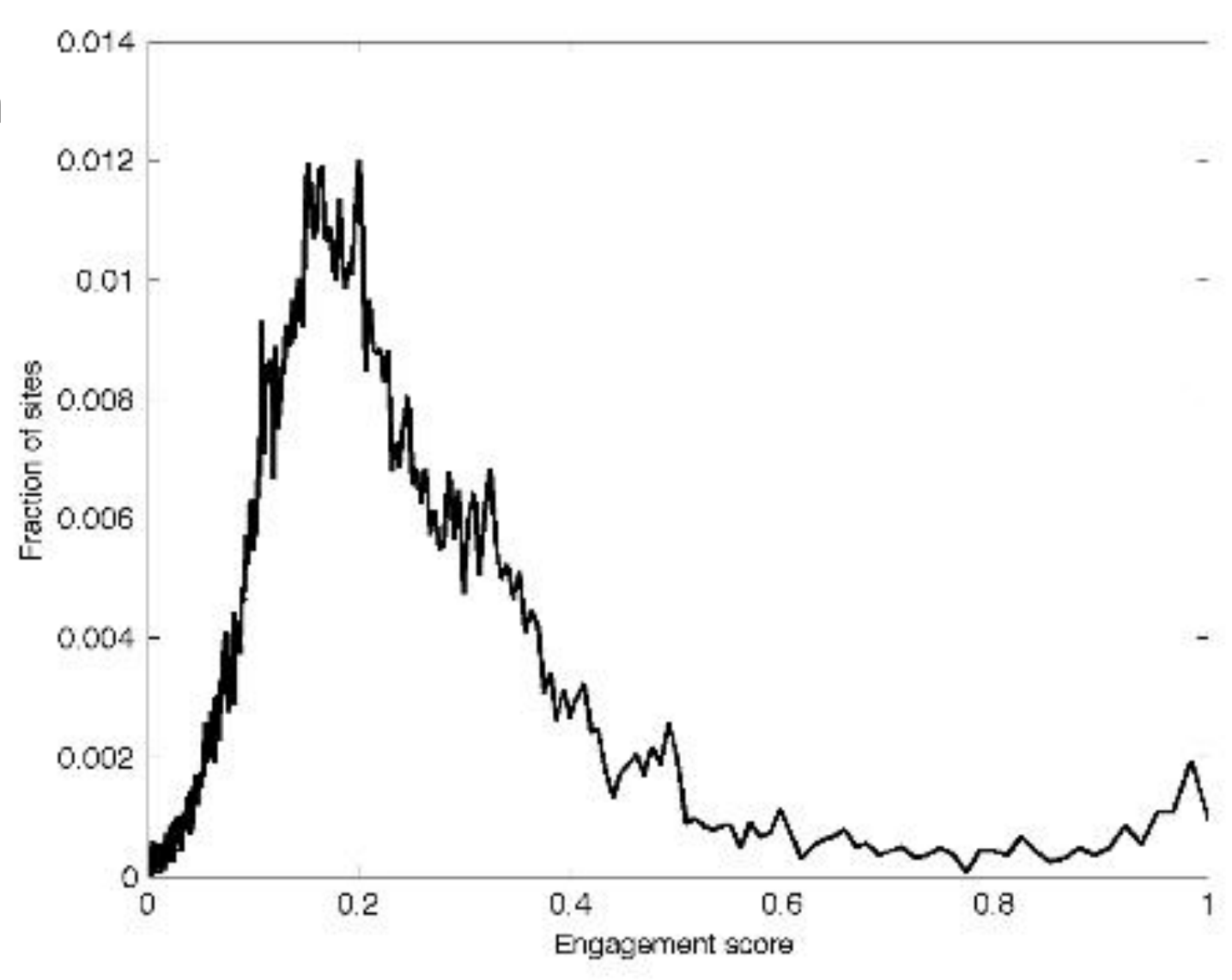

(19.4M sessions, 265,000 users, 50 sites) 
CLUSTERED DISTRIBUTION OF DOWNSTREAM ENGAGEMENT SCORES

There are different modes of downstream engagement according to site type. There are no obvious characteristics of websites that would indication their downstream distribution.

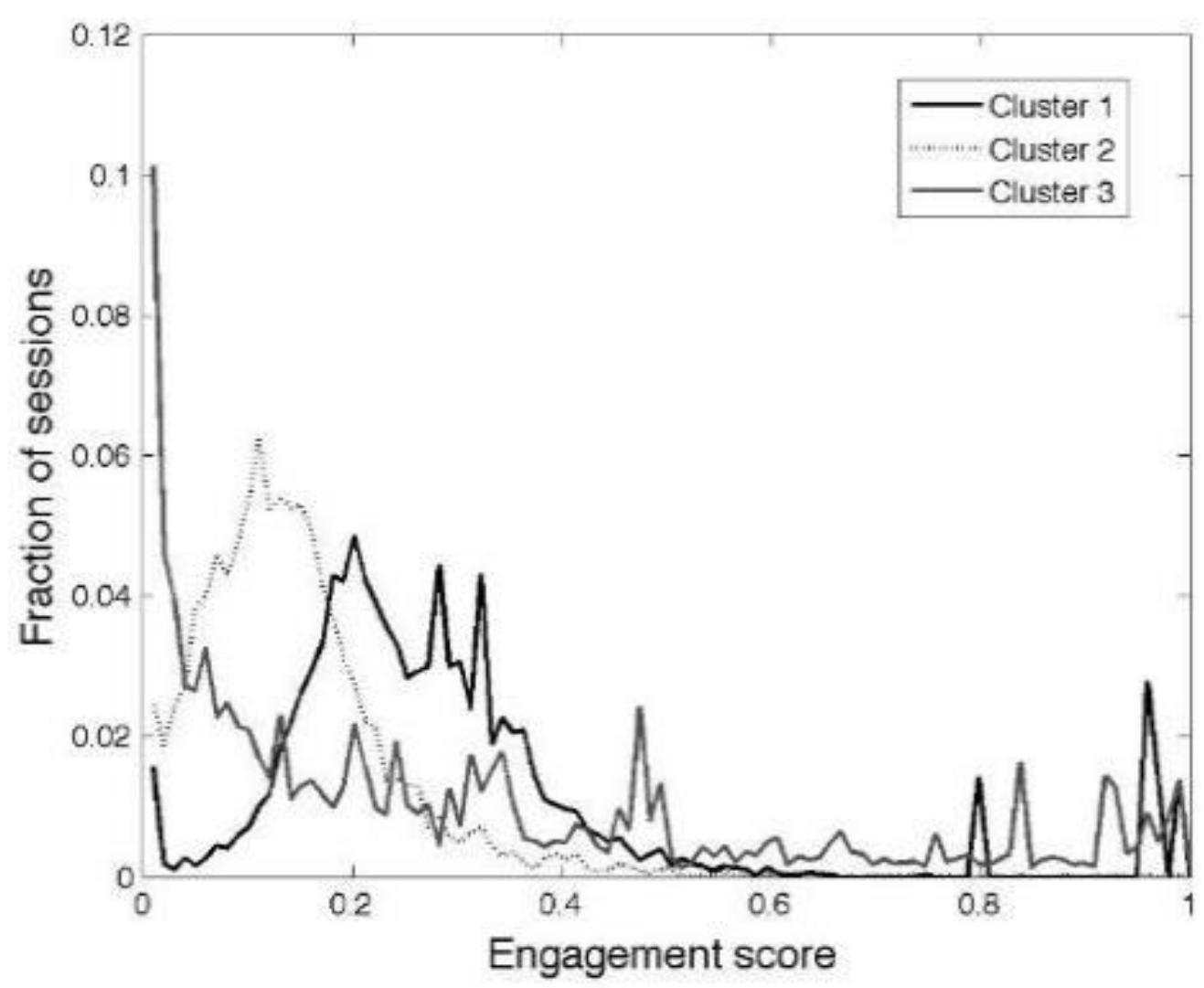

(19.4M sessions, 265,000 users, 50 sites) 


\section{DISTRIBUTION OF DOWNSTREAM ENGAGEMENT TO A LIST OF YAHOO! WEBSITES}

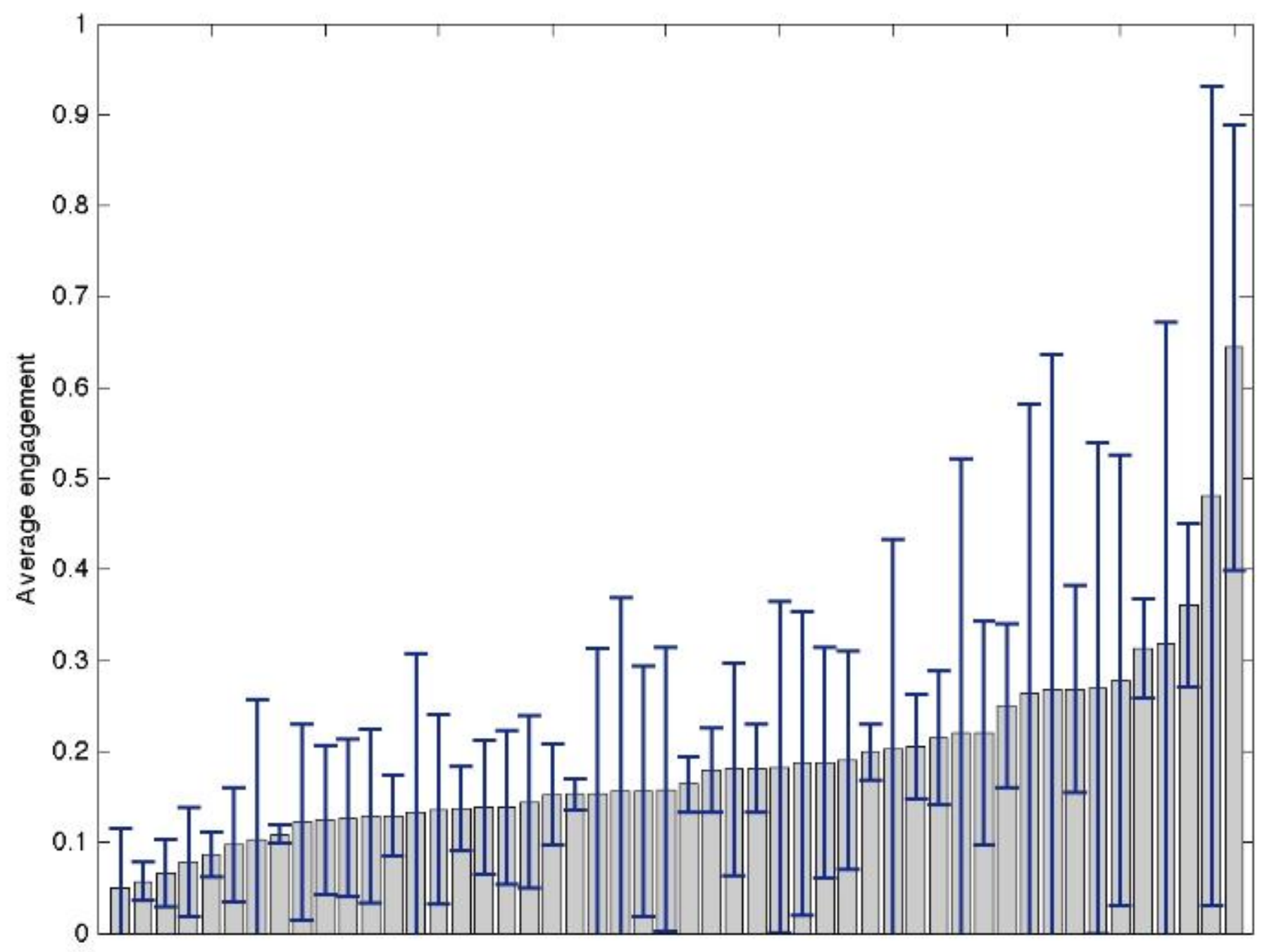

Varies across and within websites (19.4M sessions, 265,000 users, 50 sites $\left.{ }^{13}\right)$ 


\section{INFLUENTIAL FEATURES}

oTime of day

oNumber of (non-image/non-video) links to Yahoo! sites in HTML body oAverage rank of Yahoo! links on page

oNumber of (non-image/non-video) links to non-Yahoo! sites in HTML body

oNumber of span tags (tags that allow adding style to content or manipulating content, e.g. JavaScript)

- Link placements and number of Yahoo! links can influence downstream engagement

- Not new, but here shown to hold also across sites

- Links to non-Yahoo! sites have a positive effect on downstream engagement

- Possibly because when users are faced with abundance of outside links they decide to focus their attention on a central content provider, rather than visiting multitude of external sites 


\section{NETWORKED USER ENGAGEMENT}

$\circ$ Using downstream engagement to study the network effect on Yahoo! sites shows:

- Downstream engagement

- Varies significantly across sites

- Exhibits different distributions according to site type

- Can be modified through changes in page stylistics

- Certain user sessions are more amenable to downstream engagement optimization, so personalization is important

- Links offer powerful means to influence sites within and across sites

o Next:

- Can we quantify the network effect? 

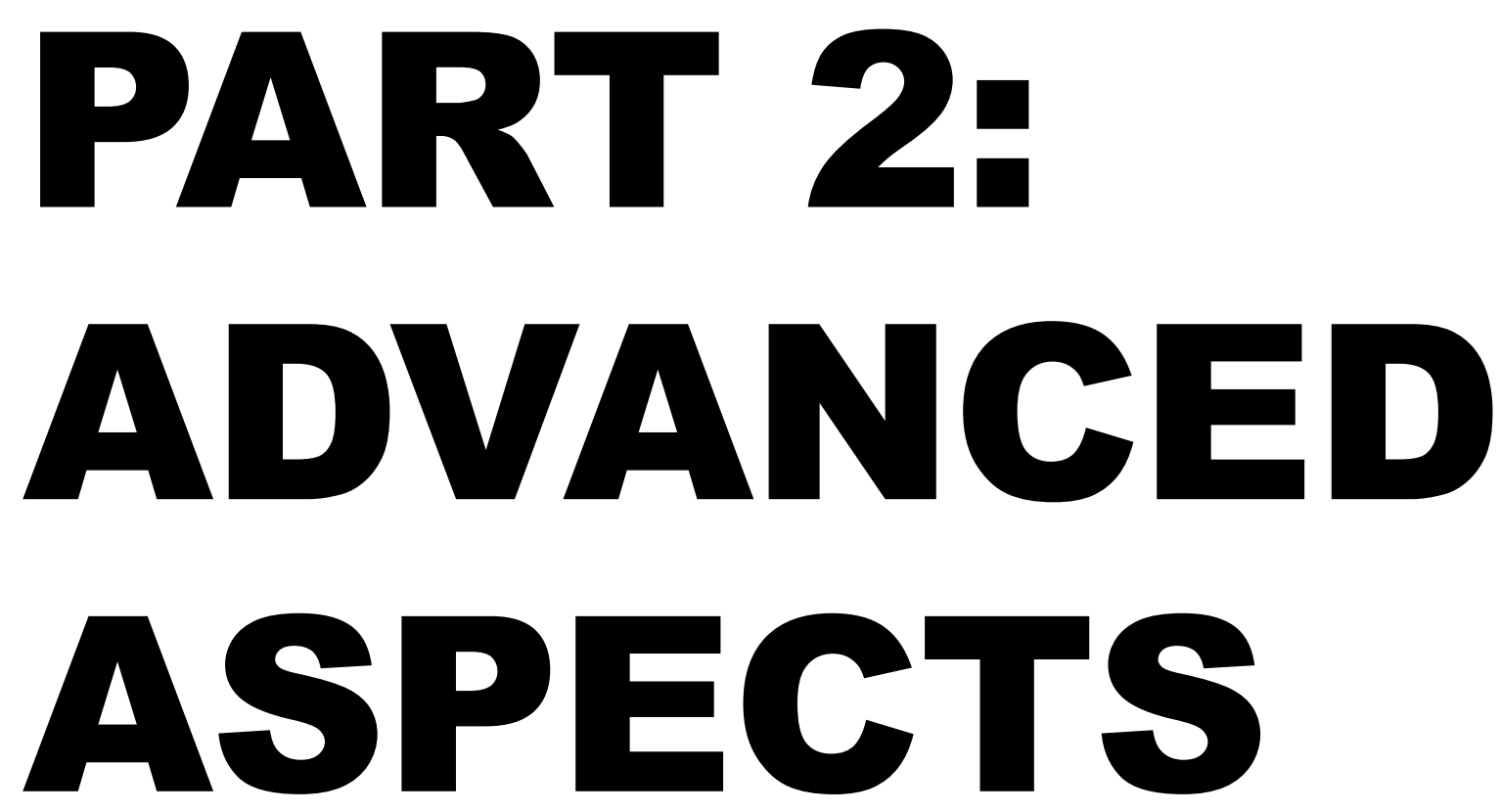

COMBINATIONS OF APPROACHES 


\section{MEASURING USER ENGAGEMENT - WE RECALL}

Measures

Self-reported Questionnaire, interview, report, engagement product reaction cards, think-aloud
Characteristics

Subjective

Short- and long-term

Lab and field

Small-scale

Product outcome

Cognitive Task-based methods (time spent, engagement follow-on task)

Objective

Short-term

Lab and field

Neurological measures (e.g. EEG) Small-scale and large-

scale

Physiological measures (e.g. eye tracking, mouse-tracking)

Interaction Web analytics + "data science" engagement

metrics + models

Process outcome
Objective

Short- and long-term

Field

Large-scale

Process 


\section{COMBINATION OF APPROACHES}

\section{SEVERAL STUDIES}

\section{USER ENGAGEMENT}

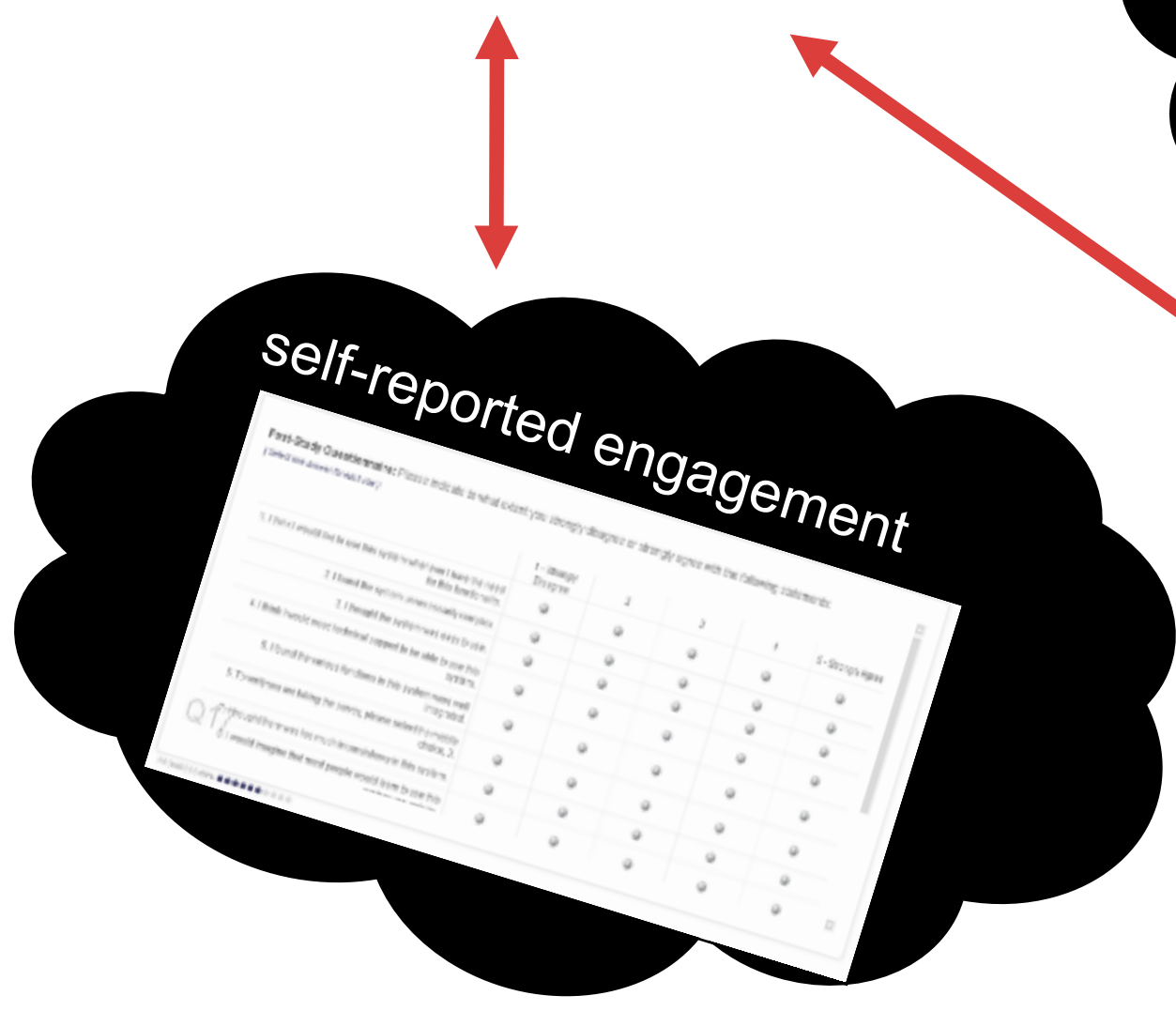

interaction engagement

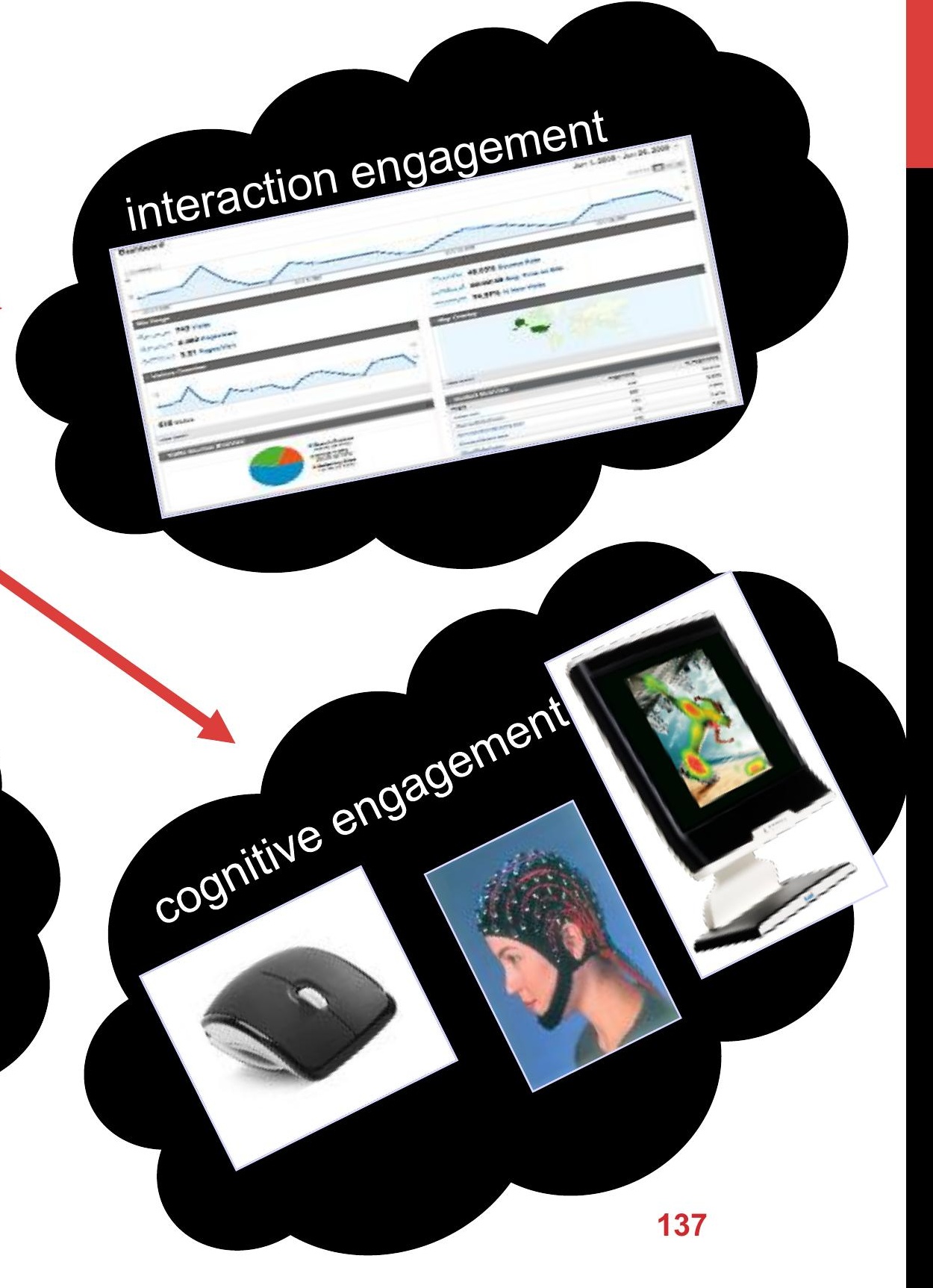




\section{STUDY I: GAZE AND SELF-REPORTING}

○ News + comments

- Sentiment, interest

○ 57 users (lab-based)

$\circ$ Reading task (114)

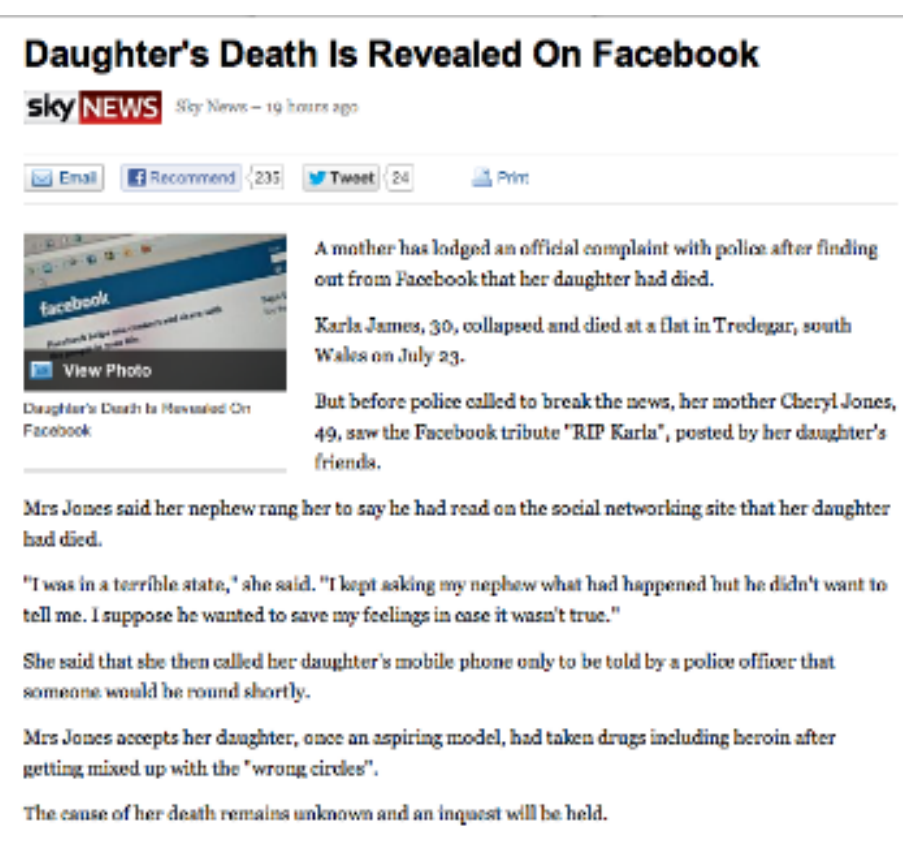

Questionnaire (qualitative data)

Record mouse tracking, eye tracking, facial expression, EEG signal (quantitative data)

Three metrics: gaze, focus attention and positive affect 
INTERESTING CONTENT PROMOTE USERS

ENGAGEMENT METRICS

$\circ$ All three metrics:

- focus attention, positive affect \& gaze

$\circ$ What is the right trade-off?

- news is news $:$

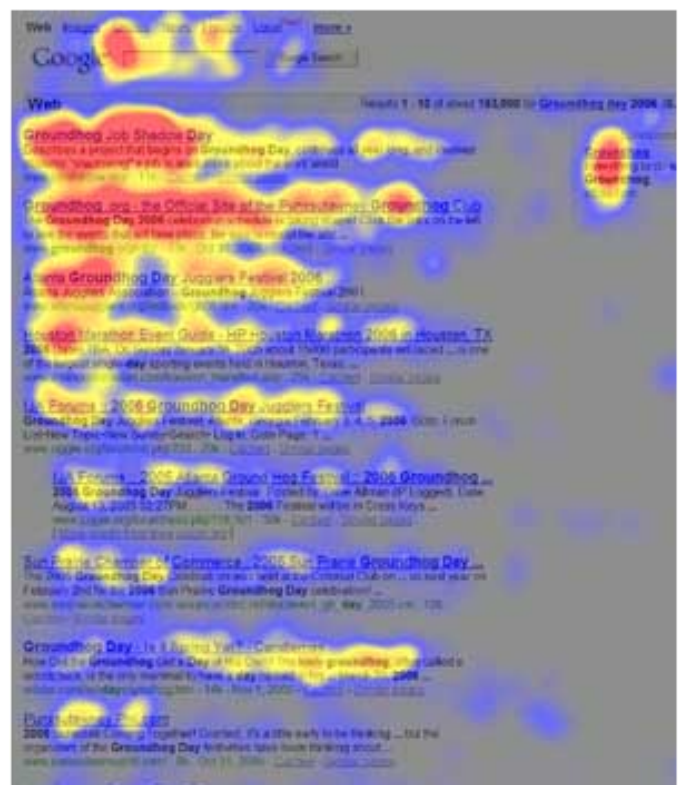

- Can we predict?

- provider, editor, writer, category, genre, visual aids, ..., sentimentality, ...

$\circ$ Role of user-generated content (comments)

- As measure of engagement?

- To promote engagement? 


\section{LOTS OF SENTIMENTS BUT WITH NEGATIVE CONNOTATIONS!}

- Positive effect (and interest, enjoyment and wanted to know more) correlates

- Positively (覓) with sentimentality (lots of emotions)

- Negatively $(\boldsymbol{\downarrow})$ with positive polarity (happy news)

SentiStrenght (from -5 to 5 per word)

sentimentality: sum of absolute values (amount of sentiments) polairity: sum of values (direction of the sentiments: positive vs negative)

(Thelwall, Buckley \& Paltoglou, 2012) 


\section{EFFECT OF COMMENTS ON USER ENGAGEMENT}

○ 6 ranking of comments:

- most replied, most popular, newest

- sentimentality high, sentimentality low

- polarity plus, polarity minus

$\circ$ Longer gaze on

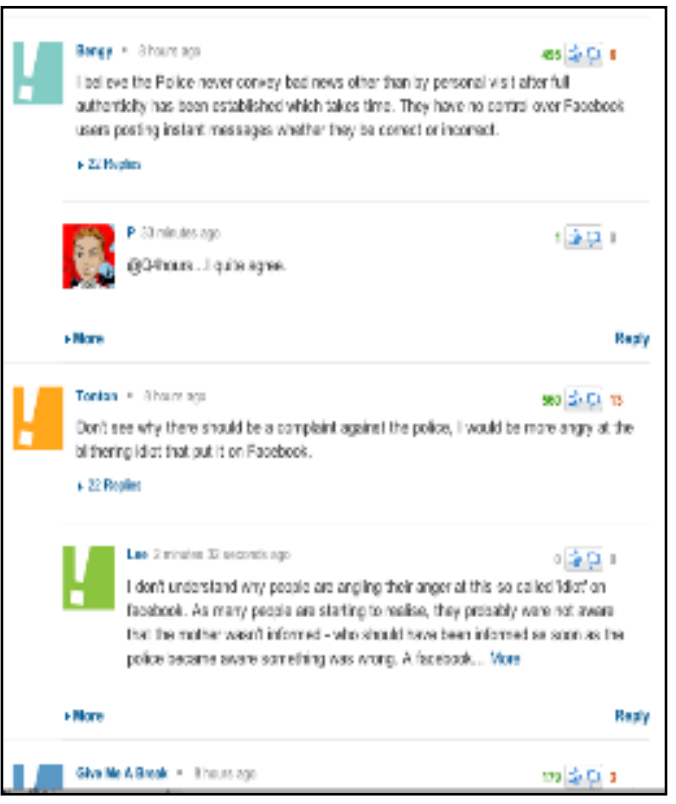

- newest and most popular for interesting news

- most replied and high sentimentality for non-interesting news

$\circ$ Can we leverage this to prolong user attention? 


\section{GAZE, SENTIMENTALITY, INTEREST}

- Interesting and "attractive" content!

$\circ$ Sentiment as a proxy of focus attention, positive affect and gaze?

$\circ$ Next

- Larger-scale study

- Other domains (beyond daily news!)

- Role of social signals (e.g. Facebook, Twitter)

- Lots more data: mouse tracking, EEG, facial expression 


\section{STUDY Il: MOUSE TRACKING AND SELF-REPORTING}

- $\mathbf{3 2 4}$ users from Amazon Mechanical Turk (between subject design)

- Two domains (BBC News and Wikipedia)

- Two tasks (reading and search)

- "Normal vs Ugly" interface

- Questionnaires (qualitative data)

- focus attention, positive effect, novelty,

- interest, usability, aesthetics

- + demographics, handeness \& hardware

- Mouse tracking (quantitative data)

- movement speed, movement rate, click rate, pause length, percentage of time still 


\section{“Ugly” vs “Normal” Interface (BBC News)}

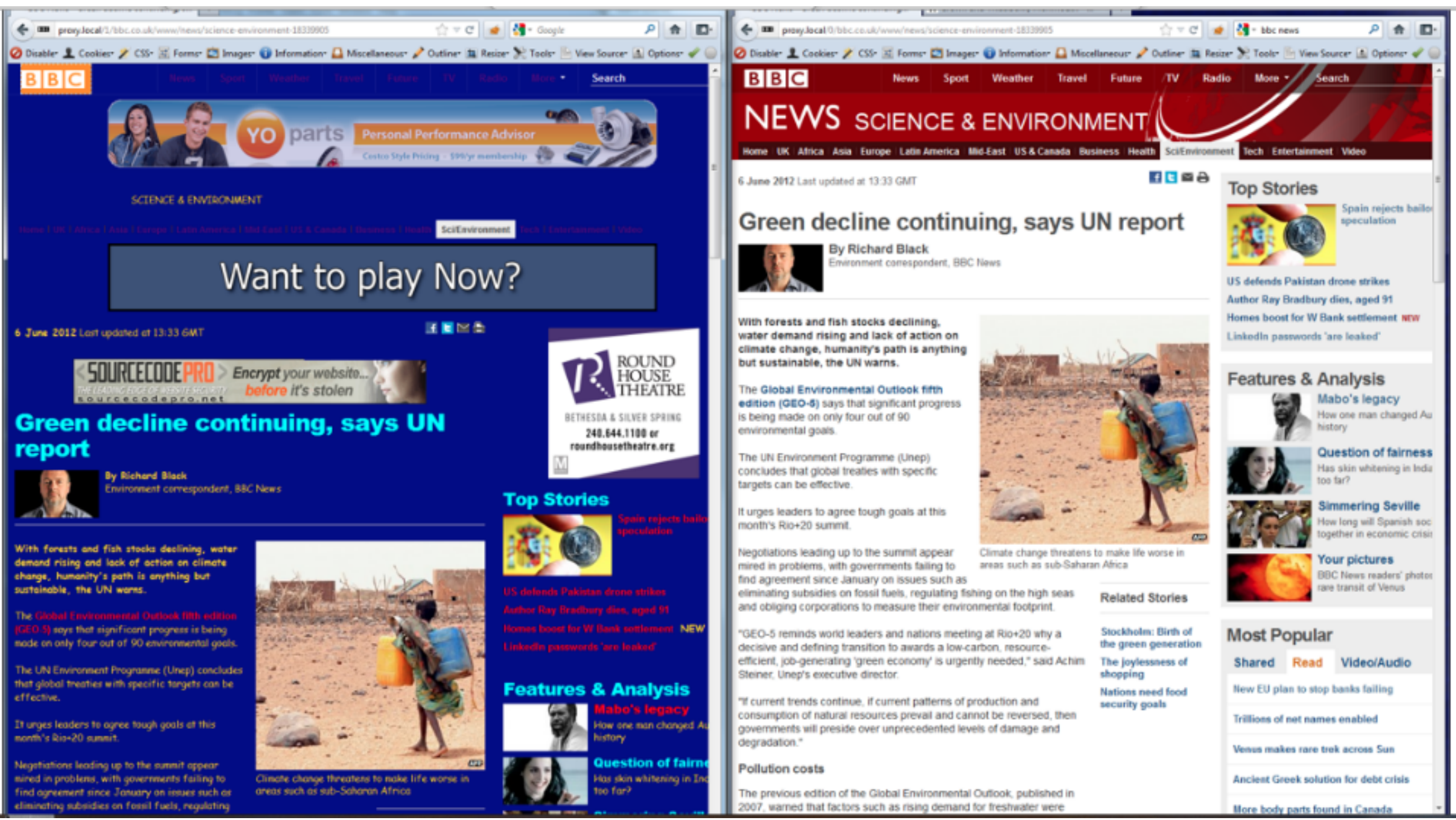




\section{“Ugly” vs “Normal” (Wikipedia)}

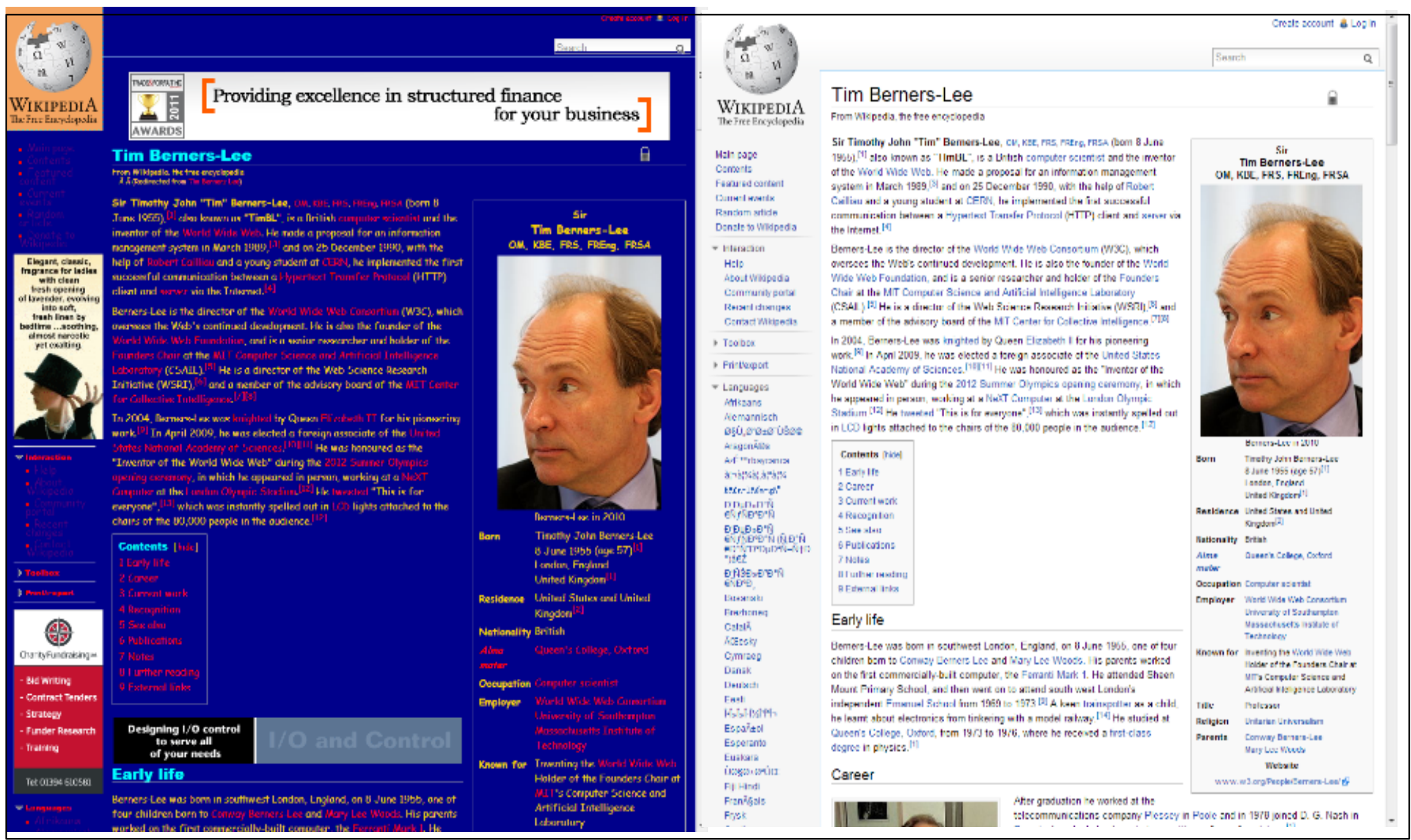




\section{MOUSE TRACKING CAN TELL ABOUT}

$\circ$ Age

○ Hardware

- Mouse

- Trackpad

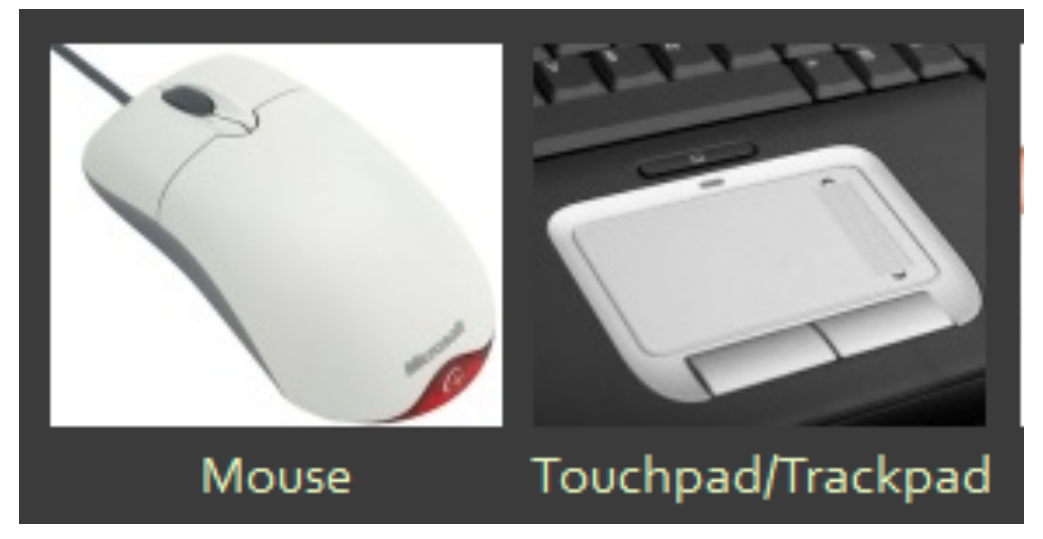

○ Task

- Searching: There are many different types of phobia. What is Gephyrophobia a fear of?

- Reading: (Wikipedia) Archimedes, Section 1: Biography 


\section{MOUSE TRACKING COULD NOT TELL MUCH ON}

\section{$\circ$ focused attention and positive affect \\ $\circ$ user interests in the task/topic}

\section{- BUT BUT BUT BUT}

- "ugly" variant did not result in lower aesthetics scores

- although BBC > Wikipedia

BUT - the comments left ...

- Wikipedia: "The website was simply awful. Ads flashing everywhere, poor text colors on a dark blue background."; "The webpage was entirely blue. I don't know if it was supposed to be like that, but it definitely detracted from the browsing experience."

- BBC News: "The website's layout and color scheme were a bitch to navigate and read."; "Comic sans is a horrible font." 


\section{MOUSE TRACKING AND USER ENGAGEMENT}

- Task and hardware

$\circ$ Do we have a Hawthorne Effect???

○ “Usability" vs engagement

- "Even uglier" interface?

$\circ$ Within- vs between-subject design?

$\circ$ What next?

- Sequence of movements

- Automatic clustering 


\section{STUDY III: SELF-REPORT AND BEHAVIOURAL DATA}

- Information Visualization System

- McGill Library Catalogue: Engineering Subject Area

- Version 1: visualization

- Version 2: visualization + audio

○ Participatory Design Study

○ Experiment

- $n=24$ engineering students

- Tasks: six information retrieval and hierarchical navigation tasks

- Data collected: self-report and performance metrics 


\section{FINDINGS}

- No difference in performance accuracy or time on task

$\circ$ Aesthetics and Perceived Usability was higher for the audio-visual system.

- Perceived ease of use was also rated higher for the audio-visual system.

- Open-ended comments offered insights into participants' perceptions and interactions. 


\section{STUDY IV: ONLINE NEWS INTERACTIONS}

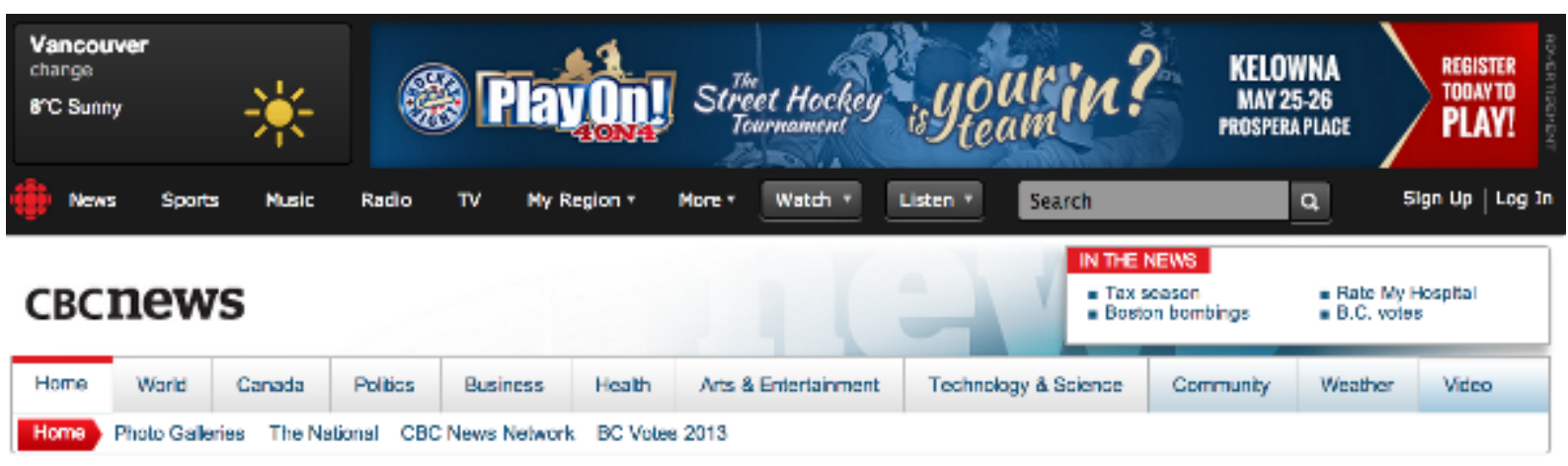

DEVELOPING Feds can't account for $\$ 3.1 \mathrm{~B}$ in antl-terrorism cash: $\mathrm{AG}$ y

LIVE Canada can't account for \$3.1B in anti-terror funding, AG finds

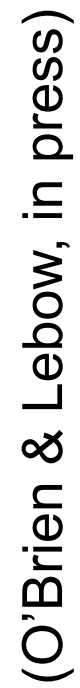

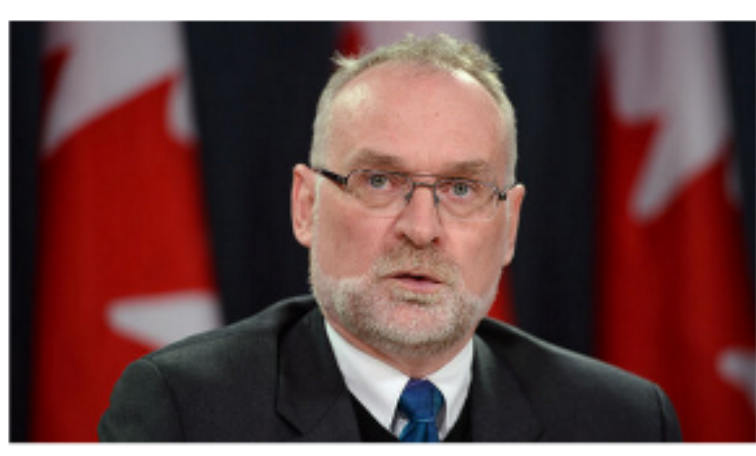

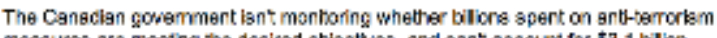
meesures are meetrg the deained chjecthos, and can' accoum for 53.1 bilion.

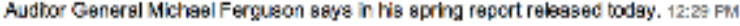
ET F

- NEW| FXha seerch and regcua must be pribrty, AB geys 12:22 FN ET - NEW| AG cels for atronger crackdom on El overpeymenta 1240 Pine

- Experta daubt lax-enitching can bring in rew reverisa 10:39 FM ET

- Otana ordared te provide all reeider tial achook documents 7:46 PX ET

$$
\begin{aligned}
& \text { More Headlines } \\
& \text { NEW | Urabanber's } \\
& \text { lawyer zo defernd Basken } \\
& \text { bornbirg suspecil a }{ }^{0}
\end{aligned}
$$

\section{http://www.cbc.ca/news/}

WE SEE

THINGS THE

SAME WAY

YOU DO.

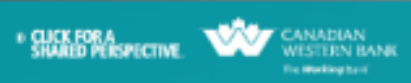

Stay Connected with CBC News

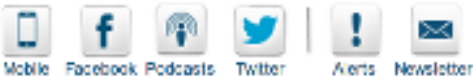

\section{Must Watch}
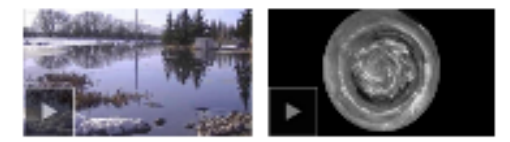

MEASURES

- Pre-task questionnaire

- Demographics + news behaviours

- Interaction with website

- Performance: Time on task, reading time, browsing time, number of pages visited within site, whether participants clicked on links to recommended content

- Physiological: heart rate (HR), electrodermal activity (EDA), electrocmytogram (EMG) [subset of participants]

- Post-session questionnaire

- User Engagement Scale (UES) (O'Brien \& Toms, 2010)

- Cognitive Absorption Scale (CAS) (Argawal \& Karahanna, 2000)

- System Usability Scale (SUS) (Brooks, 1997)

○ Think-After Interview

- Questions about the items selected for the task

- Questions about overall experience 

RESULTS

○ Self-report UES, CAS and SUS

- Positive correlations support criterion validity of the measures

- Designation of "low," "medium" and "high" scores for each group based on median

- All questionnaires were positively correlated with aggregate interest in the articles

○ES and Physiological Data

\begin{tabular}{|l|c|c|c|}
\hline & HR & EDA & EMG \\
\hline UES & -0.38 & -0.25 & -0.21 \\
\hline
\end{tabular}


SELF-REPORT, BEHAVIOR AND PHYSIOLOGICAL DATA: RESULTS

- UES and Behavioural Data

\begin{tabular}{|l|c|c|c|c|c|} 
& High M(SD) & $\begin{array}{c}\text { Medium } \\
\text { M(SD) }\end{array}$ & $\begin{array}{c}\text { Low } \\
\text { M(SD) }\end{array}$ & $\begin{array}{c}\text { Kruskal } \\
\text { Wallis }\left(x^{2}\right)\end{array}$ & $p$ \\
\hline Reading time & $6: 03(2: 34)$ & $6: 05(1: 56)$ & $6: 56(3: 29)$ & 1.15 & 0.56 \\
\hline Browsing time & $4: 03(2: 29)$ & $5: 17(3: 49)$ & $7: 29(4: 09)$ & 3.98 & 0.13 \\
\hline Total time & $10: 07(3: 37)$ & $11: 23(5: 10)$ & $14: 26(5: 02)$ & 5.09 & 0.07 \\
\hline \# pages visited & $9.5(5.0)$ & $10.3(3.6)$ & $16.3(8.4)$ & 3.89 & 0.14
\end{tabular}

- Use of Links

- UES scores were not significantly different between those who clicked on links $(M=3.8, S D=0.95)$ and those who did not $(M=4.29, S D=0.52)$

- $U(1)=51.5, p=0.15$ 
- Did participants' experiences with online news fit the process model of user engagement (O'Brien \& Toms, 2008)?

- What attributes of user engagement were significant to participants in the online news environment?

- Novelty, affect, usability, personal interest and relevance

$\circ$ Evidence of two types of engagement (O'Brien, 2011)

- Content engagement

- Interface engagement 
- Introduction and Scope

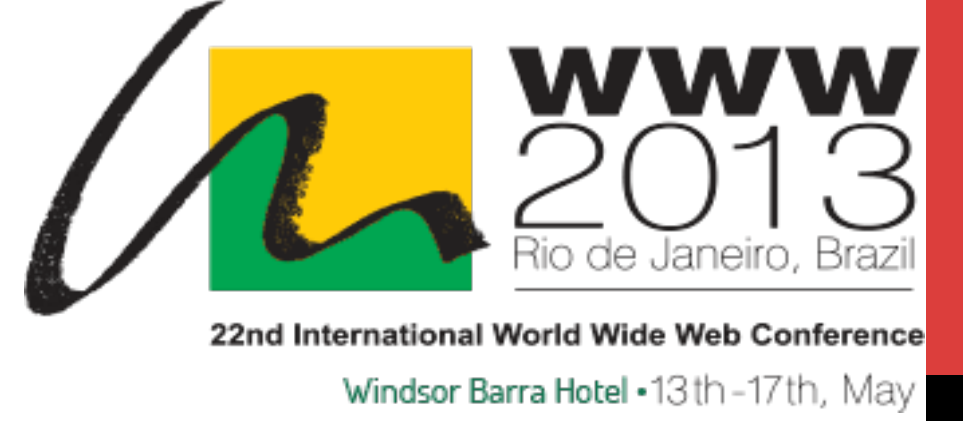

- Part I - Foundations

1. Approaches based on self-report measures

2. Approaches based on web analytics

3. Approaches based on physiological measures

- Part II - Advanced Aspects

1. Measuring user engagement in mobile information searching

2. Networked user engagement

3. Combining different approaches

- Conclusions

○ Bibliography 
- Be careful of the WEIRD syndrome (Western, Educated, Industrialized, Rich, and Democratic)

- A great deal of emphasis on users and systems, but less evidence about the role of task, device, and context on user engagement.

- We tend to focus on characteristics of users in the moment of interaction. But are their individual differences that may predict the level of engagement that can be achieved? 


\section{CONCLUSIONS}

$\circ$ We covered a range of self-report, performance and physiological metrics.

- We focused on different characteristics of measures, including short- vs. long-term; subjective vs. objective; process- vs. product-based, small-vs. large-scale; and lab vs. field.

\section{Take-Aways}

- No one measure is perfect or complete.

- All studies have different constraints.

- More details on methods used in published literature will enhance communication around UE measures, which will advance study of UE.

- Need to ensure methods are applied consistently with attention to reliability.

- More emphasis should be placed on using mixed methods to improve the validity of the measures. 


\section{ACKNOWLEDGEMENTS}

- Dr. Lalmas work in collaboration with loannis Arapakis, Ricardo Baeza-Yates, Berkant Cambazoglu, Georges Dupret, Janette Lehmann and others at Yahoo! Labs.

- Dr. O'Brien's work is supported by the Social Science and Humanities Research Council (SSHRC) of Canada and the Networks of Centres of Excellence Graphics, Animation and New Media (NCE GRAND) Project (http://www.grand-nce.cal). 